\title{
TOMOGRAFIA COMPUTADORIZADA APLICADA A ESTUDOS DE COMPACTAÇÃO DE SOLOS
}

\author{
CARLOS MANOEL PEDRO VAZ \\ Físico
}

Orientador: Prof. Dr. KLAUS REICHARDT

\begin{abstract}
Dissertação apresentada à Escola Superior de Agricultura "Luiz de Queirós", da Universidade de São Paulo, para obtenção do título de Mestre em Agronomia, Ārea de concentração: Energia Nuclear na Agricultura.
\end{abstract}

$P$ I R A C I C A B A

Estado de São Paulo - Brasil

Novembro - 1989 
Ficha catalográfica preparada pela Seção de Livros da Divisão de Biblioteca e Documentação - PCAP/USP Vaz, Carlos Manoel Pedro

V393t Tomografia computadorizada aplicada a estudos de compactação de solos. Piracicaba, 1989.

$110 p$. ilus.

Diss. (Mestre) - ESALQ

Bibliografia.

1. Solo - Compactação - Técnica nuclear 2. Solo Densidade - Técnica nuclear 3. Solo - Física 4. Tomo grafia automatizada aplicada I. Escola Superior de A gricultura Luiz de Queiroz, Piracicaba

CDD 631.43 
TOMOGRAFIA COMPUTADORIZADA APLICADA A ESTUDOS DE COMPACTAÇÃO DE SOLOS

CARLOS MANOEL PEDRO VAZ

Aprovada em: 06.12.1989

Comissão Ju1gadora:

Prof. Dr. Klaus Reichardt ESALQ/USP

Prof. Dr. Virgilio Franco do Nascimento Filho ESALQ/USP Dr. Silvio Crestana UAPDIA/EMBRAPA

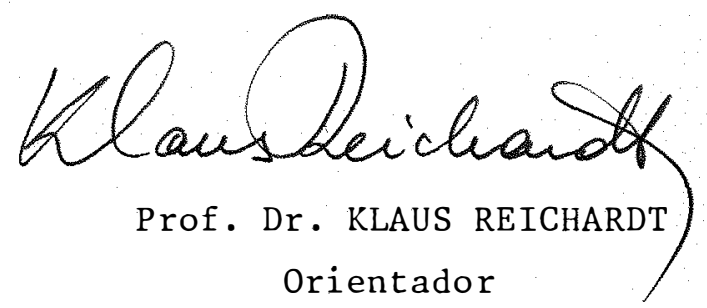


1.

Dedico este trabalho

a minha Eamilia 


\section{AGRADECIMENTOS}

- UAPDia-emBRAPA pela possibilidade da realizacão deste trabalho, através do apoio financeiro, boa infra-extrutura e recursos humanos.

- Aos pesquisadores e funcionários da UAPDIA/EMBRAPA, pelo apoio dado e amizade.

- Aos pesquisadores, funcionários e alunos da secão de Elsica do Solo do CENA/USP, pelo apoio dado e pela ótima convivencia.

- Ao Prof. Sérgio Mascarenhas e Paulo Estevao Cruvinel, pelas oportunidades e incentivo.

- Aos eng. Osny Bacchi (CENA/USP) e Rubsmar stolf (PLANALSUCAR/IAA), pelo constante apoio, incentivo, sugestões e discussão dos resultados.

- AO PLANALSUCAR/IAA e CENA/USP, pela cooperacão cientifica e apoio na realizacão deste trabalho.

- Ao Clovis, Mauro, Colnago, Ladislau Martin, Ladislau Rabello, Herrmann e wilson, pelo constante incentivo.

- Ao Ricardo Y. Inamasu, pela revisao, sugestōes ao texto e amizade.

- Ao Valentim Monzane, pela elaboracão das figuras.

- Ao Luiz Ap. Godoy, pelo apoio na área de mecănica. 
- Ao sr. Benedito, pela ajuda na construcão das trincheiras e coleta de amostras de solo.

- A Janis Ap. Baldovinotti e Vera L.C. Otaviano, pela organizacáo das referencias bibliograficas.

- A Ana M. F. Ambrosio e suzete A. B. do Carmo, pelo auxilio na datilografia.

- De modo bastante especial, agradeco silvio crestana e Klaus Reichardt pelas orientacões academicas e esforcos para que este trabalho fosse realizado. 


\section{LISTA DE EIGURAS}

pag

Eigura 1. Esquema do sistema solo, do ponto de vista da compactacão....................

Figura 2. Aplicacão do teste de densidade proctor

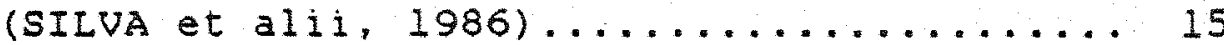

Figura 3. Esquema do processo de compactacão do solo por velculos e implementos agricolas, mostrando seus efeitos acumulativos, devido apenas ao implemento a) e a ambos b)...... 17

Eigura 4. Distribuică das pressôs imprimidas por pneus de um velculo na superficie de um solo arenoso rigido (VANDEN BERG \& GILL,

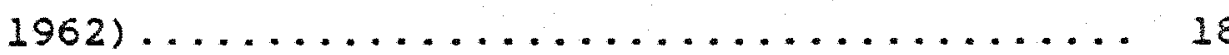

Eigura 5. Distribuicao de pressoes num plano vertical do solo sob uma pressäo de 20,3 atm $(2,06$ MPa) aplicada numa area de 0.2 m (UANDEN

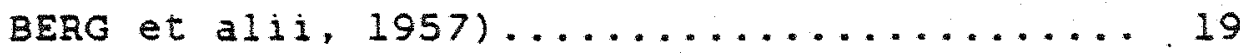

Figura 6 . Pressoes agindo num volume infinitesimal do solo sob una carga pontual.$\ldots \ldots \ldots 19$

Figura 7. Espectro das radiacós eletromagneticas.... 25

Figura 8. Representacao esquematica do processo de

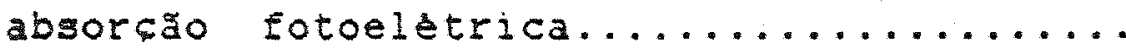


Figura 9. Representacão esquemática do processo de

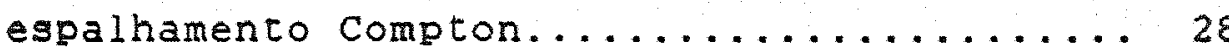

Eigura 10. Representaca esquemática do processo de

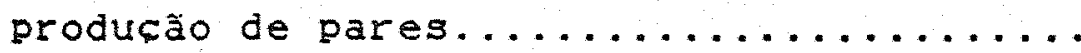

Figura 11. Coeficiente de atenuacá em massa, da agua em funcão da energia (JOHNS \& LAUGHLIN,

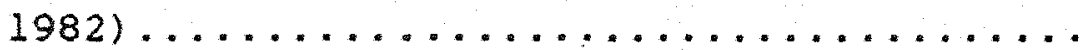

Figura 12. Diagrama de blocos de um espectrometro gama monocanal........................... 34

Figura 13. Esquema do processo da interacão de um foton gama com um cristal cintilador..... 35

Figura 14. Esquema de funcionamento de uma valvula fotomultiplicadora................. 36

Figura 15. Principio básico de operacao de um tomografo de primeira geracao na qual nedidas de transmissão são acumuladas enquanto o objeto e rodado é transladado entre a fonte e o detector (HENDEE,

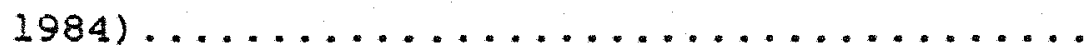

Figura 16. Movimentos de varredura na tomografia computadorizada. A)- Tomografo de primeira geracao usando um feine colimado, com movimentos combinados de translacao e rotacão. B)- Tomógrafo de segunda geracáo 
com feixe em leque, vários detectores e movimentos combinados de rotacão e translacao. c)-Tomografo de terceira geracão usando um feize em leque, uma serie de detectores e apenas movimento de rotacão. D) - Tomógrafo de terceira geracão usando um feize em leque, uma serie circular de detectores e apenas movimentos de rotacao (HENDEE, 1984).............

Figura 17. Representacão esquematica da reconstrucao com o algorltimo da retroprojeca simples..

Figura 18. Representacao dos elementos da imagem de uma seç̃o transversal de um objeto........

Figura 19. Diagrama de blocos do tomógrafo mogtrado

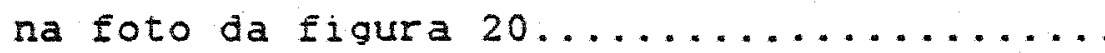
58

Eigura 20. Fotografia do tomógrafo computadorizado de raios $x$ e gama de primeira geracăo. construido na UAPDIA-EMBRAPA em Säo

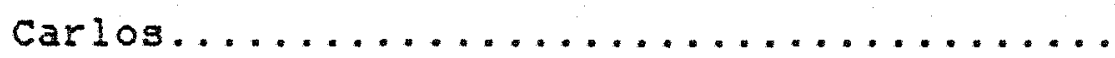

Eigura 21. Procedimento de coleta e medida de amostras indeformadas numa trincheira, utilizando a técnica da tomografia computadorizada 60

Figura 22. Relacáo experimental entre uM e 0 coeficiente de atenuacao linear para 
varios materiais...................6 61

Figura 23. Amostra para o estudo de camada de solo

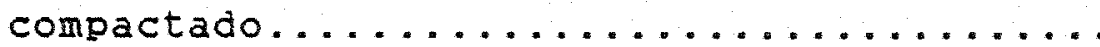

figura 24. Equipamento utilizado na compactacăo

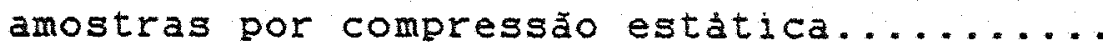

Eigura 25. Representacão esquematica da coleta de amostras, após a passagem de implementos

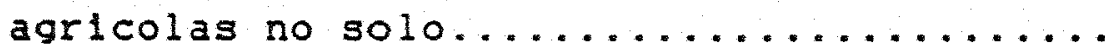

Figura 26. Representacão esquemática da coleta de amostras numa trincheira e medidas com

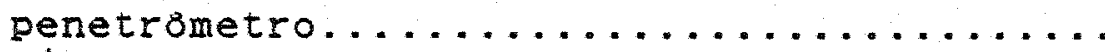

Figura 27. Medidas do coeficiente de atenuacăo linear para amostras de varias densidades em dois solos.

Figura 28. Imagens de uma secao transversal de uma amostra de solo fino peneirado, quando

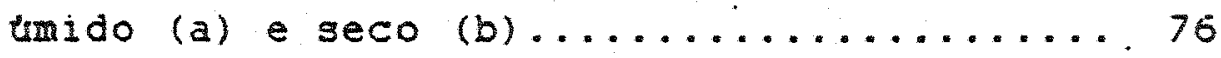

Eigura 29. Partes das matrizes imagens da tomogratia mostrada na figura 28 , quando limida (a) e seca (b) e das matrizes densidade (c) e

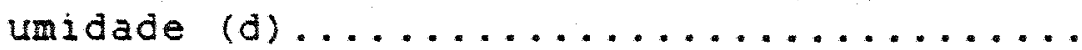

Eigura 30. Distribuicdes de frequencias dos dados das figuras 29 a) e b), para a amostra umida (a) e seca (b), respectivamente.........79 
Figura 31. Perfis das UM (a), densidades e umidades (b), relativos as inagens da figura $28 \ldots . .80$

Figura 32. Correlaca entre UM, a densidade (a) e a umidade do $\$ 010$

(b) $\ldots \ldots \ldots \ldots \ldots \ldots \ldots \ldots \ldots \ldots \ldots \ldots \ldots \ldots$

Figura 33. Imagens de duas amostras de solo com finas

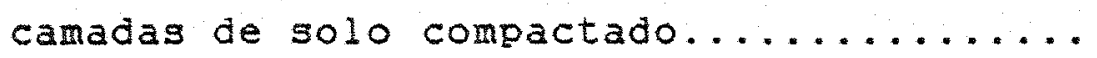

Figura 34. Perfis medios de UM, de amostras com finas

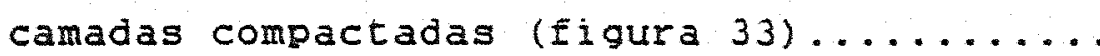

Eigura 35. Imagens de amostras de solo LVE-Säo Carlos, compactadas com varios teores de

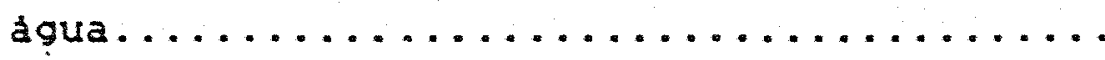

Figura 36. Gráfico da densidade media final (medida por gravimetria) e a umidade de amostras de solo compactadas por uma pressão de 0,8

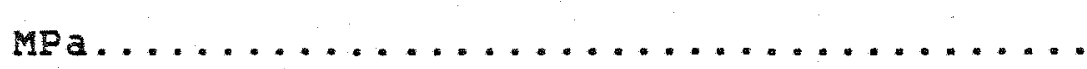
86

Eigura 37. processo de compactasa com carga constante e varias umidades, evidenciando a máxima compactaca................ 86

Figura 38. Quantificacao dos perfis, em termos de densidade do solo, de amostras compactadas com varias umidades e pressao de 0,8 MPa... 88

Figura 39. Perfil de densidades numa amostra coletada após a passagem de um sulcador (1a.

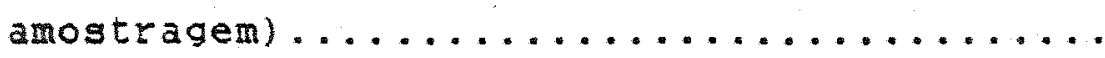


Figura 40 . Perfil de densidades numa amostra coletada após a passagem de um sulcador (2a.

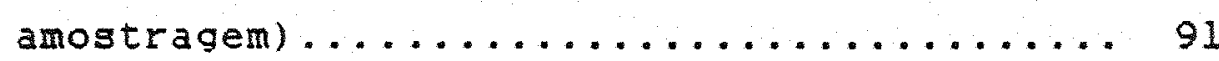

Figura 41. Ferfil de densidades numa amostra coletada apos a passagem de um sulcador (3a. amostragem) ............................

Eigura 42. Ferfil de densidades na trincheira 1 com a TC e impactos por decimetro com penetrometro, para varias umidades.......994

Figura 43. perfil de densidades na trincheira 2 com a TC e impactos por decimetro com penetrómetro.......................... 95 
pag

Tabela I. Limites dos diametros das particulas nas classificacóes granulometricas da Sociedade Internacional de Ciencia do Solo e do Departamento de Agricultura dos

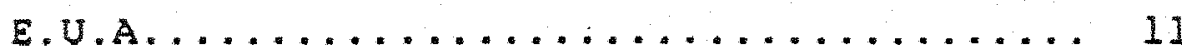

Tabela II. Coeficiente de atenuacão em massa para

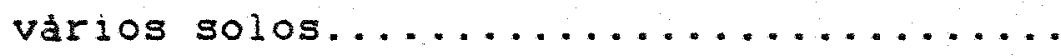

Tabela III. Resultados obtidos por gravimetria para amostras compactadas pelo teste de proctor (márima compactąa) .......... 84

Tabela IV. Resultados das quantificacôes dos pertis de densidade das amostras coletadas após a passagem de um sulcador no solo (2a. amostragem $\ldots \ldots \ldots \ldots \ldots \ldots \ldots \ldots \ldots \ldots$

Tabela $V$. Resultados das quantificacóes dos perfis de densidade, das amostras coletadas após a passagem de um sulcador no solo (3a. amostragem) $\ldots \ldots \ldots \ldots \ldots \ldots \ldots \ldots \ldots \ldots \ldots \ldots \ldots \ldots \ldots$ 
xi.

TOMOGRAEIA COMPUTADORIZADA APLICADA A ESTUDOS DE COMPACTACAO DO SOLO

Autor: CARLOS MANOEL PEDRO VAZ Orientador: Prof. Dr. KLAUS REICHARDT

\section{RESUMO}

- presente trabalho estuda a compactacao do solo, do ponto de vista da mecánica do solo, isto e, medindo as deformacoes causadas por forcas agindo neste.

- equipamento utilizado \& un tomógrafo computadorizado de primeira geracão que fornece imagens, por transmissao de radiacao, de secós transversais de amostras de solo (ate aproximadamente $10 \mathrm{~cm}$ na configuracão utilizada), com precisão de milimetros. Esta inagem uma matriz de coeficientes de atenuacão linear, os quais podem ser correlacionados com a densidade do solo através de una calibraça para cada solo.

- trabalho se divide nos seguintes experimentos: a) experimentos básicos de calibracão e resolucão do equipamento; b) medidas de finas camadas de solo compactado; c) experimentos de transmissão de pressóes no solo por implementos agricolas; d) modelanento pressäo-deformacăo em amostras de solo confinadas, com vấrios graus de umidade; e) levantamento de perfis de 
xii.

densidade, com amostras retiradas numa trincheira, comparando com a técnica do penetrometro.

De um modo geral, os resultados evidenciaram um erro de medida da densidade e umidade entre 2 e 32 para uma dada imagem, com resolucão espacial da imagem igual a $2 \mathrm{~mm}$.

No estudo de Einas camadas de solo compactado, foi possivel a quantificacão de camadas compactadas maiores que $2 \mathrm{~mm}$.

Em experimentos de campo, após a passagem de um sulcador num Latossol vermelho Escuro, para várias condiçes dè densidade, umidade e peso do implemento, foram obtidos resultados desde praticamente nenhum aumento de densidade no perfil da amostra, ate $0,08 \mathrm{~g} / \mathrm{cm}^{3}$ da superficie de contato solo-implemento para baixo.

No experimento com amostras coletadas numa trincheira, foi obtida a caracterizacá de um perfil de densidade com resolucao espacial iqual a $2 \mathrm{~mm}$, indicando a existencia de uma regiao compactada de $30 \mathrm{~cm}$, com densidade de 1,3 a $1,5 \mathrm{~g} / \mathrm{cm}^{3}$. Sondagens com o penetrometro indicaram una grande dependencia deste com a umidade do solo. Sendo que para solo seco, o perfil do penetrometro se assemelha muito com o perfil de densidade obtido con a TC.

No estudo do modelamento pressao-deformacao 
em amostras confinadas, obteve-se uma correlacão linear da densidade com a distancia da amostra, para uma carga de $0,8 \mathrm{MPa}$, numa dada umidade.

Por fim, conclui-se que a rc pode ser utilizada na maioria dos problemas de compactacão do solo, com um desempenho superior as tecnicas tradicionais, tanto em problemas de modelamento pressão-deformacão como em problemas de campo. 
COMPUTED TOMOGRAPHY SCANNER APPLIED TO SOIL COMPACTION STUDIES

Author: CARLOS MANOEL PEDRO VAZ Adviser: Prof. Dr. KLAUS REICHARDT

\section{SUMMARY}

The soil compaction problem was studied using a first generation computed tomography scanner (CT). This apparatus gets images of soil cross sections samples, with resolution of a few millimeters. We performed the following laboratory and field experiments:

a) Basic experiments of equipment calibrations and resolutions studies.

b) Measurements of compacted soil thin layers.

c) Measurements of soil compaction caused by agricultural tools.

d) stress-strain modelling in confined soil sample, with several moisture degree.

e) Characterizations of soll bulk density profile with samples collected in a hole (trench), comparing with a cone penetrometer technique. 
The results showed errors in soll bulk density and moisture content around $2 \%$ and $3 \%$, for an inage with $2 \mathrm{~mm}$ of spacial resolution.

In compacted soil thin layer studies, was possible identified layers grater than $2 \mathrm{~mm}$.

Experiments of compacted soil caused by agricultural tools provided results since zero up to 0,08 $\mathrm{g} / \mathrm{cm}^{3}$ of soil bulk density increase, in the sample profile.

In the experiment with samples collected in a trench, the results shown a compacted region of $30 \mathrm{~cm}$ between 1.3 to $1.5 \mathrm{~g} / \mathrm{cm}^{3}$. Measurements with cone penetrometer showed a close dependence with soil moisture content. For dry soils, the cone penetrometer prosile was very similar to the soil bulk density profile measured by CT.

stress-strain modelling studies with confined samples, provided an approximatly linear correlation between soil bulk density and sample length, for $0.8 \mathrm{MPa}$ preassure, for a constant moisture content.

Finally, we conclude that the $\mathrm{Cr}$ can be used in the study of soil compaction problems, with better performance than the traditional techniques. 
LISTA DE FIGURAS $\ldots \ldots \ldots \ldots \ldots \ldots \ldots \ldots \ldots$ iv

LISTA DE TABELAS $\ldots \ldots \ldots \ldots \ldots \ldots \ldots \ldots \ldots \ldots$ x

RESUMO $\quad \ldots \ldots \ldots \ldots \ldots \ldots \ldots \ldots \ldots \ldots \ldots \ldots \ldots \ldots \ldots \ldots$

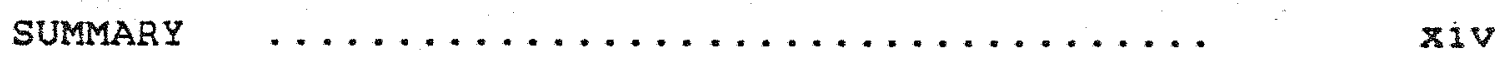

1. INTRODUCAO $\ldots \ldots \ldots \ldots \ldots \ldots \ldots \ldots \ldots \ldots \ldots$

2. ASPECTOS TEORICOS $\ldots \ldots \ldots \ldots \ldots \ldots \ldots \ldots \ldots \quad 10$

2.1. Descricão do objeto solo $\ldots \ldots \ldots \ldots . .10$

2.2. Compactacão do solo $\ldots \ldots \ldots \ldots \ldots \ldots .13$

2.3. Interacão dos raios-x ou gama com a materia $\ldots \ldots \ldots \ldots \ldots \ldots \ldots \ldots \ldots$

2.4. Atenuacão de um feize de raios-x ou gama $\ldots \ldots \ldots \ldots \ldots \ldots \ldots \ldots \ldots \ldots$

2.5. Espectrometria gama $\ldots \ldots \ldots \ldots \ldots \ldots .33$

2.6. Tomografia computadorizada $\ldots \ldots \ldots . . .37$

3. Revisao de literatura $\ldots \ldots \ldots \ldots \ldots \ldots \ldots .45$

3.1. Tomografia computadorizada ......... 45

3.2. Métodos de medidas da compactacão do solo $\ldots \ldots \ldots \ldots \ldots \ldots \ldots \ldots \ldots \ldots$

4. Materiais e metodos $\ldots \ldots \ldots \ldots \ldots \ldots \ldots \ldots .67$

4.1. Atenuacão de um feize de raios gama ... 63

4.1.1. Medidas do coef. de atenuacá en massa de solos $\ldots \ldots \ldots \ldots$

4.1.2. Coef. de atenuacăo linear e densidade do solo ......... 64

4.2. Tomografia : calibracăo e quantificacăo 64 
4.2.1. Relacăo entre UM e Ds ....... 65

4.2.2. Relacao entre UM e $\theta \ldots \ldots . . . .66$

4.3. Estudo da compactacalo de solos por

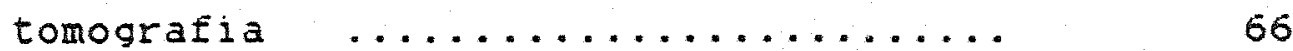

4.3.1. Finas camadas de solo compactado (1aboratorio) $\ldots \ldots \ldots \ldots \ldots$

4.3.2. Compactacâo por compressăo (1aboratório) $\quad \ldots \ldots \ldots \ldots \ldots$ 68

4.3.3. Compactacão por compressäo de implementos

4.3.4. Tomografia vs Penetrometro (campo)

5. RESULTADOS E DISCUSSAO $\ldots \ldots \ldots \ldots \ldots$

5.1. Atenuacão de um feixe de raios gama 68

5.1.1. Medidas do coef. de atenuacáo em massa de solos $\ldots \ldots \ldots \ldots \ldots \ldots$

5.1.2. Coef. de atenuacao linear e do solo $\quad \ldots \ldots \ldots \ldots \ldots \ldots \ldots$

5.2. Tomografia : calibracăo e quantificacăo 75 5.2.1. Reląăo entre UM, Ds e $\theta \ldots . .$.

5.3. Estudo da compactacăo de solos por tomografia

5.3.1. Finas camadas de solo compactado (laboratorio)

5.3.2. Compactacá por compressão (laboratorio) $\quad \ldots \ldots \ldots \ldots \ldots . . .$.

5.3.3. Compactaca por compressa de implementos 
5.3.4. Tomografia vs penetrometro

(campo) $\quad \ldots \ldots \ldots \ldots \ldots \ldots . \ldots \ldots$

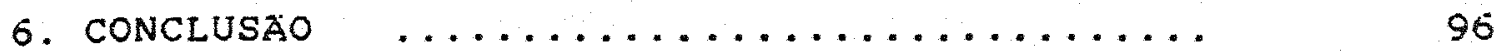

7. SUGESTOES PARA EUTUROS TRABALHOS ........ 100

8. REFERENCIAS BIBLIOGRAFICAS $\ldots \ldots \ldots \ldots \ldots$ 


\section{INTRODUCAO}

- incremento da demanda de alimentos pelos povos e o orande desenvolvimento industrial contribulram para uma mudanca radical do sistema agrário, passando do uso de tracăo animal e humana para o uso de maquinarios. usados no preparo do solo, plantio, adubafao e colheita.

Segundo MCKIBBEN (1971), entre 1948 e 1968 houve um aumento médio de 2,7 ton para 4,5 ton na massa de tratores e nesta decada, segundo GAMEDA et alii (1985), a média esta en torno de 6,8 ton, com alguns modelos alcancando 22,4 ton.

Associado ainda com um aumento de potencia - velocidade, em algumas culturas, os solos expostos a uma extensiva mecanizacao tenden a apresentarem problemas sêrios de compactacăo (GAMEDA et alii, 1985).

Alem das caracteristicas e forma de utilizacao dos maquinarios, a compactaca do solo dependers de caracteristicas e propriedades do solo, tais como a granulometria, estrutura, agregados, relevo, dureza, plasticidade, umidade a densidade deste. 
A compactacão dos solos devido a maquinarios agricolas, tem efeito acumulativo. Portanto. após vários anos de manejo numa determinada cultura, podera surgir uma compactacao que afetara a dinamica da agua, como mostram LIBARDI et alii (1982) e a dinamica dos solutos, observados por LANDINA \& KLEVENSK (1984), alem de aumentar a obstrucăo do desenvolvimento radicular e provocar uma má aeracáa deste solo.

Un caso tipico da problemática da compactacao, segundo FERNANDES (1979), a o da cultura de cana de acucar, devido ao seu alto grau de mecanizacá. uso de maquinarios pesados, principalmente no preparo e na colheita, pode levar um solo a altos niveis de compactacao, que sem durida afetam a produtividade. Tradicionalmente apos a cana-planta varias producóes de cana-soca sao colhidas, sendo sua producă quase sempre decrescente. Estima-se que cerca de 10 a $20 \%$ da producá seja perdida devido ao problema da compactacão. Por isso depois de um certo numero de socas, o canavial é renovado - dependendo do grau de compactacão recomenda-ge operacoses pesadas, tais como aracão profunda ou subsolagem.

En outras culturas, en certas condicóes de solo e manejo agricola, o problema da compactafão também ê importante. Nos cerrados. problemas semelhantes são citados pelo CPAC-EMBRAPA no seu noticiario COMPACTACAO (1985). Entre os efeitos nocivos da compactacão são ressaltados a diminuicå da altura das plantas, sintomas 
de deficiencias nutricionais, susceptibilidade a perlodos secos de curta duracăo, formacăo de camada impermeavel, dificultando a infiltracao da aqua e facilitando a erosá, e dificuldade para o desenvolvimento vertical das ralzes.

observacao similar a do cPac também foi realizada na universidade de purdue nos E.U.A por STEINHARDT (1983) a partir da pesquisa iniciada para identificar os efeitos da compactacáo de superficie no desenvolvimento e na producão de milho cultivado após a soja. Um experimento foi feito, passando-se um trator 16 vezes en uma parcela da area total a ser cultivada. Após esta operacao as parcelas foram aradas, gradeadas e semeadas. As parcelas compactadas, comparadas com as outras nå compactadas, mostraram uma reducão na altura da planta de 20 a $30 \%$, levando a uma diferenca de $1883 \mathrm{~kg} / \mathrm{ha}$ na produca final. Os solos compactados produziram 8161 $\mathrm{kg} / \mathrm{ha}$ e os nao compactados $10044 \mathrm{~kg} / \mathrm{ha}$.

Esses dados ilustram bem a importancia de se estudar e compreender bem o fenomeno da compactaca do 5010.

A compactacão do 5010 é o resultado da aproximacao de suas particulas por forcas externas ou internas, provocando uma diminuicão de sua porosidade. Compreender bem este fenomeno significa entende-1o como um sistema que relacione a variacao da densidade atribuida a compactacáo com fatores externos (forca, umidade) e com as caracteristicas do solo (granulometria, porosidade, 
resigtencia e outros), do implemento (tipo de material, angulo de ataque e outos) e forma de utilizacáo deste.

Um entendimento completo do sistema solo. do ponto de vista da compactacao (figura l) e importante, pois deste modo pode-se projetar equipamentos e buscar tecnicas de manejo que minimizem o problema da compactacão. No entanto, um modelo completo ainda esta ben longe de ser obtido devido a complexidade do sistema.

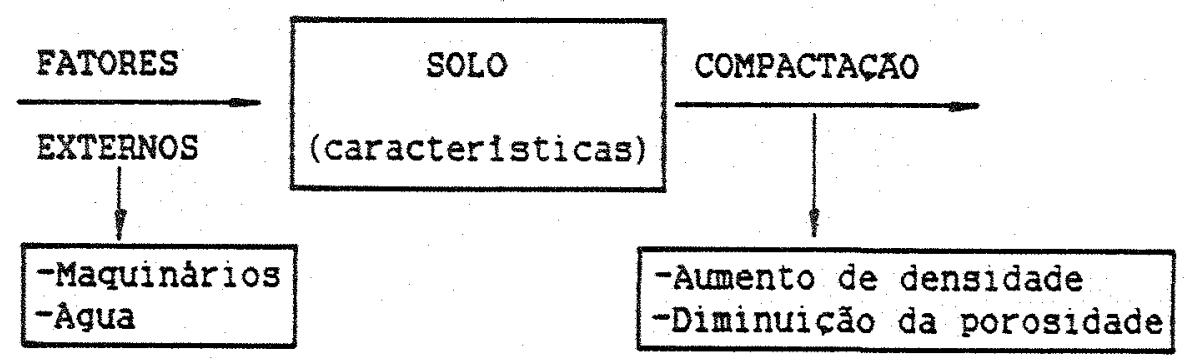

Eigura 1. Esquena do sistena solo, do ponto de vista da compactacão.

A compactacao pode ser medida pelo aumento da densidade ou dininuicao da porosidade num solo. Os métodos mais comuns de medida da densidade do solo são os metodos gravimetricos e atenuacao de um feize de raios gama, descritos com detalhes no ltem 3.2: Abaixo så feitos alguns comentarios das vantagens e desvantagens dos principais métodos de estudo da compactacão do 3010.

Metodos gravimetricos så usados para o cálculo da densidade, pela medida da massa e volume de uma 
amostra de solo. A desvantagem na utilizą̄á desta técnica \& que ela fornece uma media numa amostra de varios centimetros, ou seja, a resoluca num perfil e baixa. para amostras coletadas com amostradores, geralmente ocorre problemas de deformacão ou compactacão.

A atenuacão de um feixe de raios gama e uma tecnica que permite uma medida da densidade com boa precisão. O maior problema é que é necessario a medida da espessura da amostra, e portanto, esta necessita de formas requlares. Erros nas medidas dessas espessuras são as maiores fontes de erros desta tecnica. Utilizando-se amostradores de volumes (e portanto espessuras) conhecioos, volta-se ao problema da compactacá da amostra.

outro método muito difundido em estudos de compactacá de solos è o Penetrometro, que consiste de uma haste de metal com um cone em uma das pontas e uma carga móvel. Soltando esta carga sempre de uma mesma altura mede-se a penetracáo desta haste. Regibes compactadas oferecem maior resistencia a penetraca. os problemas desta técnica săo varios, pois ela nå quantifica o perfil en termos de densidade e a penetraca está intimamente relacionada com a umidade no perfil. No entanto, das tecnicas citadas a menos trabalhosa e bastante rapida possibilitando uma boa caracterizacá de una area. 
compactacao do solo os -transdutores de pressao ("gtraingage"), que medem a distribuifao das pressóes aplicadas no solo. Este método é mujto util em estudos da compactacão do solo, mas não fornece a distribuigå das deformacôes (variacões na densidade) ocorridas neste.

Uma técnica alternativa bastante recente de medida da densidade (e umidade) do solo é a Tomografia Computadorizada (PETROVIC et alii,1982; HAINSWORTH \& AYLMORE, 1983 e CRESTANA, 1985). Esta técnica tal como a transmissao de um feize de raios-gama e baseada no princlpio da atenuacão da radiacão $x$ ou gama pela materia, tendo a vantagem de não necessitar da medida da espessura da amostra e fornecer un mapa quase pontual (bi ou tri dimensional) da distribuicao de densidades no interior da amostra. Deste modo é possivel se determinar heterogeneidades no interior da amostra.

Segundo ANDERSON et alii (1988), recentes avancos na instrumentacão empregada na tomografia proporcionaram o desenvolvimento da tomografia computadorizada (TC) para rapidas analises bi ou tridimensionais nao destrutivas em tecidos biologicos. No entanto, as aplicacoes da TC nao se limitaram apenas ao campo da medicina. HORKINS et alil (1981) mostrou que a TC poderia ser utilizada para analise de plásico, madeira, concreto, aco e componentes eletronicos. ONOE et alii (1983) ilustrou o uso de un tomografo portatil para medida de aneis de crescimento de druores vivas. Na area 
da ciencia do solo, vários pesquisadores (PETRovic et a11, 1982; HAINSWORTH \& AYLMORE, 1983; CRESTANA et alii, 1985) introduziram e utilizaram a TC para estudos em Hica do solo.

A introducáo desta tecnica, no estudo da compactacão do solo, ira proporcionar um grande avanco no conhecimento dos processos de pressão-deformacão, possibilitando a medida espacial das deformacoes en pequenos volumes, o que ate o presente momento era impossivel, usando tecnicas tradicionais, como sera mostrado nos aspectos teoricos da compactacão do solo no captulo 2 .

o objetivo deste trabalho el justamente desenvolver as metodologias para as possiveis aplicacós da TC em diversos problemas praticos de compactacá de solos modelamentos dos processos de pressa-deformaca.

Nesta técnica as amostras nao necessitam de uma forma regular, ou seja, pode-se analisar torrós indeformados. Sendo tambem uma tecnica bastante sensivel (PETROVIC et alii, 1982, obteve una precisao para variacoes de densidades de $0,02 \mathrm{~g} / \mathrm{cm}^{3}$ ) e de alta resolucáo (comparada com as técnicas convencionais), parece ser otima para o estudo de variacós de densidade no solo.

Neste trabalho e desenvolvida a metodologia para a medida da densidade e umidade de amostras de solo de maneira a caracterizar localmente, distribuicós de 
compactafá num solo subnetido a uma pressão usando a tomografia computadorizada. Deste modo faz-se a utilizacáo de uma técnica bastante avancada, reconhecidamente poderosa no estudo de parametros fisicos do solo como a densidade e a umidade (CRESTANA et alii, 1988) num problema extremamente importante que a compactaca do de solos (COMPACTACAO, 1985).

- trabalho estuda alguns problemas de compactacå de solos encontrados em diversas situacóes naturais ou artificiais, que sao:

a) Estudo de finas camadas de solo compactado num perfil: Este problema ocorre devido aos processos naturais do intemperismo durante a formacao do solo, ou migracão de argilas para uma certa regiao do peril. causado geralmente por manejo indevido do solo. Para esse experimento sao feitas amostras com finas camadas de solo compactado envolvidas por solo năo compactado en recipientes de acrilico. Essas amostras sao analisadas com a TC de modo que se possa mostrar a aplicabilidade ou nao desta tecnica em problemas reais de tal natureza.

b) Compactacão por compressá de implementos agricolas e compressao de amostras de solo confinadas variando com a umidade: Amostras de solo sa coletadas num sulco após a passagem de um sulcador de modo a caracterizar a deformacão causada pela compressá do 
implemento no perfil. En laboratorio sao utilizadas amostras de solo confinadas er recipientes de acrilico para serem compactadas por uma pressa estatica com vărios graus de umidades. Essas amostras são analisadas com a TC de modo a se caracterizar espacialmente a deformaço imprimida no solo.

c) Caracterizacăo detalhada de um perfil de densidades: Torrós de solo sao retirados de uma trincheira num perfil vertical ate $70 \mathrm{~cm}$ e analisados pela TC para a caracterizacáo deste perfil de densidades e identificacao de eventuais regioes compactadas. Este perfil e comparado com nedidas feitas con a tecrica do penetrometro para varias umidades.

Para esses experimentos sao estabelecidos os procedimentos de preparo de amostras deformadas, coleta de amostras em campo e anâlise de amostras pela técnica da tomografia.

Por fim, deve-se levar em conta aloumas desvantagens na utilizacå da TC, que såo os altos custos dos equipamentos e a impossibilidade da medida no proprio campo. No entanto, alguns avancos tem sido obtidos no sentido de se construir equipamentos simples (CREsTaNA et a1ii, 1986; CRUVINEI, 1987), com custo sensivelmente diminusdo, como é o caso do tomografo utilizado neste trabalho. Quanto ao problema do transporte das anostras ao laboratorio, permanece ainda sem solucão. 


\section{ASPECTOS TEORICOS}

A seguir são feitas descricóes dos aspéctos teóricos ou conhecimento basico para elaboracão deste trabalho, que são: 0 solo, que é o objeto estudado, a compactacă do solo, que é o problema abordado, a espectrometria gama, interacå da radiacå com a materia e tomografia computadorizada, que dao suporte ao entendimento e descricão da metodologia utilizada.

\subsection{Descrifá do objeto solo}

- solo é formado pela açấo do clima e organismos atuando no material de origem, ao decorrer do tempo e dependendo ainda do relevo, sendo que todos os fatores atuam dependentemente.

Una definicão do solo (MARCos, 1982), com duas condicós necessárias e suficientes para identifica10 dentre os objetos da natureza e: "O solo es a parte superior do regolito, que cria condicoes que permiten que as plantas nele crescam". onde o regolito e a parte superficial que recobre a rocha consolidada e que resulta da acão e combinacáo dos processos quimicos, fisicos e biolsgicos do intemperismo. 
Como resultado desses processos de intemperizacao, o solo e constituldo de particulas dos mais variados tamanhos e natureza.

As particulas do solo sao classificadas quanto ao tamanho em tres classes distintas: argila, silte e areia. O termo tamanho è definido como sendo o diametro da esfera contida no maior comprimento da particula.

A tabela I apresenta os limites das classificacões da sociedade Internacional de ciencia do Solo (SICS) e do Depto. de Agricultura dos E.U.A. (DAEUA).

Tabela I. Limites dos diametros das particulas nas classificaçes granulometricas da Sociedade Internacional de ciencia do Solo e do Departamento de Agricultura dos E.U.A.

\begin{tabular}{|c|c|c|}
\hline $\begin{array}{l}\text { DIAMETRO DAS P } \\
\text { SICS }\end{array}$ & $\begin{array}{c}\text { RTICULAS (는) } \\
\text { DAEUA }\end{array}$ & TIPO DE PARTICULA \\
\hline$d<0,002$ & $d<0,002$ & ARGILA \\
\hline $0,002<d<0,02$ & $\begin{array}{l}0.002<d<0.05 \\
0.05<d<0.1\end{array}$ & $\begin{array}{l}\text { LIMO } \\
\text { ARETA MUITO FINA }\end{array}$ \\
\hline $0.02<d<0.2$ & $\begin{array}{l}0.1<d<0,25 \\
0.25<d<0.5\end{array}$ & $\begin{array}{l}\text { AREIA FINA } \\
\text { AREIA MEDIA }\end{array}$ \\
\hline $0.2<d<2.0$ & $\begin{array}{l}0.5<d<1,0 \\
1.0<d<2,0\end{array}$ & $\begin{array}{l}\text { AREIA GROSSA } \\
\text { AREIA MUITO GROSSA }\end{array}$ \\
\hline$d>2,0$ & $d>2.0$ & CASCALZO \\
\hline
\end{tabular}


Essas particulas podem, por meio de agentes cimentantes, se agruparem, formando agregados. A disposicão de particulas e agregados, decorrentes dos processos citados anteriormente, define a estrutura do solo, ou seja, a disposicao espacial dos componentes do sistema, uns com relaczo aos outros. A existencia de particulas de tamanhos e formas das mais diversas da a estrutura uma dificuldade muito grande de ser quantificada, a nao ser uma descrica meramente morfológica.

outro termo bastante utilizado para auxiliar na classificacão de un solo é a textura, que nada mais e que uma classificacao ou denominacáo do solo com relacão ás porcentagens de argila, silte e areia.

Aqui assume-se solo como a matriz solida, composta pelas particulas, agentes cimentantes (materia organica e oxidos) e os poros (espacos vazios entre as partlculas e entre os agregados). portanto a agua e o ar sa fatores externos ao solo, que competem pelo preenchimento do espaco poroso.

Parametros flsicos macroscópicos săo importantes no estudo das propriedades do solo. Entre eles podemos citar:

DENSIDADE DO SOLO (Ds): E a massa total de solo (Ms) dividida pelo volume dos solidos mais o volume de poros. ou seja, volume total do solo (Us): Ds $=M s / V s$ 
OBS.: No caso, a massa das particulas (Mp) e 1 gual a massa do solo (Ms).

UMIDADE OU TEOR DE AGUA NO SOLO: POde ser expresso a base de massa e a base de volume de aqua:

Massa (u) : massa de água (Ma), dividida pela massa de solo: $u=M a / M s$

volume ( $\theta$ ): volume de aqua (va) dividido pelo volume total do solo: $\theta=\mathrm{Va} / \mathrm{Vs}$

OBS.: $\theta=U . D S$

POROSIDADE DO SOLO ( $\alpha$ : VOlume de poros (vpo - vs - Vp) dividido pelo volume total do solo (Us): $\alpha=$ Upo/vs

Uma relacáo importante entre a porosidade total, a densidade do 3010 e a densidade das particulas é:

$$
\alpha=1-\frac{D s}{D p}
$$

Desta fltima relacão acima, observa-se que a densidade do solo esta intimamente relacionada com a sua porosidade.

2.2. Compactacão do solo

Sequndo BACCHI (1976) a compactacá de solos agricolas pode parecer de facil conceituacăo ge for considerado apenas o aspecto tisico, como se faz em estudos de mecacanica de solos. Entretanto o problema e 
mais complexo, envolvendo aspectos isicos, quimicose biologicos, bem como fatores climatologicos e de manejo.

Apesar do orande numero de trabalhos publicados a respeito do problema, ha deficiencias de informacôes, em relacão aos sequintes aspectos:

a) Conhecimento das caracterlsticas do solo e dos fatores externos que influenciam o fenomeno da compactacăo do solo;

b) os danos causados aos processos dinamicos que ocorrem no solo e nos espacos porosos tais como: a movimentacăo de aqua, gases, lons e calor;

c) Resposta das plantas devido ao fenomeno da compactacáo.

Uma mudanca no volume de um solo implica na mudanca do estado de compactacão deste. Esta mudanca es causada por forcas, que sao clasificadas en duas categorias: internas e externas. Forsas internas são aquelas originadas dentro do solo. Congelamento, secamento e molhamento são fontes de forcas internas.

A maioria das forcas externas sao mecanicas e relativamente faceis de serem identificadas e medidas. Por outro lado, a maioria das forcas internas sao diflceis de se identificar e medir.

De um modo geral, a intensidade da compactacão depende dos sequintes fatores: Granulometria 
(ou textura), tipo de mineral de argila, quantidade de materia organica, grau de agregaca, distribuicao de poros, densidade e umidade do solo. Depende ainda do tipo e forma de aplicacão da pressão no solo.

A influencia da umidade e determinada através de um teste padra desenvolvido para amostras deformadas, conhecido como teste de densidade proctor. A figura 2 mostra un exemplo da aplicacå deste teste. Esta relafão mostra que a compactafão do solo aumenta com o acrescimo da umidade até un determinado valor, na qual a densidade comeca a decrescer.

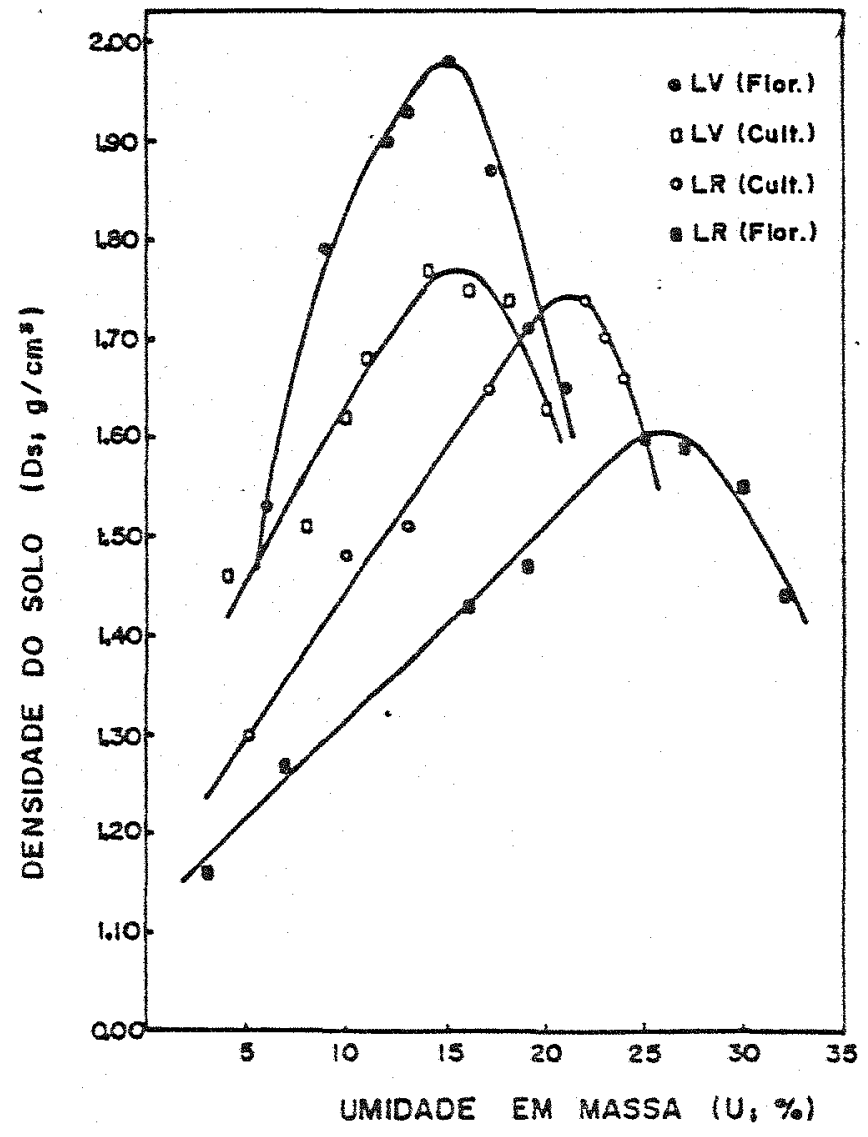

Figura 2. Aplicacão do teste de densidade proctor (SILVA et ali2, 1986). 
os outros parametros do solo mencionados, influenciam a compactacão atraves da acão e reacão as Forfas aplicadas. For exemplo, un solo cujas particulas estao bastante agregadas por agentes cimentantes è menos susceptivel a compactaca que um outro menos agregado.

Como as particulas do solo, áqua e o ar são relativamente incompressiveis, sob a acá de cargas geralmente aplicadas no solo, a mudanca no estado de compactacao depende do movimento desses componentes.

A mudanca de volume e portanto, dependente do deslocamento das particulas, para um solo insaturado. Para solo saturado depende também de como a agua escoa no interior deste, para uma dada carga.

Velculos e maquinarios agricolas causam uma compactacão, ou seja, un aumento da densidade ( ou diminuicão da porosidade) do solo, da superficie para o subsolo, num gradiente negativo. No entanto, o processo de preparo do solo para cultivo, resulta num estado menos denso da camada agricultável. Abaizo desta camada, ou seja, abaixo da base da passagem do implemento, o problema persiste e dependendo do coeficiente de friccão lou adesao) na interface de deslize solo-implemento, angulo de corte, velocidade e outros, o problema pode se agravar. A figura 3 exemplifica este processo de compactaca localizada, o qual pode gerar o chamado pé de arado ou soleira. 

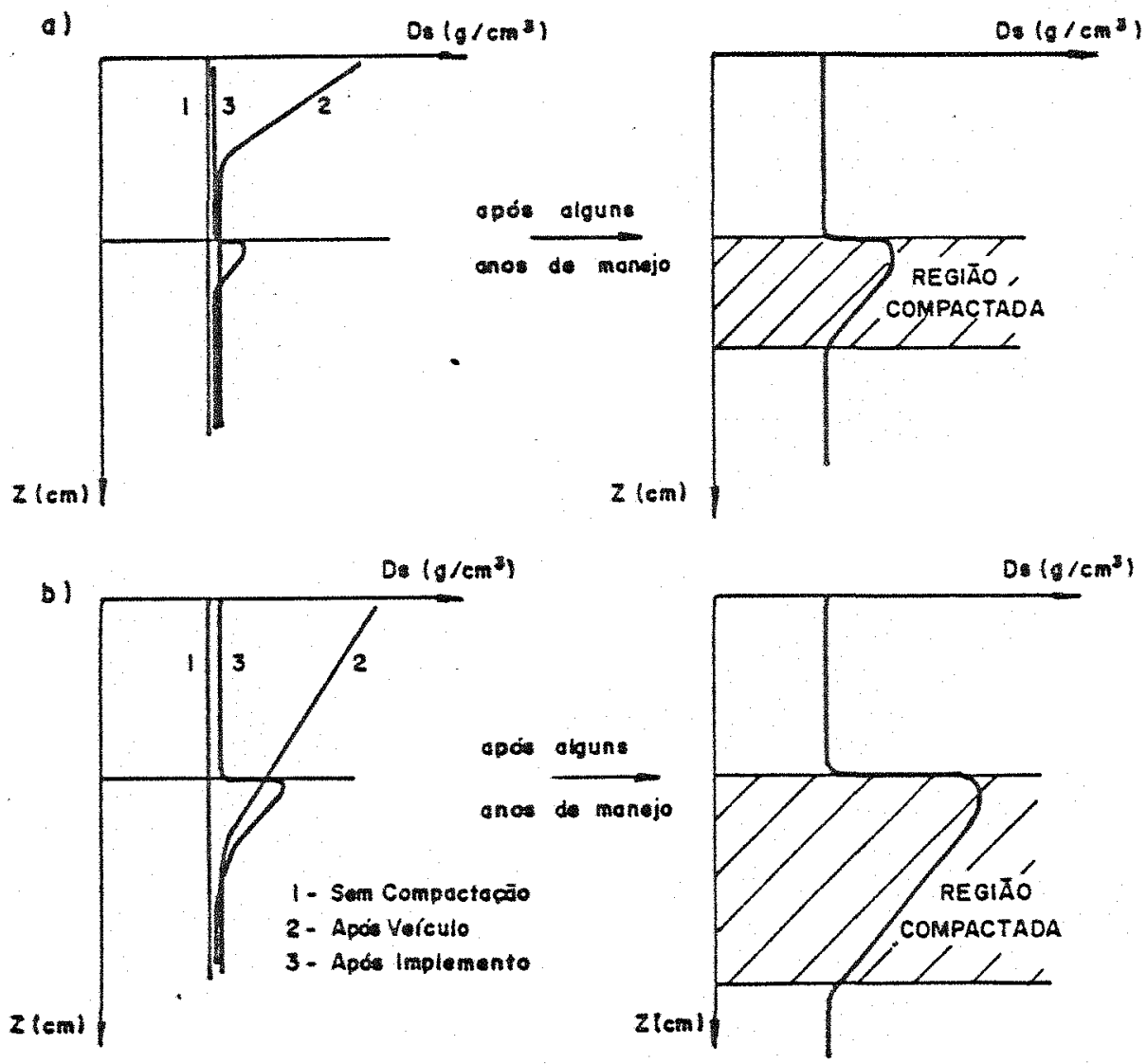

Fiqura 3. Esquema do processo de compactacão do solo por velculos e implementos agricolas, mostrando seus efeitos acumulativos, devido apenas ao implemento a) e a ambos b).

A seguir é feita uma descricão de como as pressbes imprimidas na superficie de um solo são transmitidas para o interior deste provocando deformacos e as equacoes utilizadas para descrever tal processo.

Inicialmente as pressbes (forca por unidade de area) såo imprimidas na superficie do solo e enta transmitidas no interior deste. A figura 4 mostra como ocorre a distribuicao de pressbes numa superficie rigida de um solo arenoso, por pneus lisos, nos quais foram acoplados transdutores de pressäo ("strain gage"). 


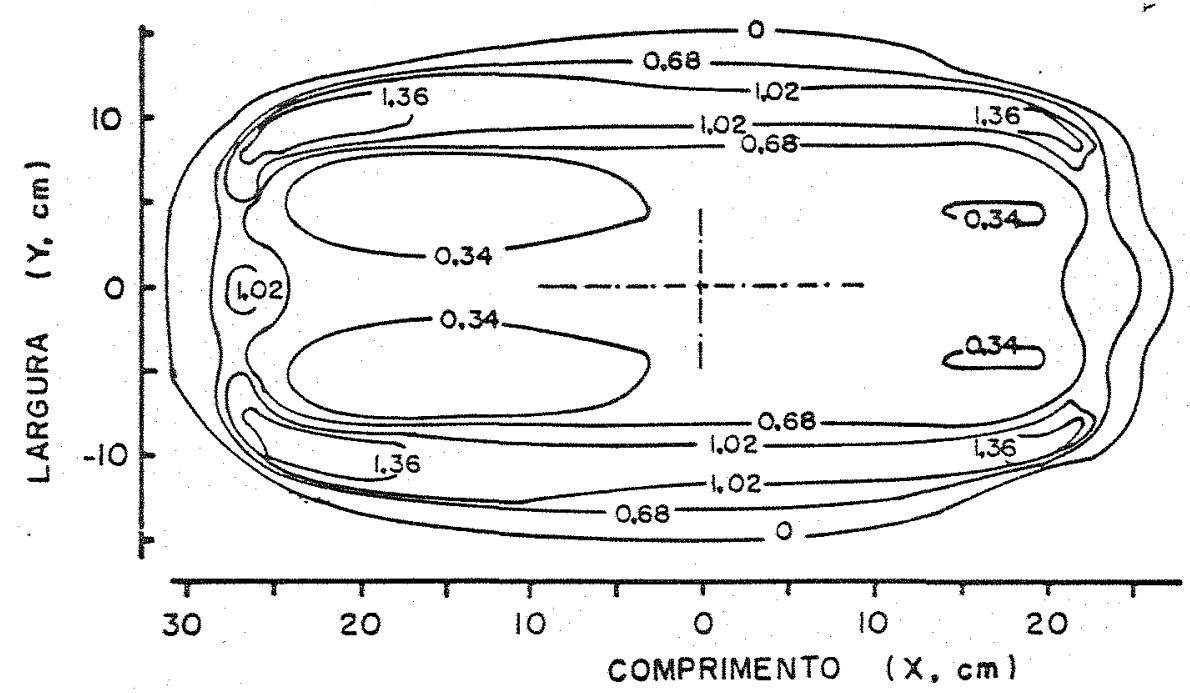

Figura 4. Distribuicăo das pressóes imprimiaas por pneus de un veiculo na superilcie de un solo arenoso rigido (Vander Bera \& Gill, $1962)$.

De um nodo geral essa distribuicá mostrada, varia com a pressão no interior do pneu, peso do velculo, numero de pneus e area de contato destes.

As distribuicões de pressores no interior de um solo sob carga, podem ser obtidas experimentalmente. introduzindo transdutores de pressão no interior deste.

- lugar geometrico de pontos de igual pressa em qualquer profundidade e uma superficie de revolucåo. E possivel tracar deste modo, uma superficie de mesnas pressoces (isóbaras) projetada num plano vertical, a qual e chanada de bulbo de pressao. A figura 5 mostra um conjunto de bulbos de pressóes obtidos experimentalmente. 
também ser estimada, utilizando a teoria matematica da elasticidade. No entanto, algumas aproximacoes e consideracdes devem ser assumidas e mesmo assim, devido d grande variedade de solos e processos, nem sempre essa teoria descreve bem a distribuicao das pressoes num solo sujeito a uma carga.

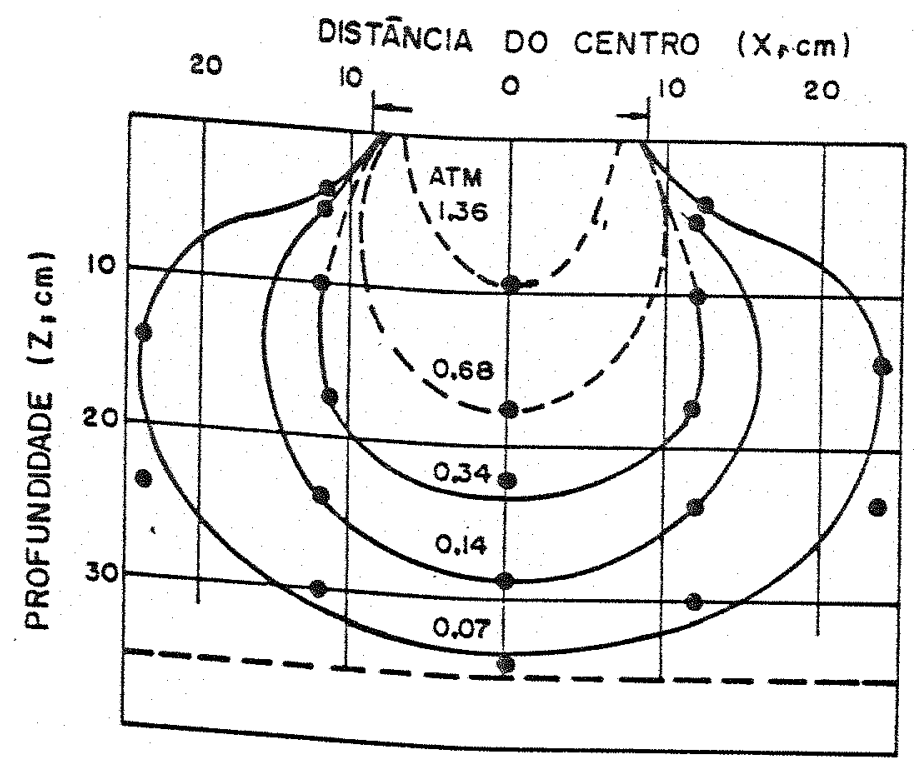

Figura 5. Distribuicão de pressões num plano vertical do solo sob uma pressáo de 20,3 ata $(2,06 \mathrm{MPa})$ aplicada numa area de $0,2 \mathrm{~m}^{2}$ (vander Berg et alis, 1957)

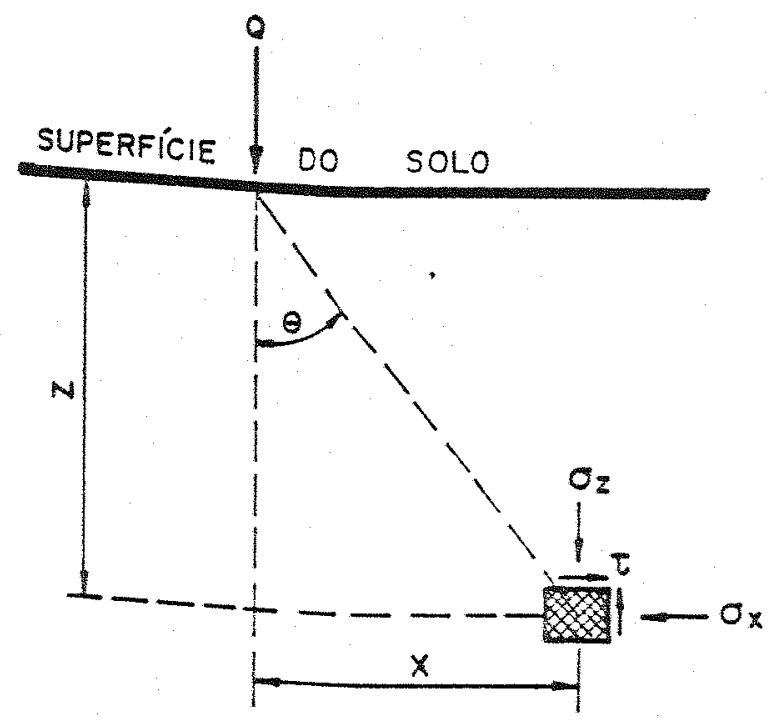
Figura 6. Pregsóes aginco num volume intinitesimal do solo sob ua
carga pontual $Q$. 
20.

Boussinesq foi 0 primeiro a obter uma solucăo da distribuicăo de pressóes num meio semi infinito, elastico, homogeneo e isotrópico, que seque a lei de Hooke (COHRON, 1971). Boussinesq obteve as seguintes relaçóes:

$$
\begin{aligned}
& \sigma_{z}=\frac{3 \cdot Q}{2 \cdot \pi \cdot z^{2}} \cdot \cos ^{5} \theta \ldots \ldots \ldots \ldots \\
& \sigma_{x}=\frac{Q}{2 \cdot \pi \cdot R^{2}} \cdot 3 \cdot \cos ^{\theta} \cdot \operatorname{sen}^{2} \theta-\frac{m-2}{m} \cdot \frac{1}{1+\cos \theta} \\
& \tau=\frac{3 Q}{2 \cdot \pi \cdot R^{2}} \cdot \cos ^{2} \theta \cdot \operatorname{sen} \theta \ldots \ldots \ldots \ldots \ldots
\end{aligned}
$$

onde $m=1 / p$ ( $p=c o e f i c i e n t e$ de poison ou coeficiente de compressibilidade, o qual depende do tipo de solo - ver BARATA, 1984), $\sigma_{z}, \sigma_{x}$ são as pressós verticais e horizontais num elemento de volume, $\tau$ a tensa de cisalhamento, \& a forca aplicada, $R$ a distancia entre o ponto de aplicacão da forca e o elemento de volume do solo. Todos esses parâmetros e ainda mais $\theta, x$ e sa esquematizados na figura 6 .

segundo BARATA (1984), en geral, solos se afastam das condiczes ideais de validade da teoria de Boussinesq, pois não são materiais elásticos, homogeneos e isotropicos. No entanto, a teoria es considerada razoavel, observadas as seguintes condicoes:

a) Nå pode haver rachaduras no interior do solo; 
b) A resistencia ou módulo de deformacão, deve ser constante na profundidade. Este aspecto é mais real para solos argilosos;

c) Para solos muito heterogeneos, usa-se uma correcao estabelecida por Burmister (ver BARROS, 1966);

d) A solucão de Boussinesq é valida para carga concentrada, o que equivale a dizer que a teoria so se aplica para profundidades razoavelmente grandes. Fara profundidades menores deve-se utilizar cargas aplicadas numa area e nao nais pontual.

Tendo em vista as limitacós da teoria de Boussinesq, Frohlich introduziu un fator de concentracao $v$, pois de observacoes experimentais, notouse que haviam naiores concentracões de pressões em torno da vertical do eizo de aplicacão da carga. Quanto maior o valor de $v$, maior a concentracão de pressöes, no eixo vertical. Frohlich obteve as seguintes expressodes:

$$
\begin{aligned}
& \sigma_{z}=\frac{v \cdot Q}{2 \cdot z^{2}} \cdot(\cos \theta)^{v+2} \ldots \ldots \ldots \\
& \sigma_{x}=\frac{\nu \cdot Q}{2 \cdot \pi \cdot R^{2}} \cdot(\cos \theta)^{v-2} \cdot \operatorname{sen} \theta \\
& \tau=\frac{v \cdot Q}{2 \cdot \pi \cdot R^{2}}(\cos \theta)^{v-1} \cdot \operatorname{sen} \theta \ldots
\end{aligned}
$$

Segundo SOEHNE (1958), $v=3$ para solos homogeneos, isotrópicos, com comportamento elástico. para 
solos não homogeneog e comportamento năo só elástico, mas um tanto plastico, $v$ varia entre 4 e 6.0 fator de concentrafão ideal, deve ser obtido experimentalmente.

Alem dessas solucbes, existem outras, onde cada qual se adapta melhor ou pior a determinados tipos de solos e condicós especificas de compactacöes. BARATA (1984) apresenta algumas outras solucôs de distribuicões de pressões e cálculos de deformacões de solos. Tambem NOGUEIRA (1988) apresenta uma revisão dos principais metodos de estudo das transmissoes das pressós en solos.

Embora grande avanco tenha sido obtido na descrịão das transmissōes das pressões no solo, usando a teoria da elasticidade, as equacós descritas nå evidenciam a variacão de volume, isto e, a variacão de densidade ou porosidade.

para suprir esta deficiencia, muitas equacóes empiricas foram desenvolvidas, relacionando a pressão com a deformacão do solo. A eq. (8) mostra uma dessas relacós (HARRIS, 1971):

$$
e=e_{0}-c \cdot \log \left(P / P_{0}\right)
$$

onde $e_{0}$ e a relacáo de vazios (volume de vazios/volume de solidos) na pressão inicial $p_{0}, c$ o coeficiente angular num grafico semi logaritimico e $p$ a pressăo aplicada.

$$
\text { Para estudos de resistencia á compactacão }
$$
de solo perturbado e confinado, REAVES \& NICHOLS (1955) 
encontraram a sequinte relacao:

$$
p=a \cdot e^{b \cdot z}
$$

onde $a$ e b sao constantes que dependem de parametros do solo, $p$ e a pressa aplicada e $z$ e eixo normal a superficie.

HOVANESIAN \& BUCHELE (1959) encontraram para uma massa finita de solo, que a densidade Ds se relaciona com a pressão o pela fórmula geral:

$$
D s=D s_{0}+B \cdot \ln \frac{\left(\sigma / \sigma_{0}+C\right)}{1+C}
$$

onde $B$ e $C$ sao constantes, Ds $e$ a densidade inicial sob condicao de carga inicial o, e Ds a densidade sob condicao de carga o.

Desses e outros resultados empiricos. conclui-se que a relacão entre a carga externa aplicada e - volume de vazios não e linear, mas sin logaritimica ou exponencial. Nas constantes das eq. (8), (9) e (10) estao embutidas as propriedades do solo e a forma de se compactar este solo.

Associando as equacoes emplricas citadas acima, com as equacoes de Frohlich (que mais se aproxima das condicoes reais do solol, e possivel obter uma expressão semi emplrica, que relaciona a variacao de densidade, com a pressão aplicada neste. 
GUPTA et alii (1985) obteve uma expressão experimental (eq.11), semelhante a eq. $-(10)$ :

$$
D s=\left[D s_{0}+x\left(s_{1}-s_{0}\right)+C \cdot \log \left(\sigma_{z} / \sigma_{0}\right)\right]
$$

onde Ds e a densidade calculada, Ds。 a densidade numa pressão conhecida $\sigma_{0}, \sigma_{z}$ a pressáo normal aplicada, $C$ uma constante, $x$ a tangente a curva de saturacao cdensidade vs umidadel para uma pressao o, aplicada, so o grau de saturacão correspondente a $D s_{0}$ e $s_{1}$ o grau de saturacáo utilizado.

Associando a eq. de Frohlich, com a eq. (11), Gupta obteve un modelo para o caleulo da densidade de un solo sob carga, no qual a diferenca entre valores medidos e calculados variaram de 0,1 a $0,3 \mathrm{~g} / \mathrm{cm}^{3}$.

\subsection{Interacáo da radiacå gama com a materia}

A radiacão gama é uma onda eletromagnética. sua energia (E) vale: $E=h \cdot v$, onde $v$ a frequencia $e$ h a constante de Planck $\left(6.6625 \times 10^{-27}\right.$ erg.s $)$ e seu momento (p) vale: $p=h \cdot v / c$. Temos ainda que $c=h \cdot v$ onde $e$ comprimento de onda e $c$ a velocidade da luz. A Eigura 7 localiza esta radiacão no espectro das radiacós eletromagneticas.

Quando por aloum processo natural ou artificial, ha um desarranjo na estrutura do nucleo de um atomo, este nucleo se torna excitado. Na volta a uma 


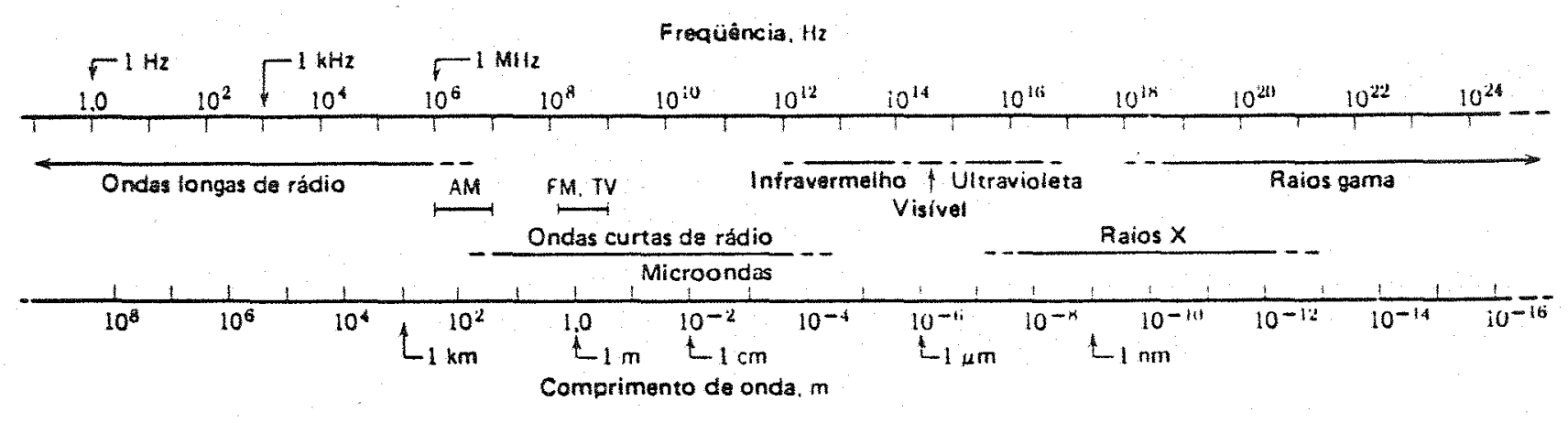

Fioura 7. Espectro das radiacoes eletromagnéticas.

configuracão estável ocorre processos de desexcitacós nucleares. Un desses processos e chamado de desexcitacão gama, ou seja, a emissão de radiaca gama pelo nucleo. Essa degexcitacão é secundaria, pois só ocorré apos algum outro processo, como a emissão de particulas $\alpha, \beta^{+}, \beta^{-}$, a captura eletronica e outros.

A energia da radiaca gama possui un valor unico, ou seja, e monoenergetica, vai desde algumas dezenas de kev até alguns Mev.

Por ser radiafao eletromanetica de energia relativamente alta, os raios gama tem alto poder de penetrąåo num meio, se comparado com particulas a. $\beta^{+} \cdot \beta^{-}$. No entanto o poder de jonizacão dos raios gama e muito menor que o das referidas particulas.

Na interaçăo da radiacáo gana (fotons) com a materia de um meio, variog fenomenos de transferencia de energia podem ocorrer. os processos de interacá da radiacăo com a materia dependem da sua energia e do número 
atomico do material. Fotons de baiza energia podem interagir somente com os eletrons mais externos do atomo. Fotons de energia maior, podem interagir con eletrons fortemente ligados e finalmente fótons de altisima energia, interagem nos campos dos nucleos dos atomos. Os principais processos de interacáo säo: efeito fotoeletrico, efeito compton e producão de pares. 0 espalhamento Rayleigh a exemplo de outros tambem presentes nos processos de interacå da radicáo com a matéria tem contribuifao despresivel no caso que estamos estudando. segue-se entao uma breve descrifao desses processos (mais detalhes podem ser encontrados em JoHNS \& LAUGHLIN, 1982):

a) Efeito fotoeletrico

Fotons de baixa energia podem interagir com a materia por efeito de colisao direta entre fotons e um dos eletrons. o elétron ejetado do atomo é chamado fotoeletron. A energia cinetica $\left(T_{*}\right)$ do eletron ejetado é dada por $T_{*}=E-E_{L}$ onde $E$ é energia do foton $e E_{L} a$ energia de ligacão do elétron (figura 8). Como o eletron caminha pouco num meio, ele transfere toda sua energia a este neio e diz-se que pelo efeito fotoeletrico toda energia e transferida para o meio.

- processo somente ocorre se $E>E_{L}$. quando ha fotons de baixa energia as interacoes ocorrem con eletrons mais externos. Com un incremento da energia as interacões comesam a ocorrer com eletrons mais 
fortemente ligados, ate quando $E$ for maior que $E_{K}$ (energia de ligacá da camada $k$ ). Assim todos os eletrons podem tomar parte do processo fotoeletrico. No entanto. pode-se mostrar que o processo ocorre mais comumente com um dado eletron quando a energia do foton e levemente maior que a de ligacão do eletron. Nä ha ocorrencia de efeito fotoeletrico para un eletron livre.

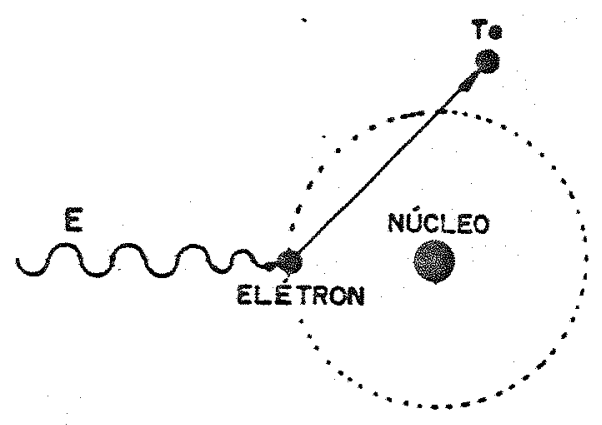

Figura 8. Representafão esquemática do processo de absorcão fotoeletrica.

A ocorrencia do processo de absorcão Fotoeletrica aumenta com $O$ incremento do numero atomico do absorvedor e diminui com o aumento da energia da radiaca.

b) Efeito Compton

Este processo é uma colisao elastica entre um Eoton e um eletron que está essencialmente livre, ou seja, a energia do foton é muito maior que a energia de ligacão do elstron no átomo. 
28.

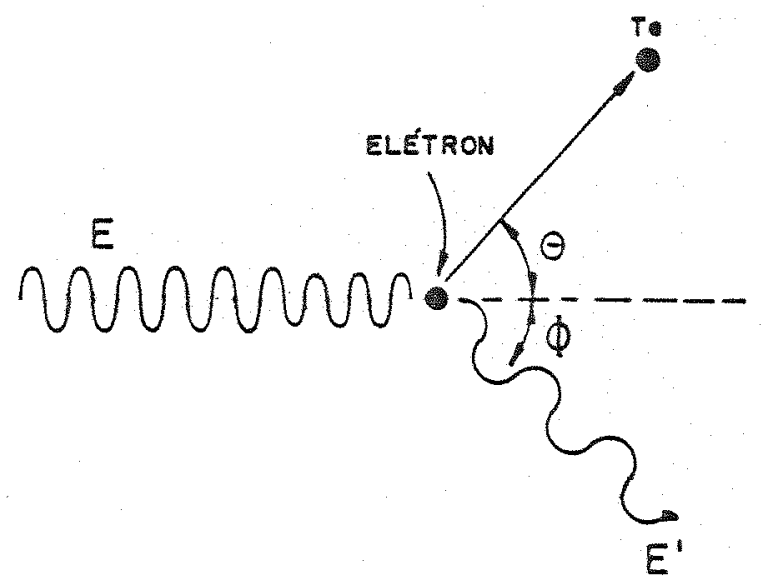

Fiqura 9. Representaca esquenatica do processo de espalhamenco compton.

- Eston incidente de energia $E$, colide com um eletron considerado inicialmente em repouso. o elétron e espalhado com energia T., fazendo um angulo com a direcáo do foton incidente. O foton espalhado tem a energia reduzida a $E^{\prime}$ e é espalhado de um angulo $\Phi$ com a direcão do foton incidente, como mostra a figura 9.

De acordo com a lei de conservacåo da energia e do momento, tem-se que:

$$
E^{\prime}=\frac{E}{1+\frac{E}{m_{0} \cdot c^{2}}(1-\cos \theta)} \ldots \ldots \ldots \ldots \ldots
$$

onde $m_{0}$ e a massa de repouso do eletron.

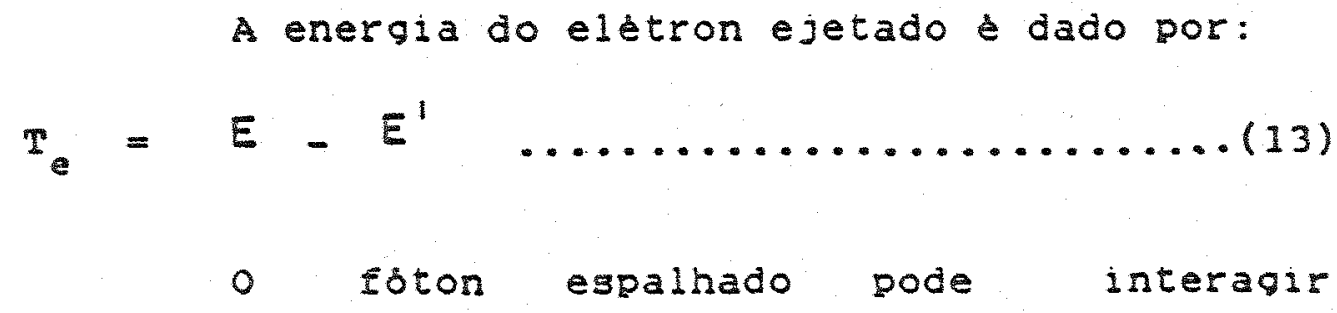
novamente com a materia e dependendo da dimensao do meio, toda sua energia pode ser absorvida ou na. 
c) producão de pares

ocorre quando a energia do foton incidente for maior que 1,02 Mev, ou seja, duas vezes a energia de repouso do eletron. Isto ocorre nas prozimidades do nucleo e o foton é completamente absorvido.

Sua energia e convertida em massa de repouso de um eletron e um pósitron, os quais possuem cargas iquais, mas sinais contrarios e o restante em energia cinetica dessas. As energias cineticas dessas partlculas săo dadas por:

$$
T_{e^{-}}=T_{e^{+}}=\frac{E-2 \cdot m_{0} \cdot C^{2}}{2}
$$

- eletron perde completamente sua energia para o meio. o pósitron tambem interage com 0 meio e quando a sua energia atinge aproximadamente $10 \mathrm{ev}$, ocorre uma reacão de aniquilamento deste positron com um outro eletron qualquer do meio.

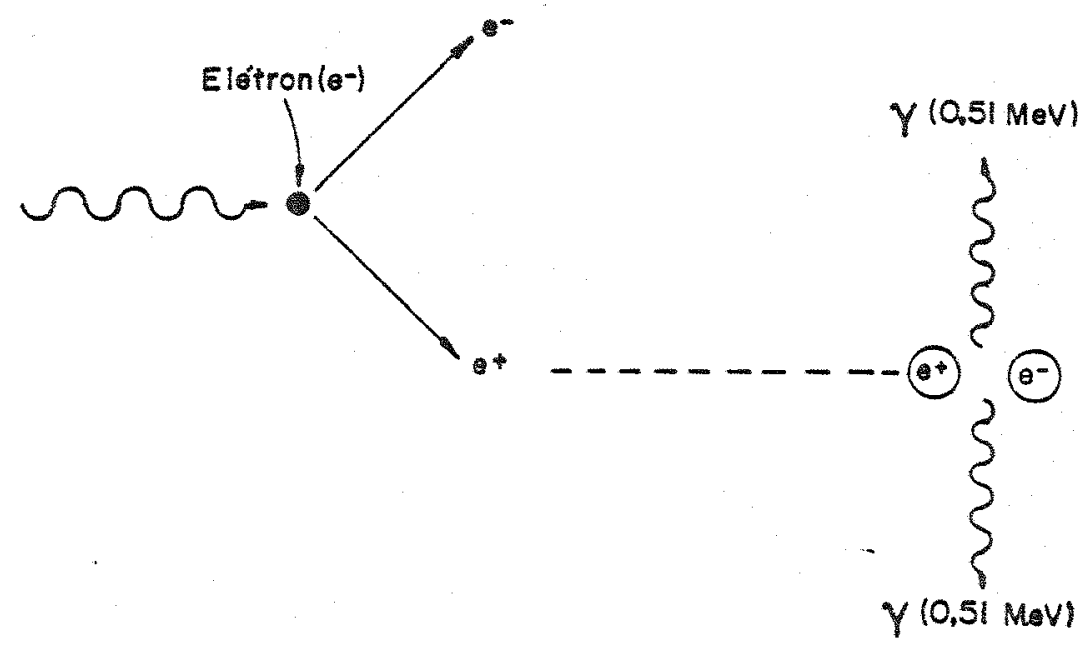

Eigura 10. Representacào esquematica do processo de producão de pares. 
Neste processo de aniquilacào os dols eletrons săo consumidos e dao origem a dois raios gama de $0.51 \mathrm{MeV}$. que saem num angulo de 180 graus entre eles. Um esquema da producăo de pares é mostrado na figura 10.

\subsection{Atenuacão de um feixe de raios gama}

Devido ás interacốes descritas no 1 tem 2.3 , um feixe de raios gama ao passar por um material, sofre uma atenuacao, ou seja, parte dos fotons passam sem interagir e outra parte trangfere total ou parcialmente sua energia a matéria, isto e, sao absorvidos.

A relacao entre o feize incidente $\left(I_{0}\right)$ e $\circ$ emergente (I), num determinado meio material homogeneo de espessura $x$ e:

$$
I=I_{0} \cdot \exp (-\mu \cdot x)
$$

onde $\mu$ e uma constante de proporcionalidade chamada coeficiente de atenuacão linear $\left(\mu ; \mathrm{cm}^{-1}\right)$.

- coeficiente de atenuacá linear depende de varios parametros. Entre eles a energia da radiacáo, a composicao quimica e a densidade do material absorvedor.

Como o coeficiente de atenuacão linear varia com a densidade do material (D). e conveniente expressar a atenuaca em termos do coeficiente de atenuacão em massa $\left(\bar{\mu} ; \mathrm{cm}^{2} / g\right)$, que es uma constante para 
un determinado material:

$$
\bar{\mu}=\mu / D
$$

- coeficiente de atenuacáo pode ainda ser expresso em termos de atomos e eletrons:

COEF, DE ABSOR. ATOMICO $=\frac{\mu}{D} \cdot \frac{A}{N} ; c \mathbb{W}^{2} /$ atomo $\ldots . .(17)$ COEE. DE ABSOR. ELETRONICO $=\frac{H}{D} \cdot \frac{A}{N} \cdot \frac{1}{Z} ; \mathrm{cm}^{2} /$ elét... (13) onde A é ótomo-grama, 2 o numero atomico e $\mathrm{N}$ o numero de Avogadro.

Cada processo de interacão da radiaca com a materia contribui independentemente para o coef. de absorcao total de um material, como mostrado na figura 11.

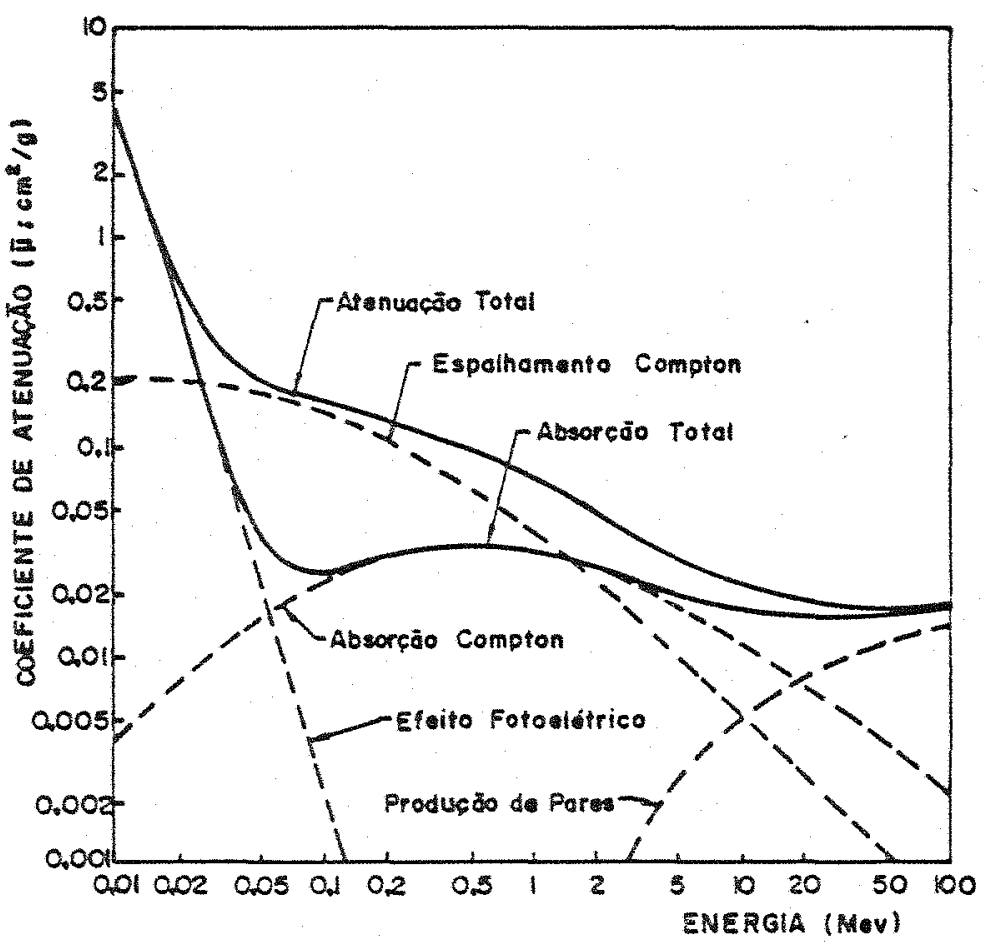

Fiqura 11. Coeficiente de atenuacão em massa, da aqua en funcâo da energia (JOHNS \& LAUGHLIN, 1982). 
Para un material composto de vârios elementos quimicos, o coeficiente de atenuacão em massa é aproximadamente iqual a soma proporcional dos coeficientes de cada elemento quimico, presente no material, ou seja:

$$
\left.\bar{\mu}=\sum \bar{\mu}_{i} \cdot \mathrm{P}_{\mathrm{i}}:\right) / 100
$$

onde $P_{i}$ é a porcentagem em massa do i - ésimo elemento no material. Experimentalmente obtem-se uma pequena diferenca do valor obtido pela eq. (19) devido ás alteracóes causadas pelas ligacóes entre atomos e moléculas.

- solo é um material poroso. composto de uma grande quantidade de elementos quimicos. o seu coeficiente de atenuacao en massa reflete entao, a somatória dos coeficientes de cada um desses elementos.

No entanto, para um dado solo è possivel se calcular experimentalmente o coeficiente de atenuacăo atraves da medida do feide de radiaca que incidiu e que energiu do material, da espessura percorrida pelo feixe e da densidade do material. Alteracbes na atenuacao $\left(\mathrm{cm}^{-1}\right)$ para uma determinada amostra de solo, e atribuida a variacóes da densidade (ou umidade). A partir dál, pode-se calcular a densidade e a umidade do solo, como mostram as equacōes 20 e 21 , abaixo:

$$
\begin{aligned}
& I=I_{0} \cdot \exp \left[-\left(\bar{\mu}_{s} \cdot x_{s}+\bar{u}_{a} \cdot x_{a}\right)\right] \ldots \\
& I=I_{0} \cdot \exp \left[-x \cdot\left(\bar{\mu}_{s} \cdot D s+\bar{\mu}_{a} \cdot \theta \cdot D a\right)\right]
\end{aligned}
$$


onde $\mu_{3}$ e $\mu_{0}$ så os coeficientes de atenuacão lineares do solo e da água respectivamente, $\bar{\mu}_{\text {, }}$ e $\bar{d}_{0} 0$ coeficiente de atenuacão em massa do solo e da água, $x$ a espessura do solo atravessada pelo feixe de fótons, Ds e Da a densidade do solo e da agua respectivamente $e \theta$ a unidade do solo.

Um detalhamento da passagem da eq.

para (21), pode ser encontrado em CRESTANA (1985).

Finalmente, dividindo a eq. (21) pela

e Fazendo $\mathrm{Da}=1 \mathrm{~g} / \mathrm{cm}^{3}$, obtem-se:

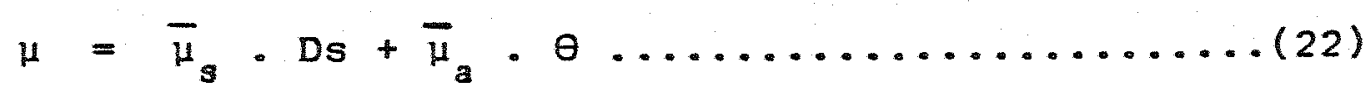

A eq. (22) mostra que na medida do coeficiente de atenuacão linear de un solo, estao embutidos os parametros densidade e umidade. Esta informacao e especialmente imporatante para o entendimento da tecnica da tomografia computadorizada no estudo de parametros fisicos do solo, que seră abordado no item 2.6 .

\subsection{Espectrometria gama}

Todo o suporte para a detecáo da radicåo gama e determinacăo de seu espectro, é conhecido como espectrometria gana. Na figura 12 e apresentado um diagrama de blocos de um espectrometro gama (monocanal), ou seja, de un medidor de radiacăo gama. 


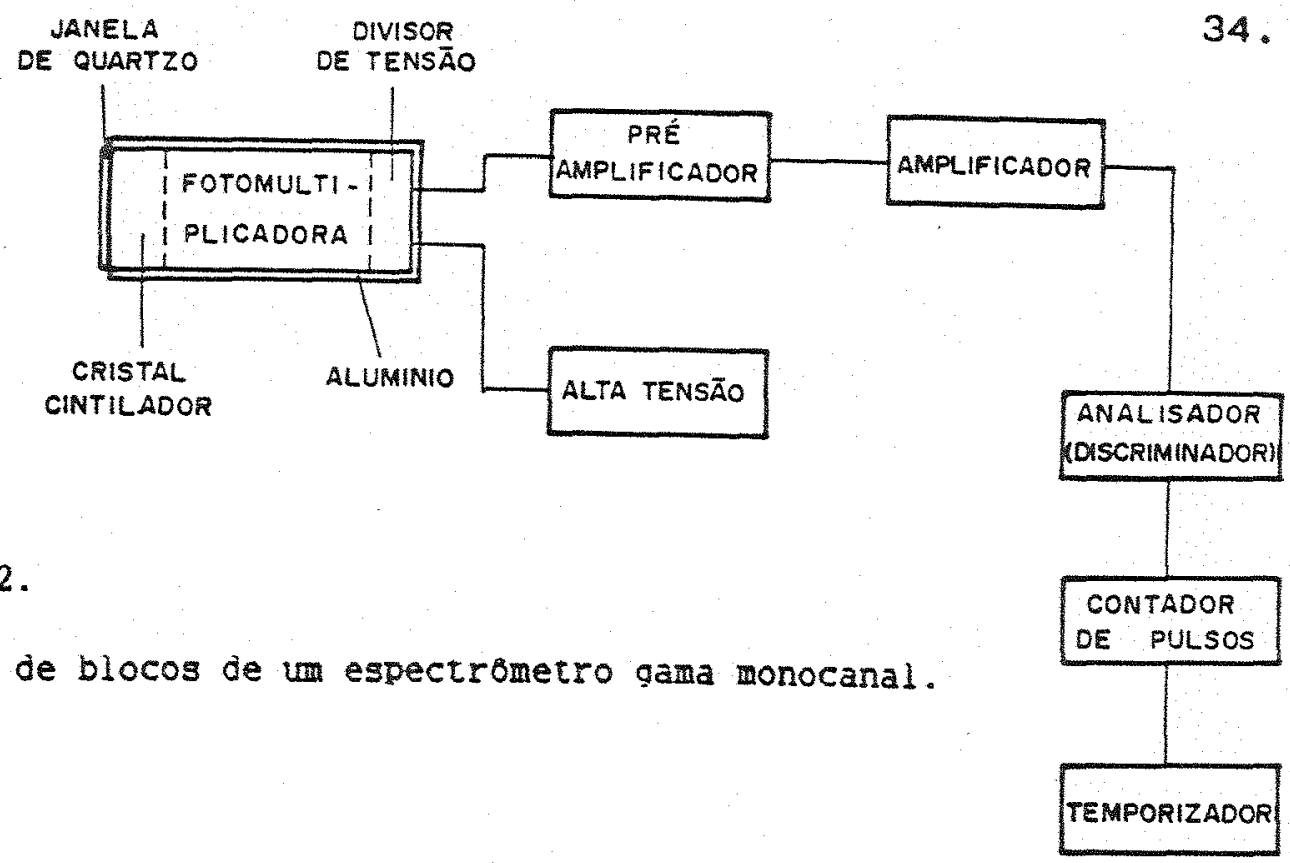

Eigura 12.

Diagrama de blocos de um espectrometro gama monocanal.

segue-se agora uma descrifá dos principais componentes deste sistema:

CAISTAL CINTILADOR

A radiacão gama a ser detectada pelo sistema de espectrometria gama incide num cristal cintilador, por exemplo de NaI(Tl) e retira eletrons deste através dos processos de interacáo descritos anteriormente. Esses eletrons interagem com a rede cristalina do NaI fazendo-a vibrar, ou seja, se excitam. Na desexcitacão ha emissão de radiacáo eletromagnética, que para o caso do NaI(T1) esta na regia do vigivel em torno de $430 \mathrm{~nm}$. A figura 13 esquematiza tal processo.

para que toda a radiacăo gama incidente seja detectada, deve haver absorcao total e consequente transformacao desta en luz. No efeito fotoeletrico, toda energia es absorvida. Ja no efeito compton e producão de 


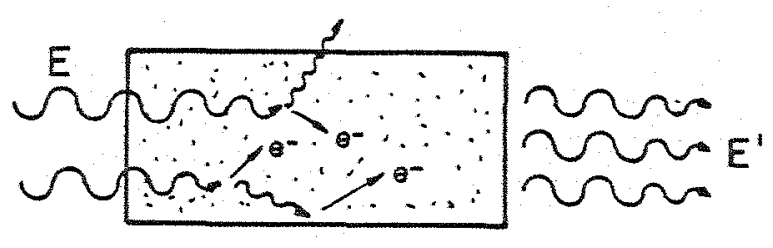

CRISTAL CINTILADOR

Eigura 13. Esquema do processo da interacăo de un toton gama con un cristal cintilador.

pares nem toda a energia é transferida para o cristal. pois os fotons gama espalhados e criados podem sair do cristal. Un aumento do tamanho do cristal cintilador. aumenta a eficiencia de deteção.

VALUULA FOTOMULTIPLICADORA

A luz proveniente do cristal incide, numa valvula fotomultiplicadora, passando pela janela de quartzo e vindo a colidir com o fotocatodo (fina camada de uma liga de cesio - Antimonio). A energia de ligacão dos eletrons do fotocatodo e aproximadamente 1,5 ev e a do foton incidente $3 \mathrm{ev}$. Portanto por efeito fotoeletrico, os eletrong são retirados do fotocatodo e acelerados por uma diferenca de potencial entre o catodo e o primeiro dinodo.

os dinodos sao tambèm recobertos com $\mathrm{Cs}-\mathrm{Sb}$ * separados por uma diferenca de potencial crescente. Deste modo, depois de percorrer varios dinodos, os eletrons multiplicados sao coletados no anodo (figura 14 ). 


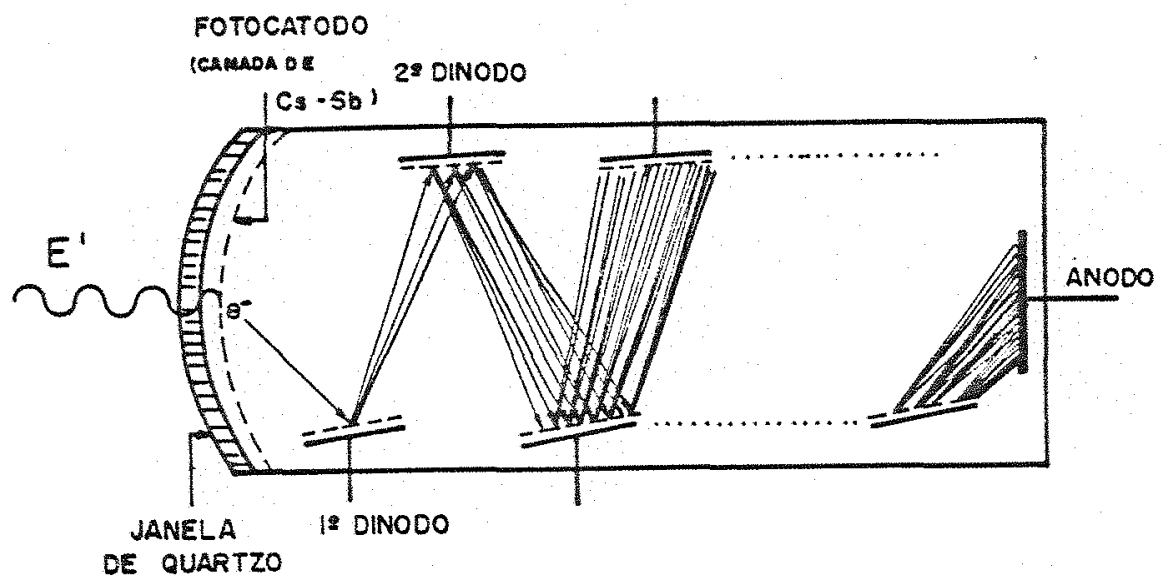

Figura 14. Esquema de funcionamento de uma válvula fotomiliplicadora.

A amplitude do pulso será proporcional à energia da radiacão incidente, pois quanto maior a energia dos fótons maior será a quantidade de elétrons criados.

DIUISOR DE TENSAOO E ALTA TENSAO

A fotomultiplicadora e alimentada com alta tensăo, pois a diferenca de potencial entre o catodo e o anodo ê de aproximadamente 800 volts.

Um divisor de tensão e utilizado para dividir a alta tensão entre os dinodos que tem diferencas de potenciais crescentes.

PRE-AMPLIFICADOR E AMPLIEICADOR

A funcão do prè-amplificador è manter a amplitude do sinal que e transmitido por um cabo, para que 
este nao seja perdido pela resistencia ohmica do cabo.

$$
\text { - amplificador aumenta o sinal (amplifica) }
$$

deixando num nivel em que possa ser utilizado pelo resto do sistema eletronico.

ANALISADOR MONOCANAL

A amplitude do pulso que sai do amplificador e proporcional a energia da radiacăo. A ocorrencia do efeito compton e producão de pares faz coll que aparecam fotons de energias diferentes das que incidem no cristal cintilador e portanto formam-se pulsos com amplitudes variadas, dando ao espectro de energias uma distribuicão normal com o valor máximo no fotopico.

- analisador discrimina os pulsos com amplitudes acima de um determinado valor (modo integral) ou entre dois extremos de amplitudes (modo diferencial)

CONTADOR E TEMPORIZADOR

- contador identifica os pulgos discriminados no analisador, contando-os num intervalo de tempo, selecionado no temporizador.

2.6. Tomografia computadorizada

Na tomografia computadorizada por

trangmiså, um feixe de raios $x$ ou gama é varrido numa 
gecao trangversal de um objeto, como mostra a figura 15. Se a radiacá é monoenergetica, a transmissáo é dada pela eq. (15), quando para um objeto homogeneo.

Se a radiacăo atravessa duas regiós com coeficientes de atenuacão lineares $\mu_{1}$ e $\mu_{2}$ e espessuras $x_{1}$ e $x_{2}$, a transmissao e dada por:

$$
I=I_{0} \cdot \exp \left[-\left(\mu_{1} \cdot x_{1}+\mu_{2} \cdot x_{2}\right)\right]
$$

$$
\text { Para (n) regibes com diferentes }
$$

coeficientes, tem-se:

$$
I=I_{0} \cdot \exp \left(-\sum_{i}^{n} \mu_{i} \cdot x_{i}\right)
$$

Com apenas uma medida de transmissäo, os coeficientes de atenuacão nå podem ser determinados, pois existem muitos valores desconhecidos na eq. (24). No entanto, com multiplas medidas de transmissoes para diferentes orientacoes do feire, os coeficientes de atenuacao lineares na secáo transversal poden ser determinados.

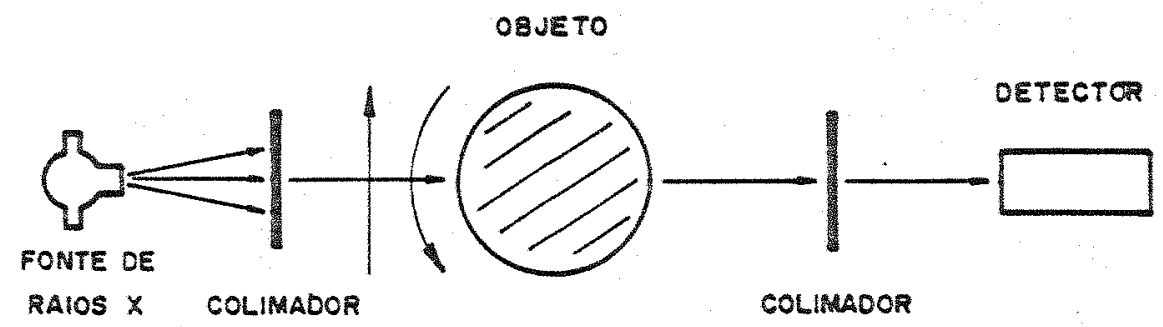

Fiqura 15. Principio basico de operafăo de u tomorato de primeira geracáo na qual medidas de transmissao săo acumuladas enquanto o objeto e rodado e transladado entre a ronte e 0 detector (HENDEE, 1984). 

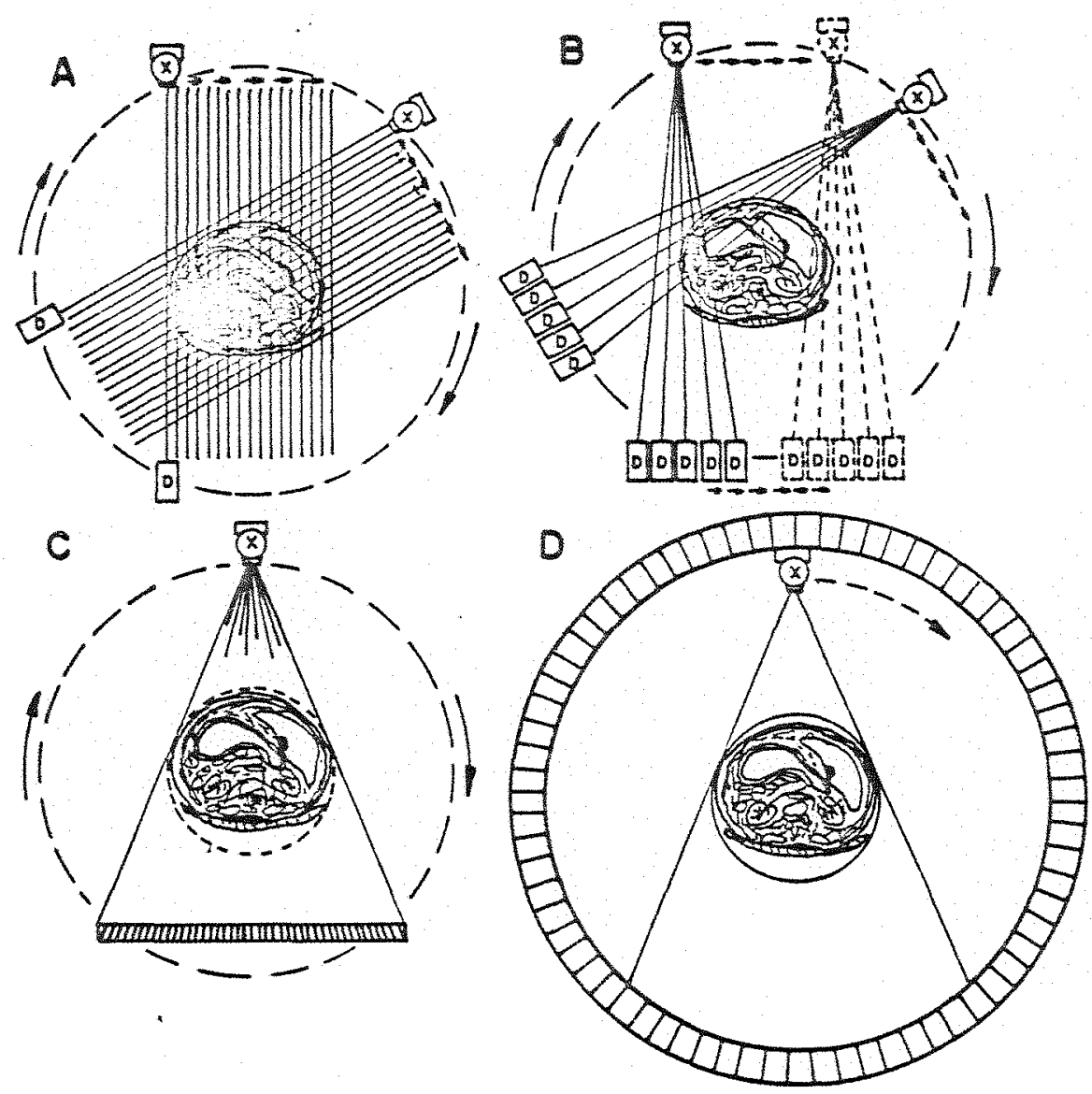

Eigura 10. Movimentos de varredura na tomografia computadorizada. A)Tomógajo de primeira geracăo usando un rejze colimado, com movimentos combinados de translacáo e rotacäo. B)-Tomograio de segunda geracão com Ielxe ell leque, varios detectores e movimentos combinados de rotacăo e translacào. C)- romografo de terceira geracăo usando um resxe en leque, uma serie de detectores e apenas movimento de rotacá. D)-Tomograro de terceira gerafăo usando in remze em leque, uma serie circular de decectores e apenas movimentos de rotacáo (AENDEE, 1984).

Esses valores de coeficientes de atenuacao lineares de uma secão transversal espacialmente distribuidos, formam uma imagem quando se atribui a eles tonalidades de cinza, cores ou quantidade de pontos.

Tomografos de primeira geracă, fornecem imagens de objetos atraves de movimentos combinados de 
sotacão e translacão (do objeto ou fonte e detector). com um feise colimado de radiacão, sendo a radiacão medida apenas com um detector (figura 16a). Tomografos de segunda geraఢão, fornecem imagens por movimentos combinados de rotacao e translacáo de varios feixes colimados ou un en forma de leque e a utilizacáo de varios detectores, movimentando-se juntamente com a fonte (figura $16 \mathrm{~b}$ ).

Nos tomografos de terceira geraca, as imagens săo obtidas somente por movimentos de rotacá de um feixe en forma de leque, com um numero ainda maior de detectores, movendo-se juntamente com a fonte (fig. 16c). Existem atualmente tomógrafos mais modernos que utilizam uma cadeia de detectores parados, bastando o movimento de rotacão da fonte para se obter una imagem (fig. I6d).

Num tomografo de primeira geracao, o tempo para aquisicão dos dados varia de alguns minutos a algumas horas. Já nos tomógrafos de segunda geracá, o tempo de aquisicao varia de 20 a 60 segundos. Nos tomografos de terceira geracao, o tempo para a aquisicao e de poucos sequndos.

Como resultado final da aquisicáo de dados. a partir da transmissa dos fotons, tem-se uma matriz com valores dos coeficientes de atenuaca lineares, referentes a secão transversal da amostra. Cada linha da matriz e uma projecăo, a qual e obtida com cada movimento de rotacáo. As colunas referem-se ás transmissoes nas translacoes ou 
en cada transmisgåo do feixe em leque.

A matriz de dados e transformada numa matriz imagem atraves de algoritimos de reconstrucão, que podem ser de quatro tipos distintos. Em HERMAN (1980) encontra-se uma descricão detalhada dessés algoritimos. com todos os procedimentos matematicos envolvidos. A sequir é feita uma breve descrica desses metodos:

a) Retroprojecão simples: Neste metodo cada medida de transmissão (ou elemento) é dividido num nimero (n) de elementos. Pela soma da atenuacáo para cada elemento $\left(\mu_{i} / n\right)$, sobre todas as projecóes que interceptam o elemento para cada orientacảo angular, ou projecáo $\left(\mu_{1}, \mu_{2}, \ldots, \mu_{k}\right)$, obtem-se o coef. de atenuacao linear no dado elemento e assim para todos os elementos da matriz (figura 17). Este tipo de reconstrucão produz imagens com artefatos (manchas), nas extremidades.

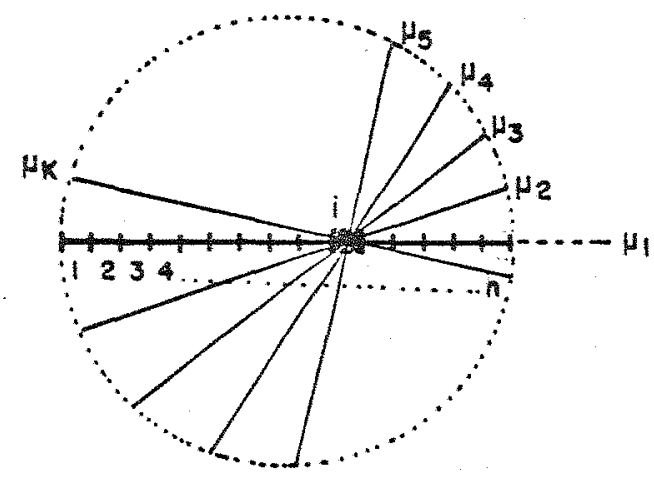

Figura 17. Representacão esquemática da reconstrucáo como algoritimo da retroprojecào simples. 
b) equacós integrais: Este algoritimo de reconstrucão usa uma equaca integral unidimensional, para Eiltrar os artefatos provenientes da retroprojecao simples atráves de um filtro que remove os componentes de altas frequências.

Este método é chamado também de convolucão ou retroprojecá filtrada e é o mais popular algoritimo de reconstrucão usado atualmente na tomografia computadorizada (HENDEE, 1984).

c) transformada de Fourier: Neste metodo as transmissões em cada orientacăo angular săo separadas em componentes de frequencia de varias amplitudes. Desses componentes, toda a matriz e trabalhada no espaco de frequencia e então reconstrulda por un processo de transformada de Fourier inversa.

d) expansão-em series: Nesta técnica, dados de atenuacão numa orientacão angular (linha da matriz de dados) så divididos em elementos iqualmente espacados. Esses dados são comparados com dados similares em diferentes orientacoes angulares e diferencas na atenuaca em duas orientacôes såo somadas iqualmente para elementos adequados. Este processo e repetido para toda orientacao angular, com un decréscimo da fracá da diferenca de atenuacao somada a cada tempo, para assegurar convergencia da reconstrucão dos dados.

A imagem nada mais e que un mapa de 
coeficientes de atenuaca lineares de uma secăo transversal do objeto, ou seja, uma fatia deste. A espessura dessa fatia depende da espessura do feixe de radiąa, o qual é definido pela abertura no colimador situado a frente do detector.

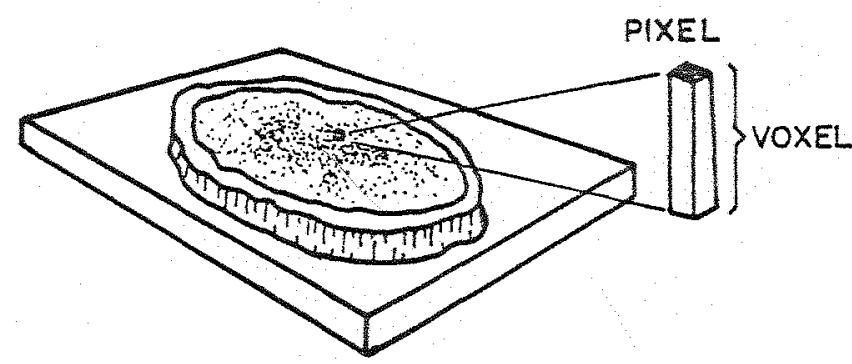

Siqura 18. Representacào dos elementos da image de una secăo transversal de un objeto.

A area de cada elemento na imagem é chamado de PIXEL, o qual multiplicado pela espessura da secão transversal, define un voxel, que es um elemento de volume (figura 18 ).

Un pixel possui um valor numèrico chamado UNIDADES HOUNSEIELD ( o qual define uma tonalidade ou cor na imagem), que nao é exatamente iqual ao coeficiente de atenuacão linear, mas relacionado diretamente com este pela sequinte equacão:

$$
U H=\frac{\left(\mu-\mu_{a}\right)}{\mu_{a}} \times 10^{3}
$$

onde $\mu$ e o coeficiente de atenuaga linear do material na poraa em que o feixe de radiaca esta interagindo e $H_{0}$ 
coeficiente de atenuacão da água.

Como foi visto nas secões 2.3 e 2.4 , o coeficiente de atenuaca linear, varia com a energia da radiaca incidente, con o numero atomico e a densidade fisica do objeto. Fixando a energia e o numero atomico a tomografia passa a depender apenas da densidade do objeto. Para materiais porosos, como o solo, depende ainda de sua umidade.

substituindo $\mu$ da eq. (22) na eq. (25), obtem-se que:

$$
\mathrm{UH}=\left(\frac{\bar{\mu}_{s}}{\bar{\mu}_{a}} \cdot D s+\theta-1\right) \times 10^{3}
$$

ou seja, o valor numérico de un pixel da imagen de uma determinada amostra de solo. varia com a densidade e umidade deste. 
3. REVISAO DE LITERATURA

3.1. Tomografia computadorizada

- desenvolvimerto de técnicas de recontruço de imagens se deu no inicio do seculo. inicialmente nas areas de astronomia solar (producão de mapas de radiaça de microondas da superficie do sol). micrografia eletronica (imagens por transmissa de eletrons) e numa grande variedade de problemas opticos.

Na decada de 70, a tomograta computadorizada por transmissao de raios $x$, fol introduzida na area de imagens médicas, com um grande impacto na historia da radiologia. Em HERMAN (1980) encontramos uma detalhada descricao sobre a teoria de reconstrucao de imagens e HENDEE (1983) fornece uma lista de referencias com algumas aplicacoes nessas areas e taz tambem uma descrica dos princlpios tisicos da TC.

o potencial da recontrusão tomogratica como tecnica de imagens clinicas, teve reconhecimento primeiramente por OLDENDORE (1961), que construiu $\circ$ primeiro prototipo congtituido de uma fonte de ${ }^{\mid 31}$ I e um detector de cintilaqao, no qual o objeto rodava e 
transladava entre a fonte e o detector. No entanto, os métodos de reconstrucão matematica năo forneciam imagens muito nitidas. O IIsico CORMACK (1963 e 1964) introduziu correcós na teoria da reconstrucá para corpos nao homogeneos, sendo seus trabalhos publicados em revistas cientificas de fisica, os quas lhe valeram (juntamente com G.N.HOUNSFIELD) o premio nobel de Fisiologia e Medicina por seu trabalho pioneiro na reconstrucao tomografica.

No fim da decada de 60 e inlcio de 70 , vários pesquizadores exploraram a reconstruca tomografica como possivel tratamento clinico. No entanto, foi apenas com o trabalho de HOUNSFIELD (1972), um engenheiro do laboratório de pesquisa central da Electro - Musical Instruments (EMI) Ltd, que a tomografia alcancou grande avanco na area médica. Hounsfield, concordando com Cormack, mostrou que uma seccão transversal do interior do corpo humano poderia ser obtida por atenuacao de rajos $x$ ou gama com uma precisao de $0.5 \%$ no coeficiente de atenuacá, sem expor o paciente a doses excessivas de radiacão.

A partir dal houve grandes avancos, chegando-se a equipamentos muito sofisticados, rapidos e seguros, tornando a tecnica muito util e bastante difundida nos dias de hoje.

o primeiro trabalho de aplicacáo da técnica 
da reconstrucăo tomografica por transmissăo de radiacao em ciencias do solo surgiu com peTRovic et alii (1982), 0 gual usou a TC para determinar a distribuicão espacial das densidades de amostras de solo com um tomografo medico (imagens tri - dimensionais). Neste trabalho petrovic observou que ha uma linearidade entre a densidade do solo e a tonalidade da imagem, representada pela unidade Housfield (UH). No entanto, embora tentasse, foi incapaz de correlacionar UH com a variacáo de umidade em amostras de solo.

Um ano apOs, HAINSWORTH \& AYLMORE (1983) apresenta um exame da possibilidade do uso da TC para estudar mudancas espaciais no conteudo de agua (umidade) num solo, com um estudo da difusão da agua do solo para uma raiz de rabanete, concluindo que a técnica (usa um tomógrafo com imagens bi dimensionais) é muito potente para se estudar o sistema agua-solo-planta, embora näo tenha discutido o problema da calibracão das UH com a unidade.

concomitantemente CRESTANA (1985) e CRESTANA et alii (1985) propos um novo método para o estudo da infiltracao da aqua no solo em tempo real. usando a tomografia bi e tri-dimensional de raios $x$ e gama. Além dos estudos dinamicos de aqua no solo, onde foram medidas velocidades da ordem de $6 \mathrm{~mm} / \mathrm{min}$ foram obtidas tamben calibracoes mostrando a linearidade entre densidade, umidade do solo e UH. 
- custo aproximado de um tomograto médico pode variar de $100 \mathrm{mil}$ a um milhao de dolares, tornando-se uma grande limitacão para uma maior difusa da técnica na ciencia do solo. A partir desta consideracão, CRESTANA et ali1 (1986) e CRUUINEL (1987) propuseram e construlram um minitomografo computadorizado de raios $x$ e gama, utilizando tecnologia nacional atraves da UAPDIA-EMBRAPA en sao carlos-sp, para estudos em ciencia do solo, cujo custo é de cerca de vinte a cincoenta mil dolares, abrindo novas possibilidades para uma naior difusao desta tecnica.

Seguindo a mesma linha anterior do trabalho de 1983 HAINSWORTH (1986) apresentou um trabalho onde estudou a extraca de agua por uma ralz de rabanete submetida a duas condicóes iniciais distintas de umidades, ambas com altas e baixas taxas de transpirafão. Comparando os dados experimentais obtidos com modelos de aproximacóes analiticas, o autor mostrou que os modelos não descreviam satisfatoriamente o processo de extracão de aqua.

BROWN et alii (1987) revisou alguns conceitos da TC para aplicacós en meios porosos e estudou a distribuifao espacial da aqua en tres meios porosos artificiais distintos.

ANDERSON et alii (1988) encontrou relacoes Iineares entre o coeficiente de atenuaco linear e a densidade do solo para dois solos e atribuiu diferencas encontradas entre esses solos as diferencas de quantidades 
de ferro. variando as quantidades de ferro para varias amostras de um mesmo solo, obteve também uma relacăo linear entre a concentracá de ferro e UH . Finalmente chama a atencão da necessidade de una relacão universal entre o coeficiente de atenuacăo linear e a densidade do 3010.

CRESTANA et alii (1988) apresenta vărios resultados de aplicacós da TC em pesquisas de solos. Entre eles destaca-se a simulacão dinamica tri-dimensional da irrigacao por gotejamento em uma coluna de solo de 7.5 cm de altura e $8.3 \mathrm{~cm}$ de diametro interno. 0 fluxo de gotejamento foi mantido constante em $4.8 \mathrm{~cm}^{3} / \mathrm{min}$ e mesmo assim observou-se direcoes preferenciais no movimento da água, indicando heterogeneidades no solo.

outra aplicacão bastante interessante neste trabalho è o estudo da germinacá de sementes e absorvcá de áqua pelas raizes. Um acompanhamento periódico de uma semente de milho germinando num recipiente com solo, revelou que do inlcio ao fin da germinacão a intensidade da imagem na semente variou de 268 a -16 UH. A regiao negativa indica a presenca de ar. Conclui-se com esses resultados que no processo de germinacăo de uma semente ha um enorme consumo de nutrientes em certas regiōes da semente, levando a um volume cheio de ar.

outro estudo realizado neste trabalho foi a Utilizacáo de tracadores no acompanhamento da solucão do 
$3010 \mathrm{com}$ a tomografia diferencial, que é baseda no fenomeno da descontinuidade fotoeletrica presente em alguns elementos quimicos.

Tambem recentemente JENSSEN et alii (1988) utilizou a TC para estudar heterogeneidades em colunas de solo arenoso usados em experimentos de transporte de agua e purificaç̃o de áquas poluldas. Os resultados mostraram que a TC é uma ferramenta bastante util para avaliar procedimentos de prepararo de colunas de solo usadas em experimentos de laboratorio.

A TC ainda não fol utilizada, ate o presente momento, em estudos de compactacão do solo, mas PETROVIC et alii(1982) citou o grande potencial da técnica en estudos dessa natureza, fazendo alguns experimentos basicos, nos quais detectou problemas como o endurecimento do feixe e determinou a sensibilidade para variacốs de densidade. Também CRESTANA (1985) e CRESTANA et alij (1988) enumerou varias possibilidades de aplicacaso da TC. Uma delas tol o estudo da compactacáo do solo. tema desta ¿issertacão.

3.2. Métodos de medidas de compactacáo do solo

A quantificacáo da compactaca do solo pode ger felta atraves de medidas de parametros do solo diretamente relacionados com o fenomeno, que segundo 
51.

FREITAG (1971) são: Porosidade (total e distribuica de tamanho de poros) e a matriz do solo, que refleten a geometria relativa e orientacá das particulas e espacos vazios associados. Esses metodos podem ser divididos em tres classes:

a) Estudo da compactacão pela medida das caracteristicas do solo alteradas no processo:

- Medida da densidade (ou porosidade) média.

- Medida da distribuicão de tamanho de poros.

- Medida da distribuicão espacial da densidade em volumes infinitesimais (suficientemente pequenos).

b) Estudo da compactaca pela medida das propriedades do solo alteradas no processo :

- Medida da condutividade hidralica do solo.

- Medida da difusão de gases no solo.

- Penetrometro : medida da resistancia de penetraca de uma haste no solo.

c) Estudo baseado em medidas de transmissäo de pressões no solo através de transdutores de pressäo.

Abaixo e feita uma revisão dos principais metodos de medidas em cada uma das classes descritas:

a.1) Densidade do solo por gravimetria

og metodos mais comuns de determinacão da 
densidade do solo são baseados no calculo da massa e volume de uma amostra de solo. Em FREITAG (1971) encontrase uma boa revisão dos principais métodos de medida da densidade do solo, concluindo que a maior dificuldade na medida da densidade e a determinacão do volume, principalmente para amostra irregulares. uma grande variedade de métodos foram desenvolvidos para determinar volumes, mas nenhum pode ser considerado ideal para todos os casos.

Para amostras com formas irrequlares é comum introduzi-las num fluido (por exemplo mercurio) e medir o volume deslocado. quando a amostra é selada com parafina, pode ser medido um volume deslocado de água.

Outra forma de medir o volume é introduzir um amostrador no solo, de modo que se obtenha uma amostra de volume conhecido. Diferentes tipos de amostradores tem sido usados em trabalhos de solo, muitos deles especialmente desenvolvidos para um tipo particular de 5010. HVORsLEV (1949) taz una exaustiva descricáo de equipamentos e técnicas usadas em amostragens para fins de engenharia civil.

KIEHL (1979) apresenta como principais métodos de determinacão da densidade do solo, a) Metodo do balão volumetrico, que utiliza um baläo de vidro com volume constante, no qual e colocado solo fino seco ao ar e peneirado; b) Metodo do anel volumetrico, que utiliza um 
53.

anel de aco, o qual é introduzido no solo e retirada uma amostra; c) Método do torrão impermeabilizado, no qual um torrăo de solo é envolvido com parafina, de modo a impermeabiliza-lo e o seu volume medido pelo volume de água deslocado ou pela medida do empuxo na aqua; d) Metodo da escavacão, que consiste em se cavar um buraco no solo, pesar a massa (seca) retirada e medir o volume adicionando areia ou um balão de borracha cheio de água.

LAUNDRE' (1989) compara os metodos do buraco com areia,' ou agua e amostrador de volume constante, chegando a conclusão que não apresentam diferenca gignificativa para os tres solos testados.

a.2) Densidade do solo por atenuacão de um feixe de raios gama

Atraves da interaço de un feixe de raios gama com uma amostra de solo é possivel calcular a densidade deste solo quando seco. FERRAZ \& MANSELI (1979) fornece uma descricao completa da tecnica com inumeras medidas para varios solos do Brasil, nas energias de 60 e $660 \mathrm{kev}$ e aplicacoes em problemas agronomicos praticos.

a.3) Distribuigào de porosidade

A distribuicano de porosidade de un solo pode ser obtida atraves da medida da umidade residual apos a aplicacão de pressöes infinitesimais, isto e, da curva 
caracterlstica tensäo-umidade.

Muitos pesquisadores, entre eles BATEMAN (1963) e VOMICIL \& FLOCKER (1961), observaram que a compactacão esta melhor relacionada com a porosidade e a retencão de água, no ponto de capacidade de campo do que com a sua curva inteira.

- efeito da compactacão pode ser observada comparando curvas de distribuiazo de poros em varios estágios de aplicasão de compressoses num solo. A compactacao tende a reduzir a porosidade total e aumentar a porcão de porns pequenos.

b.1) Condutividade de um fluido no solo

MITCHELl et alii (1965) e LAMBE (1960). mostraram que è possivel relacionar a compactacăo do solo com a medida da condutividade hidraulica do solo atraves de testes feitos em laboratorio. No entanto a grande variafão da condutividade hidraulica em pontos distintos do solo e o tempo longo das medidas são limitacóes na utilizacão da medida da condutividade hidraulica como um indicador da compactacão do solo.

NIMMO \& AKSTIN (1988) mediram a condutividade hidraulica de um solo submetido a vários tipos diferentes de compactacăo, provocando uma variacá de 33,3 a 38 na porosidade total do solo. Neste caso a condutividade variou entre $7 \times 10^{-11}$ e $2 \times 10^{-8} \mathrm{~m} / \mathrm{s}$. 
Da mesma forma CAMPBELL et alii (1986)

utiliza a medida da taxa de difusa de gases no solo, como um indicador do efeito da compactacáo desse solo.

b.2) Penetrometro

E bastante usado en estudos de compactacão de solos agricolas e mecanica de solos. No entanto. BOLLING (1985) mostra que alem da densidade do solo, a medida do penetrometro depende do tipo de solo, velocidade de penetracão e conteudo de água. Portanto são necessarias calibracões para cada condicão especial de solo. equipamento e umidade.

No entanto, este metodo fornece bons resultados qualitativos. MANTOVANI (1984) utilizou um penetrometro para avaliar a compactacão de um solo submetido a vários tratamentos distintos de compressa por velculos e uso de subsolador, mostrando diferencas significativas entre os tratamentos.

SIMMONS \& CASSEL (1989) relacionaram medidas do penetrometro com as propriedades flsicas do solo. A melhor correlacáo fol obtida entre o indice do penetrometro (IP) e o logaritimo da condutividade hidraulica. Foram obtidas relacões entre IP, densidade e profundidade. 
c.1) Transdutores de pressão

- conceito básico da medida da pressão no solo é introduzir nele uma celula que experimentará as mesmas pressōes num volume equivalente de solo e que portanto fornecam a magnitude dessa pressão (CoOpER et ali1. 1957). Essas medidas näo revelam o estado de compactacão diretamente, mas elas fornecem informacŏes que em conjunto com medidas diretas de compactacăo, leva a um entendimento do processo mecanico da compactafão.

Segundo FREITAG (1971), existem tres métodos de medidas de pressōes com cêlulas sensitivas:
a) Pressão num fluido;
b) "Strain gage";
c) Cristal piezoeletrico;

As dificuldades associadas com medidas de pressós no solo com celulas sensitivas, surgem de duas deficiencias: A celula nâ responde ás forcas da mesma maneira que o solo e o processo de colocar a celula no solo causa perturbacão deste.

Uma boa aplicacão do método de transmissăo de pressões é feita por BoLLING (1985), onde en conjunto com o metodo do penetrometro e com relacóes de calibracá, estabelece um método de medir a compactacáo do solo. devido ao trafeso de velculos agricolas. 


\section{4. materiais e metodos}

E utilizado un tomógrafo computadorizado de raios $x$ ou gama de primeira geracao (minitomógraio), para obtencăo de imagens (por transmissão) de secós transversais de objetos, construido na UAPDIA/EMBRAPA em Sao Carlos-SP (CRESTANA et alii, 1986 e CRUVINEI, 1987). A Eigura 19 mostra um esquema em blocos e a figura 20 uma foto do equipamento utilizado.

o sistema fonte-detector é composto de uma Eonte radioativa emissora de raios gama ( ${ }^{241}$ An ; $E=59,6$ Kev) com atividade de $300 \mathrm{mci}$ (1.11 GBq), cristal cintilador de $N a I(T I)$ de $3^{n} x^{n}$ tipo plano e fotomultiplicadora. os colimadores sa variáveis e neste trabalho são utilizados colimadores de $2 \mathrm{~mm}$. A fonte e o detector podem ser movimentados num trilho ate uma distancia máxima de $23 \mathrm{~cm}$.

Entre a fonte e o detector existe uma mesa que eretua movimentos de rotacão e translacão, na qual b colocada a amostra que se quer fazer a imagen. Esses dois movimentos são realizados por dois motores de passo, que sá controlados por un computador Apple (B bits), atraves de uma interiace. 
58.

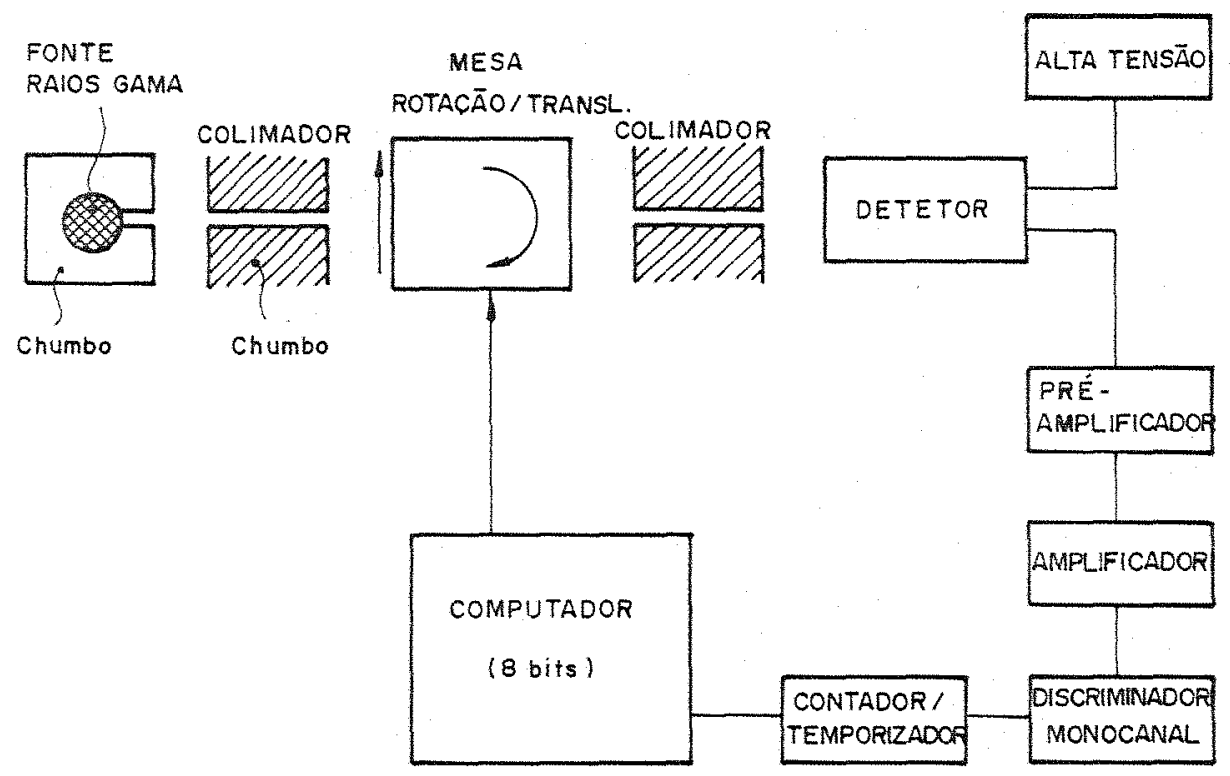

pigura 19. Uiagrama de blocos do tomograto moscrado na folo da tiaua 20.

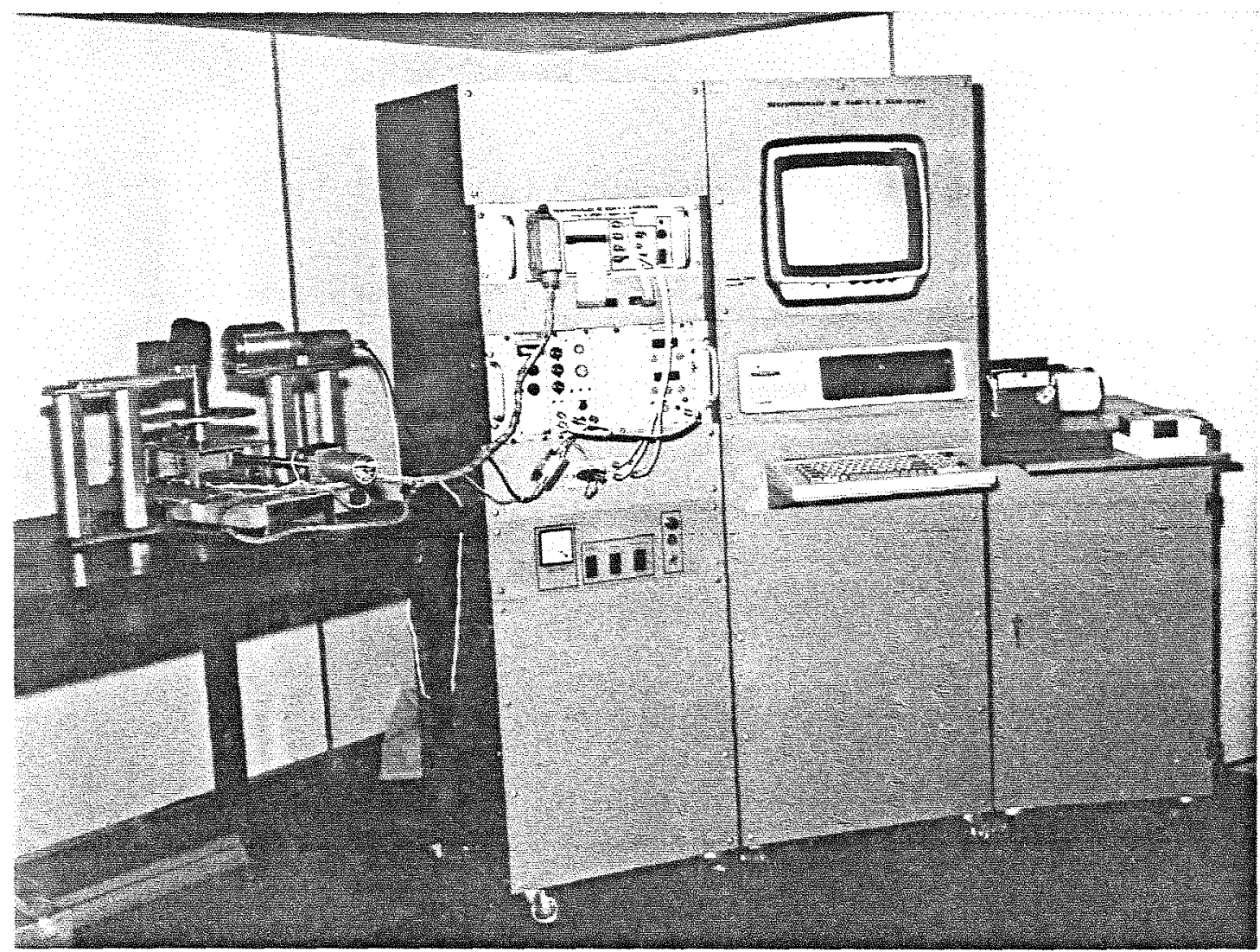

Fioura 2u. Fotograria do tomóraro compuradorizaco de raios $x$ e gama de primeira geracao, construldo na UADDIA-EMBRApa en sao Carlos. 
Após cada combinacão de um movimento de rotacá e translacao, éfita a contagem num tempo determinado (alguns sequndos), do feixe colimado que chega ao detector, apos interagir com o objeto. Cada fóton que chega ao detector, gera um pulso de amplitude proporcional a sua energia. Um sistema composto de pre-amplificador, amplificador, analisador monocanal, contador e temporizador, conta este pulso e o armazena na memória do computador, enviando-o posteriormente a um disco magnético.

- tempo total para a aquisicão de dados é definido em Euncão de alguns parametros impostos pelo tipo e tamanho de amostra, resolucão desejada, precisão da medida e pelo equipamento. Por exemplo, se for escolnido um feixe com diametro de $2 \mathrm{~mm}$ (em funcào de uma resolucão desejada de $2 \mathrm{~mm}$ ) e uma amostra de $100 \mathrm{~mm}$, deve-se utilizar un passo de translacăo de $2 \mathrm{~mm}$ e portanto o numero de colunas da matriz de dados e matriz imagem será $(100 / 2)=50$. Deste modo pode-se obter una natriz de orden $50 \times 50$, se for utilizado um passo de rotacão de 3,6 graus $(180 / 50)$

- tempo de cada aquisigão é escolhido em funcáo da precisão desejada, ou seja, è importante que se tenha uma boa estatistica de contagem para que se tenha una boa precisao. Em primeira aprozimacao o erro de uma contagem de rotons e iqual a raiz quadrada deste valor. portanto para se obter uma precisao de 2 e necessaria uma 
60.

contagem de 2500 Iotons. A quantidade de fotons que chega no detector e funcão da densidade e do tamanho da amostra. Para se aumentar a contagem basta efetuar a medida num tempo mais longo.

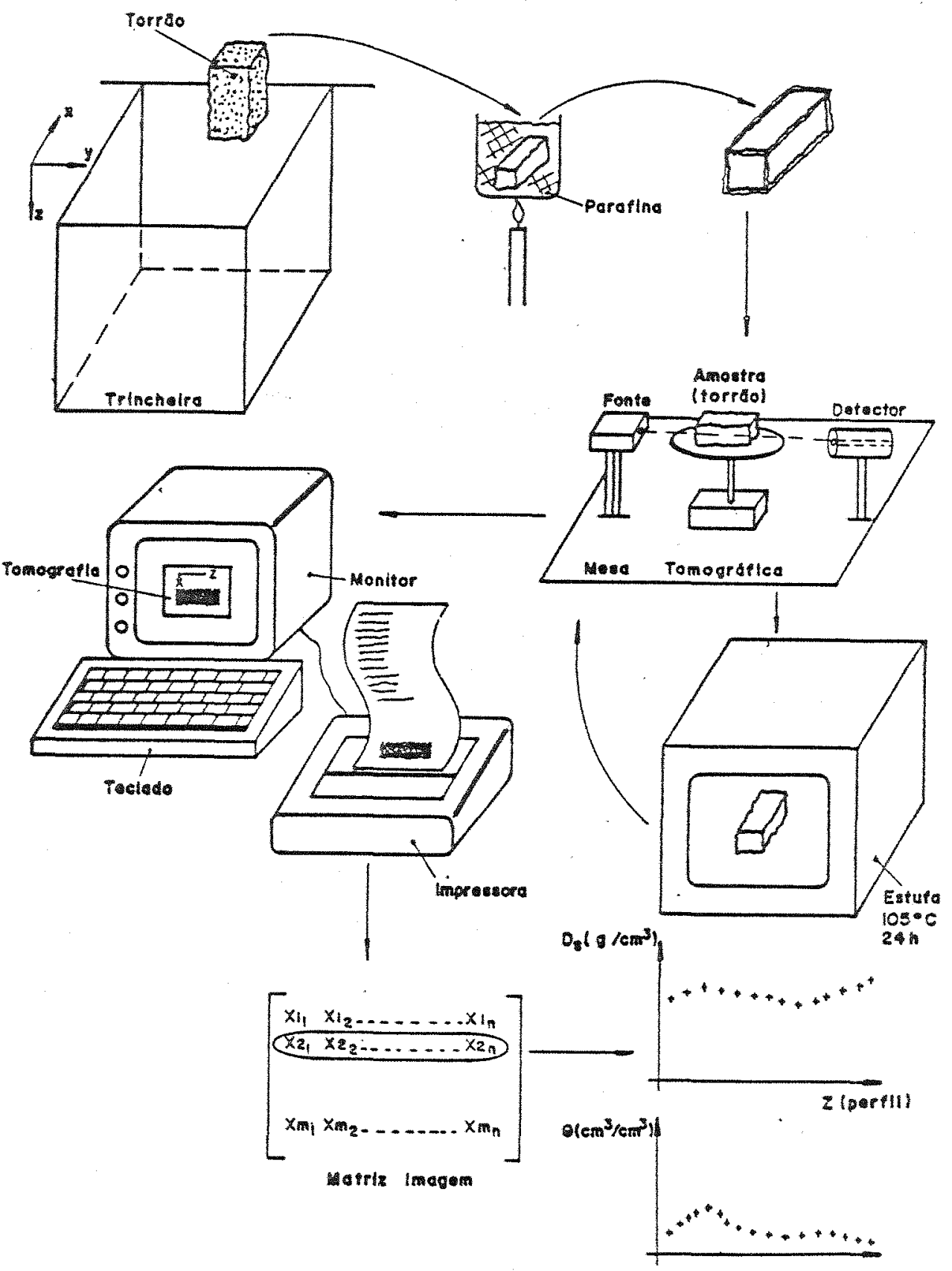

Eigura 21. procedimento de colera e medida de amostras inderormadas numa trincheira, utilizando a tecnica da tomogratia computadorizada. 
A taxa de contagem obtida para uma distancia entre fonte e detector de $100 \mathrm{~mm}$ e colimadores con diametros de $2 \mathrm{~mm}$ e de aproximadamente 5000 cps (contagens por segundo). Nos experimentos realizados neste trabalho os tempos totais para a aquisicão dos dados de una tomografia variaram de 1 a 6 horas.

A imagem e reconstrulda por um algoritimo matemático (equacoes integrais ou convolucao), podendo ser apresentada no monitor ou na impressora. E possivel também imprimir a matriz de dados (fotons transmitidos) e a matriz imagem ( CRUUINEL, 1987).

Um esquema do procedimento de medida e quantificacão da densidade e umidade de amostras de solo, pela tècnica da TC é mostrada na figura 21.

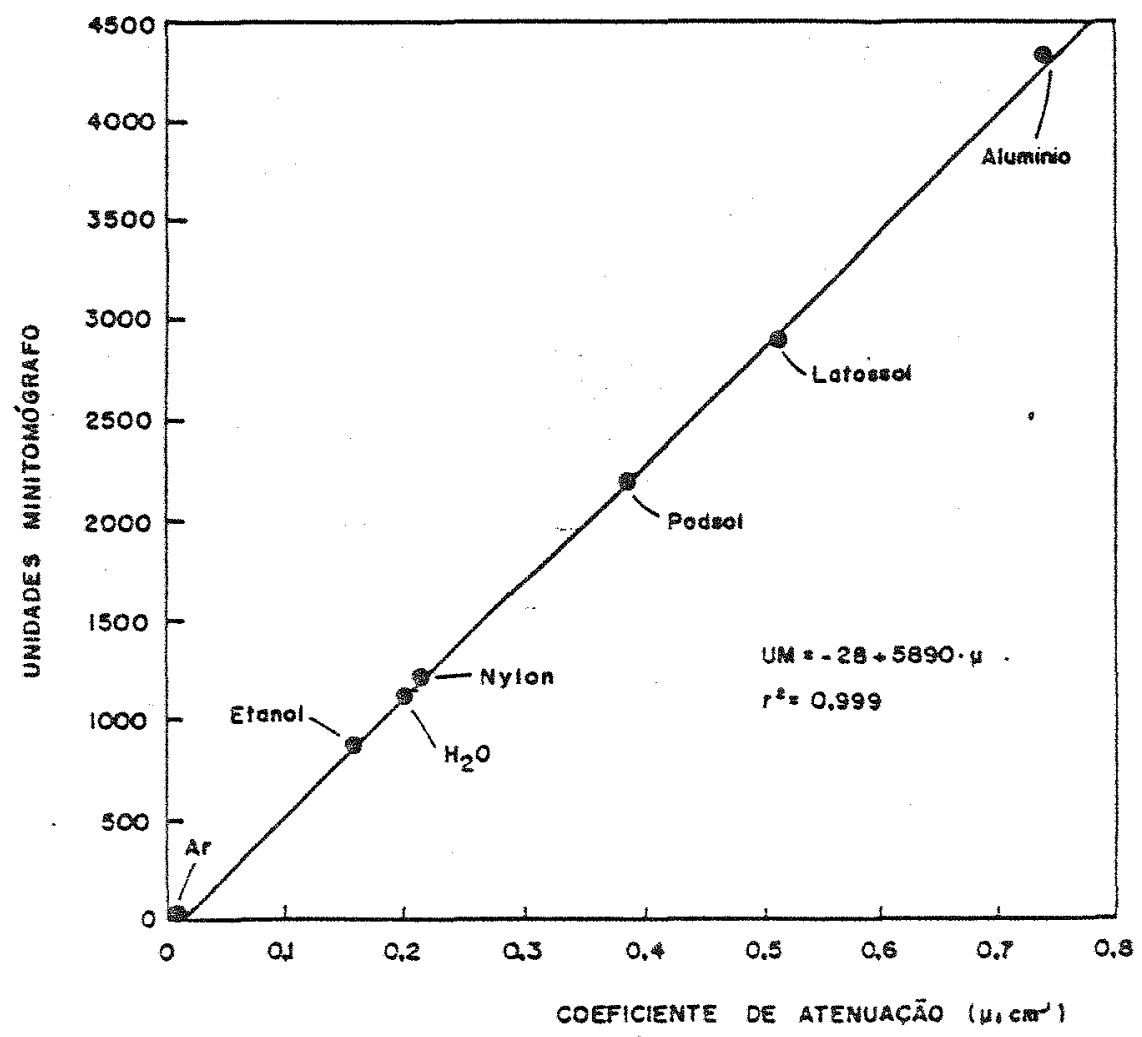

Pioura 22. Relacào experimental entre UM e o coericiente de atenuacao linear para varios macerials. 
As unidades dos elementos da imagem no tomografo utilizado nao sao as uguais unidades houngtielo (UH), mas outra relacionada linearmente com ela e que denominaremos unidades Minitomografo (UM). A Iigura 22 mostra uma relacão linear obtida experimentalmente entre UM e coeficiente de atenuacao linear. substituindo essa relacão na eq. (22), obtem-se :

$$
\mathrm{UM}=5890 \cdot\left(\bar{\mu}_{s} \cdot \mathrm{Ds}+\bar{\mu}_{\mathrm{a}} \cdot \theta\right) \ldots \ldots \ldots \ldots(27)
$$

A densidade e umidade do solo podem ser determinadas numa secão transversal da amostra, usando o seguinte procedimento descrito:

a) Mede-se o coeficiente de atenuacáo em massa do solo e da àqua. Com esses dados, determina-se a curva de calibracäo para este solo, utilizando a eq. (27);

b) Faz-se uma tomografia na posicão desejada com a amostra trinida;

c) Seca-se a amostra em estura a $105^{\circ} \mathrm{C}$ por $24 \mathrm{~h}$;

d) Faz-se uma nova tomograija na mesma posicão, com a amostra seca. Euito importante a colocacăo da amostra na mesma posicão da tomograía anterior. portanto é recomendável que se faca alquma marca na amostra ao se iniciar a medida;

e) Determinacao da densidade : Com os dados da amostra seca, $\theta=0$. A eq. (27) Eica reduzida a UM $=5890 \cdot \bar{\mu}_{s} \cdot D s$ 
63.

portanto para cada pixel da imagem, calcula-se com os valores de UM, as densidades correspondentes;

E) Determinacăo da umidade : Para a imagem da amostra Umida, $\theta>0$. Portanto: $U M_{2}=5890 \cdot\left(\mu_{s} \cdot D s+\bar{\mu}_{0} \cdot \theta\right)$. Para cada pixel da imagem, calcula-se a umidade a partir da subtracăo dos 2 valores de UM correspondentes:

$U M_{2}-U M_{1}=5890 \cdot \bar{\mu}_{0} \cdot \theta$

\subsection{Atenuacão de um feixe de raios $x$ ou gama}

4.1.1. Medidas do coeficiente de atenuacão em massa de solos e outros materiais

- minitomógrafo descrito anteriormente pode ser utilizado para medidas de coeficiente de atenuacao em massa. Para isso, basta desconectar a interiace e assim o sistema nuclear pode ser utilizado manualmente.

- coeficiente de atenuacão em massa ê calculado medindo-se o numero de fotons incidentes (I.), emergentes (I), a espessura da amostra $(X)$, sua densidade media (Ds) e substituindo-os nas eq. (15) e (16).

sao utilizadas como amostras, uma relacão de 18 solos, coletados na Usina sta Barbara em sta Barbara d'oeste-sp, dois solos da região de săo carlog (LVA e LUE) e outro de Barretos-sp (LVA). 
estufa a $105^{\circ} \mathrm{C}$, peneirado em malha de I $\mathrm{mm}$ e acondicionado em recipientes de acrilico $\left(25 \times 25 \times 50 \mathrm{~mm}^{3}\right)$. São feitas tambem medidas dos coeficientes de atenuacao em massa para agua destilada e aluminio.

4.1.2. Correlaøå entre coeficiente de atenuacá linear e densidade do solo

Neste experimento são utilizados dois solos, un latossol vermelho escuro da regiao de Araras-sp e un latossol vermelho amarelo da regia de sao carlos-sp.

As amostras sá coletadas numa trincheira, com aneis volumetricos (aco) de raios e alturas iguais a 5 cm. Essas amostras são secas a $105^{\circ} \mathrm{C}$ por $24 \mathrm{~h}$ e entao suas densidades são calculadas, medindo-se suas massas e os volumes dos aneis. Depols disso o coeficiente de atenuacão Inear e determinado para todas as amostras, medindo-se o Eeixe emergente (I) e incidente (I0) e usando o valor da espessura do solo $(x)$.

\subsection{Tomografia : calibracao e quantificacão}

Uma calibracăo deve ser feita para cada tipo de solo, para que se possa quantifica-lo em termos de densidade e umidade. Para tanto basta medir o coeficiente de atenuacao em massa para este solo e para a água.

$$
\text { Para una dada inagem de uma amostra, a }
$$
quantificacäo da densidade e umidade pode ser feita em 
termos da média ou moda dos valores da amostra. Fazendo a distribuicao de frequencias dos dados de uma imagem é possivel estudar a homogenidade da amostra, pois quanto mais homogenea, menor a dispersão dos dados em torno da moda e menor a diferenca entre a media e a moda.

quando a amostra e heterogenea, o estudo è feito analisando as variacóes atraves dos dados da matriz imagem. Isso pode ser feito analisando um perill ou uma media deles, numa direcão de interesse.

Nestes experimentos que se sequem, são utilizados colimadores com diametros de $2 \mathrm{~mm}$. Deste modo, utilizando passos de translacăo de $2 \mathrm{~mm}$ define-se uma resolucão de $2 \mathrm{~mm}$.

os recipientes utilizados nos experimentos com amostras de solo deformado, peneirado em peneira de 1 ma, são de acrilico ( $3 \mathrm{~mm}$ de espessura) e tem dimensoes internas de $25 \times 25 \times 50 \mathrm{~mm}^{3}$.

\subsubsection{Relacáo entre UM e Ds}

são utulizadas amostras de um Latossol Vermelho Escuro, da regia de Araras-sp. No preparo das amostras, 0 solo é seco á $105^{\circ} \mathrm{C}$ e peneirado com peneira de $1 \mathrm{~mm}$. Esse solo é introduzido nos recipientes de acrilico. de modo a se obter 8 amostras com densidades distintas e homogeneas. 
66.

para cada recipiente é feita uma imagem de uma seqao transversal. Na regia da imagem referente ao solo, faz-se uma media das UM. A densidade de cada amostra e calculada por gravimetria e entao esses dados sao apresentados num gratico UM vs DS.

\subsubsection{Relacão entre UM $e \theta$}

São utilizadas amostras de um latossol Vermelho Amarelo, da regia de Barretos-sp. No preparo das amostras, o solo e seco, peneirado (1mm) e introduzido nos recipientes de acrilico, de modo a se obter 8 amostras com densidades constantes e homogeneas.

Para cada recipiente efeita a imagem de una secáo transversal e obtida a media das uM no interior desta. A umidade de cada amostra é medida por transmissäo direta de raios gama. Os dados são apresentados num grafico UM vs $\theta$.

4.3. Estudo de compactacao dos solos por tomogratia

4.3.1. Finas camadas de solo compactado (laboratorio)

Neste experimento è utilizado um Latossol

Vermelho Escuro, da regiao de sao carlos, seco e peneirado (1 $\mathrm{mm})$, cujo coeficiente de atenuacáo vale $0,342 \mathrm{~cm}^{2} / 9$. Portanto sua equaca de calibracá है:

$U M=2014.0 s+1196 . \theta$ 
As amostras são feitas utilizando os recipientes de acrilico, conforme mostra a ilgura 23 . Para se obter essas amostras, utiliza-se dois pedacos de alumimio com as faces planas e dimensöes de $24 \times 24 \times 100$ $\mathrm{mm}^{3}$ de tal modo que esses possam ser usados para compactar uma certa quantidade de solo (umidecido para facilitar a compactacăo ederencia), na regia central do recipiente.

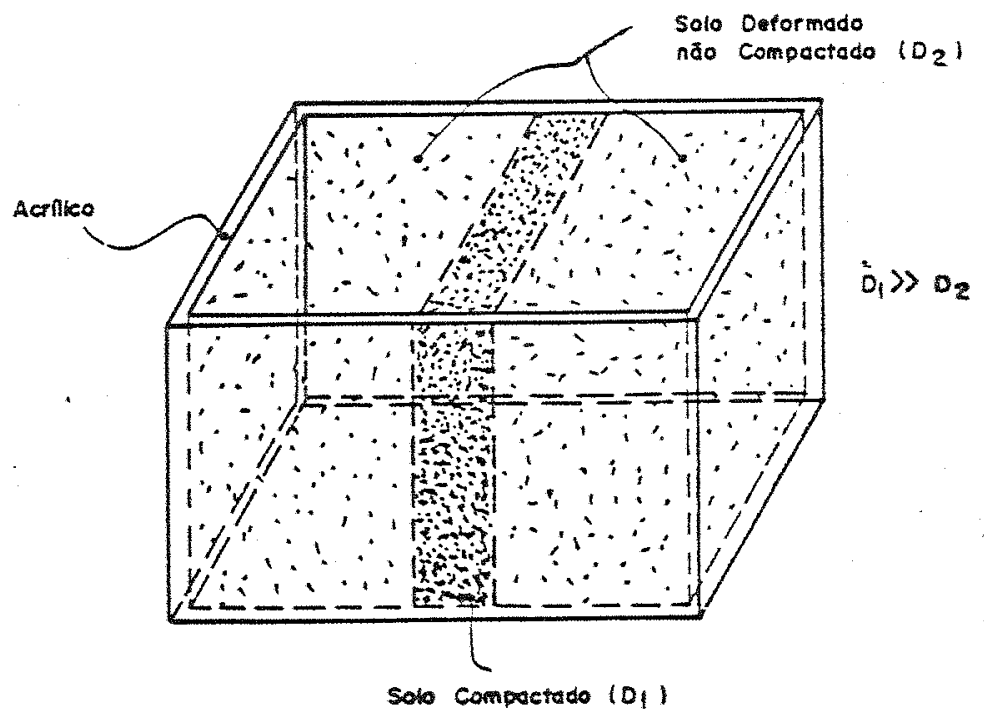

Figra 23. Amostra para o estudo de camada de solo compactado.

Depois disso, preenche-se o restante do recipiente, com solo peneirado e leva-se novamente a estufa para secagen.

Com essas amostras, sã feitas imagens de secoes transversais e essas quantificadas em termos de densidade atraves da matriz imagem, analisando-se perfis na direca perpendicular a lamina compactada. para cada imagem e obtido um perfil medio entáo os dados são 
colocados num grafico, com a densidade na ordenada e a distancia na amostra na abscissa.

\subsubsection{Compactacáo por compressao (laboratório)}

- solo utilizado neste experimento e o mesmo do 1tem anterior (4.3.1). As amostras são feitas, utilizando os recipientes de acrilico, de modo a se obter amostras com densidades homogeneas em todos os recipientes.

A essas amostras são fornecidas certas quantidades de água, de modo a deixa-las com umidades iguais a zero (seca), 0,$10 ; 0,20 ; 0,30$ e $0,369 / 9$.

Utilizando a montagem da figura 24 , imprimi-se una pressão de $0,8 \mathrm{MPa}$, na superficie superior de cada amostra, por un certo tempo, ate que cessem as deformacoes no interior do solo.

Depois disso, as amostras sao secas e enta analisadas pelo tomógrafo, num plano paralelo ao ela de aplicacáo da pressäo.

As amostras sao quantificadas em termos de densidade, em perfis paralelos ao eiso de aplicacao da pressäo, de modo a caracterizar as deformacóes nesta direcá. Esses dados sá apresentados num oratico, com a densidade na ordenada e a distancia na amostra na abscissa. 


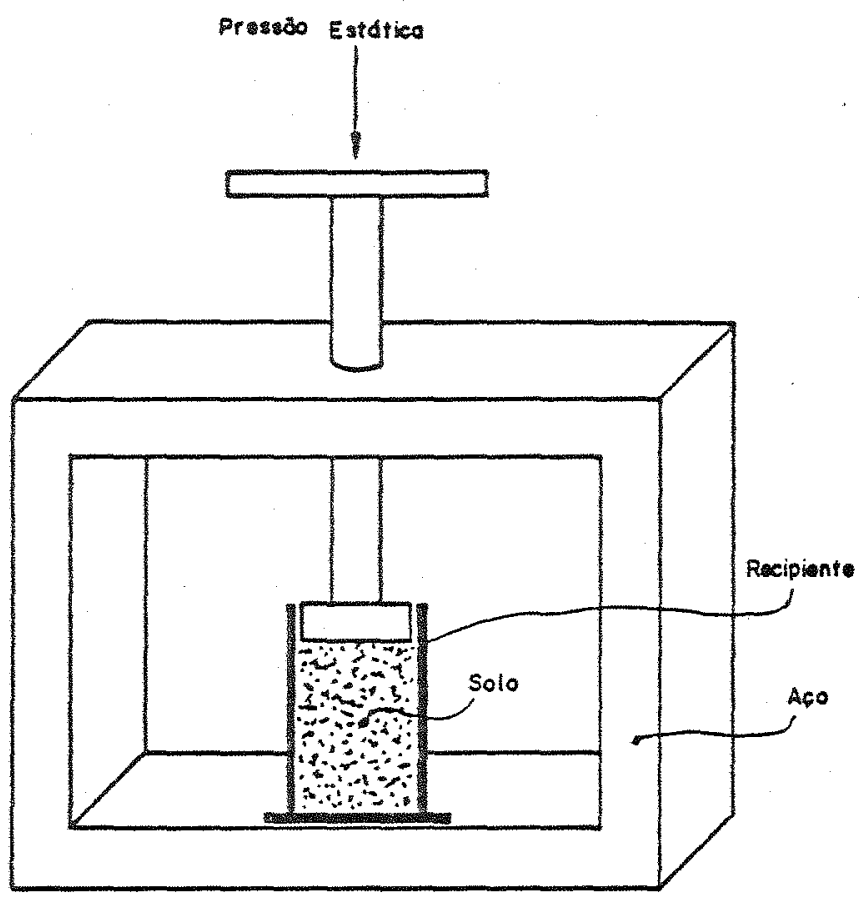

Figura 24. Equipamento utilizado na compactacăo de amostras de solo por compressão estatica.

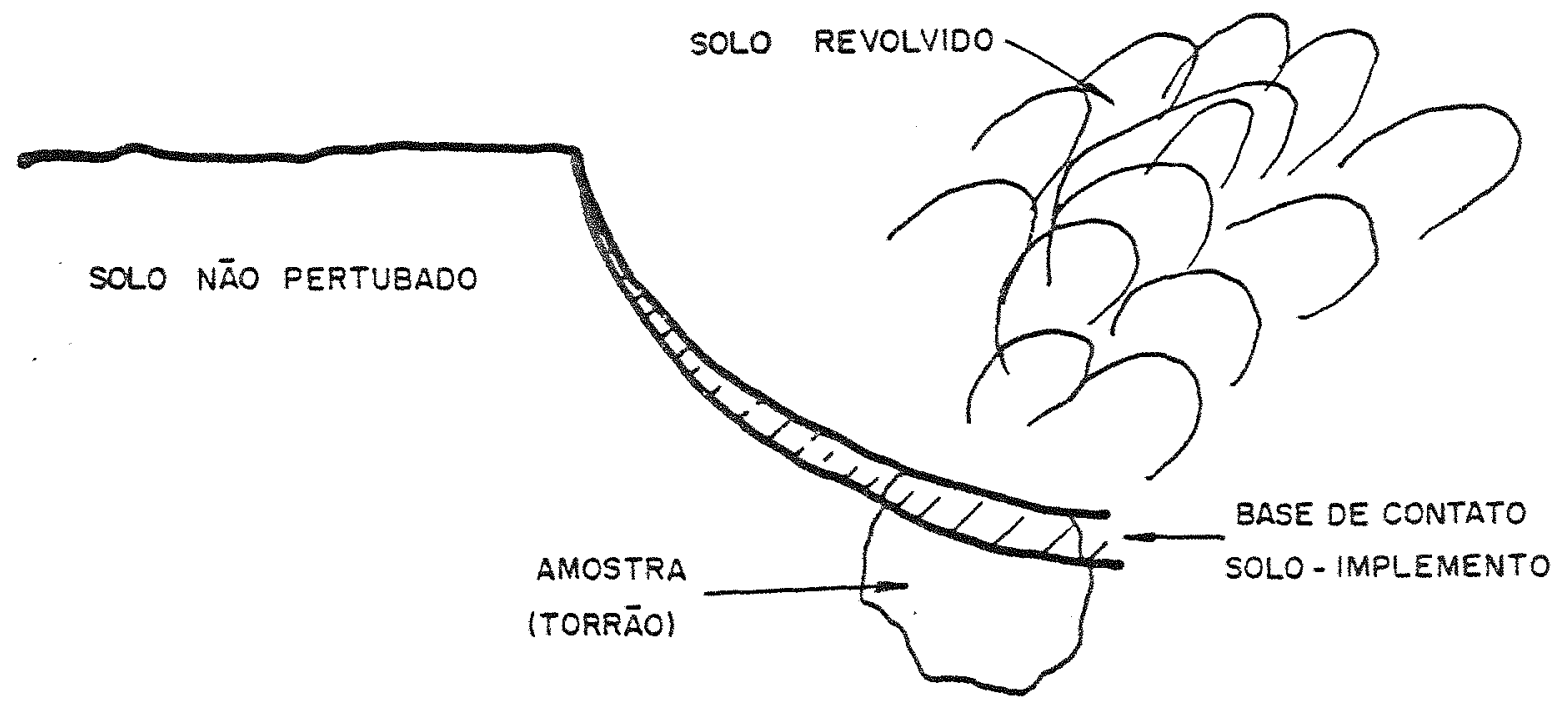

Ejqura 25. Representacão esquematica da coleta de amostras, apos a passagen de implementos agricolas no solo. 
4.3.3. Compactacáo por compressão de implementos (campo)

Neste experimento e utilizada uma area experimental do IAA/PLANALSUCAR en Araras-SP, cujo solo e um Latossol Vermelho Escuro. O coeficiente de atenuacăo deste solo vale $0,433 \mathrm{~cm}^{2} / 9$, portanto sua equacão de calibracăo vale: $U M=2550 . D s+1196 . \theta$

As amostras são coletadas com un instrumento cortante, de modo que se obtenha amostras indeformadas (torróes), após a passagem de um implemento sulcador, conforme ilustra a figura 25.

são realizadas vărias amostragens em condicoes distintas de densidade, umidade, peso e abertura das laminas do implemento.

Após cada coleta, as amostras sào envolvidas con parafina fundida para que conservem suas umidades originais e possam ser levadas ao laboratorio sem se quebrarem. Com uma caneta porosa, anota-se a direcăo na qual as pressões agiram nessas amostras.

Apos ser retirada a parafina das amostras, essas sao secas e entao feitas imagens de secós transversais paralelas a direcáo de propagacão das pressaes, de modo a se caracterizar as deformacóes causadas neste solo, devido a compressa do implemento. 
4.3.4. Tomografia vs penetrometro (campo)

s utilizada uma area experimental na UEPAE/EMBRAPA em sao carlos, cujo solo e un latossol vermelho escuro, com un coeficiente de atenuacăo de 0,342 $\mathrm{cm}^{2} / 9$. Essa área no passado, foi extensivamente utilizada para o cultivo de cereais e atualmente apresenta um acentuado problema de compactacão causado por implementos (pè de arado).

Nesta area são abertas duas trincheiras. separadas por una distancia de 10 metros, com dimensóes de $1.5 \times 1.5 \times 1.5 \mathrm{~m}^{3}$. Nessas trincheiras, sáo coletadas amostras em, forma de torrós indeformados, de modo a caracterizar o pertil de densidades na profundidade. Essas amostras são retiradas da parede da trincheira, com uma ferramenta cortante e envolvidas com paraina derretida, de modo que possam ser transportadas até o laboratorio com sequranca, evitando que se quebrem. Na superficie da parafina faz-se uma marca do eiso $z$ (profundidade), com uma caneta porosa, para nao se perder a referencia. A Eigura 21 apresenta un esquema da coleta, analise e quantificacão dessas amostras.

Ao redor das duas trincheiras, Eaz-se sondagens com um penetrometro de impacto imodelo IAA/PLANALSUCAR/STOLF) para vátas situacós de unidades e retiradas amostras para o calculo das umidades a base de massa. 
72.

A Eiqura 26 mostra un esquema do experimento descrito.

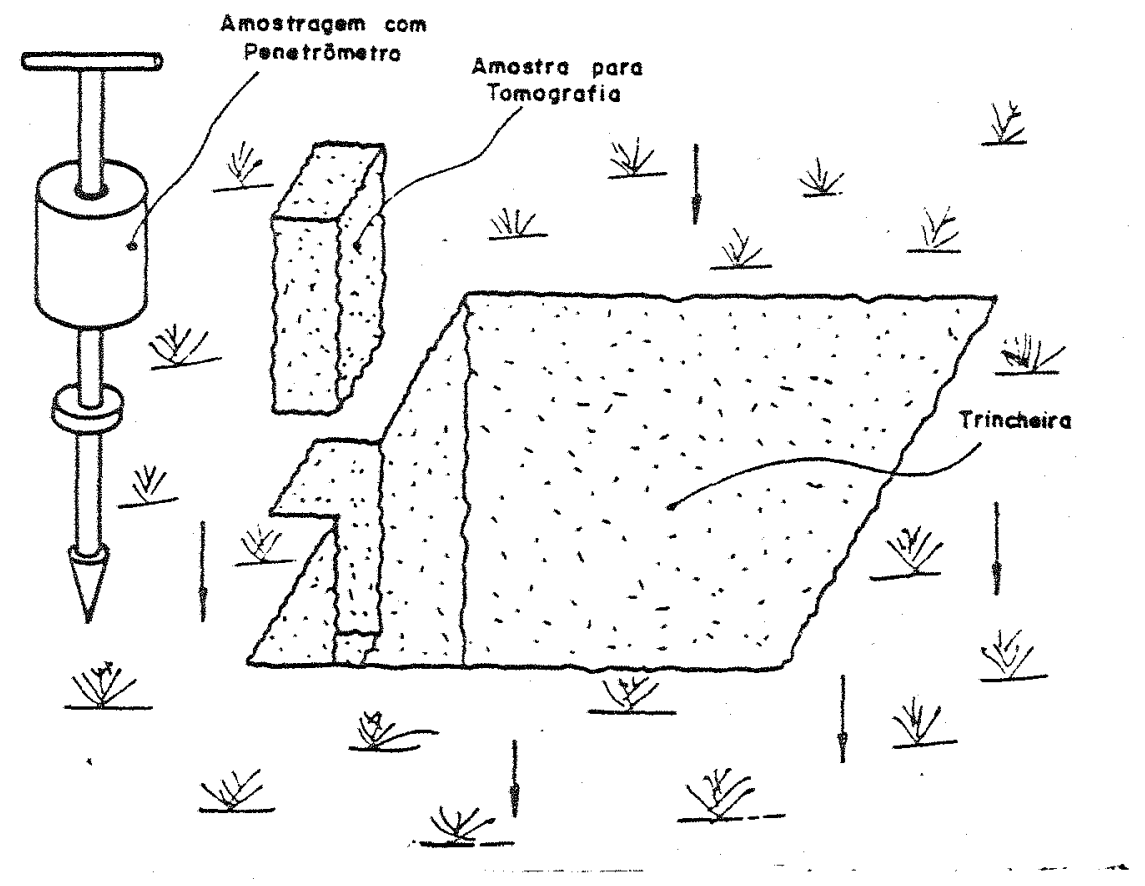

Fiqura 26. Representacão esquematica da coleta de amostras numa trincheira e medoas com penetromecro. 
73.

5. RESULTADOS E DISCUSSAOO

5.1. Atenuacáo de un feire de raios gama

5.1.1. Medidas do coeficiente de atenuacão em massa de solos e outros materiais.

Tabela il. Coeficiente de atenuacão en massa para vàrios solos.

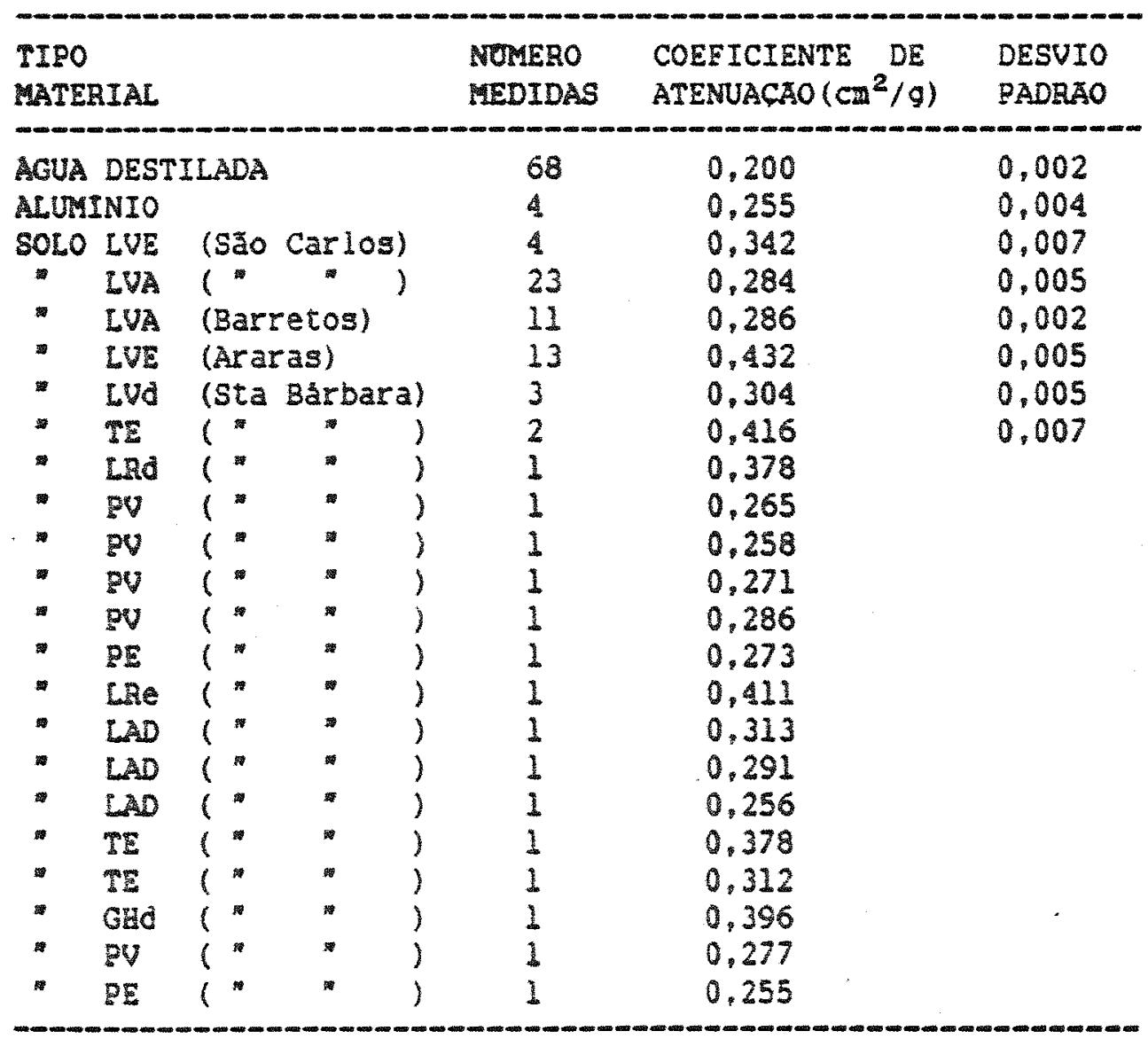


Vários coeíicientes de atenuacão em massa de solos, aqua e outros materiais foram medidos na energia de $60 \mathrm{keV}$. Esges dados são apresentados na tabela II.

os resultados mostram uma variaca media em torno de $1 \%$, no calculo do coeficiente de atenuacáo em massa. Precisão semelhante fol encontrada por FERRAZ \& MANSELL (1979). para os mais variados tipos de solos, os coeficientes de atenuacáo possuem uma grande variacá, indo de aproximadamente $0,25 \mathrm{~cm}^{2} / 9$ para solos com altos teores de areia, a aproximadamente $0.43 \mathrm{~cm}^{2} / 9$ para $3010 \mathrm{~s}$ argilosos e com altos teores de ferro.

5.1.2. Correlacăo entre o coeficiente de atenuacão Iinear - a densidade do solo

- coeficiente de atenuacaio linear de um solo, possui una correlacäo linear com a densidade deste. conforne mostra a eq.(22). Na figura 27 e mostrado 0 resultado do experimento conduzido para determinar esta correlacao. Abaixo são apresentadas as regressoes obtidas:

$$
\begin{aligned}
& \text { (LVE-Araras), } \mu=0.032+0.406 \cdot D s \\
& \text { (LVA-S. CarIos). } \mu=0.001+0.275 . \text { Ds }
\end{aligned}
$$

como esperado, obteve-se uma correlacao Inear, onde os coeficientes angulares das retas säo aproximadamente iouais aos coeficientes de acenuacão em massa desses solos. 
75.

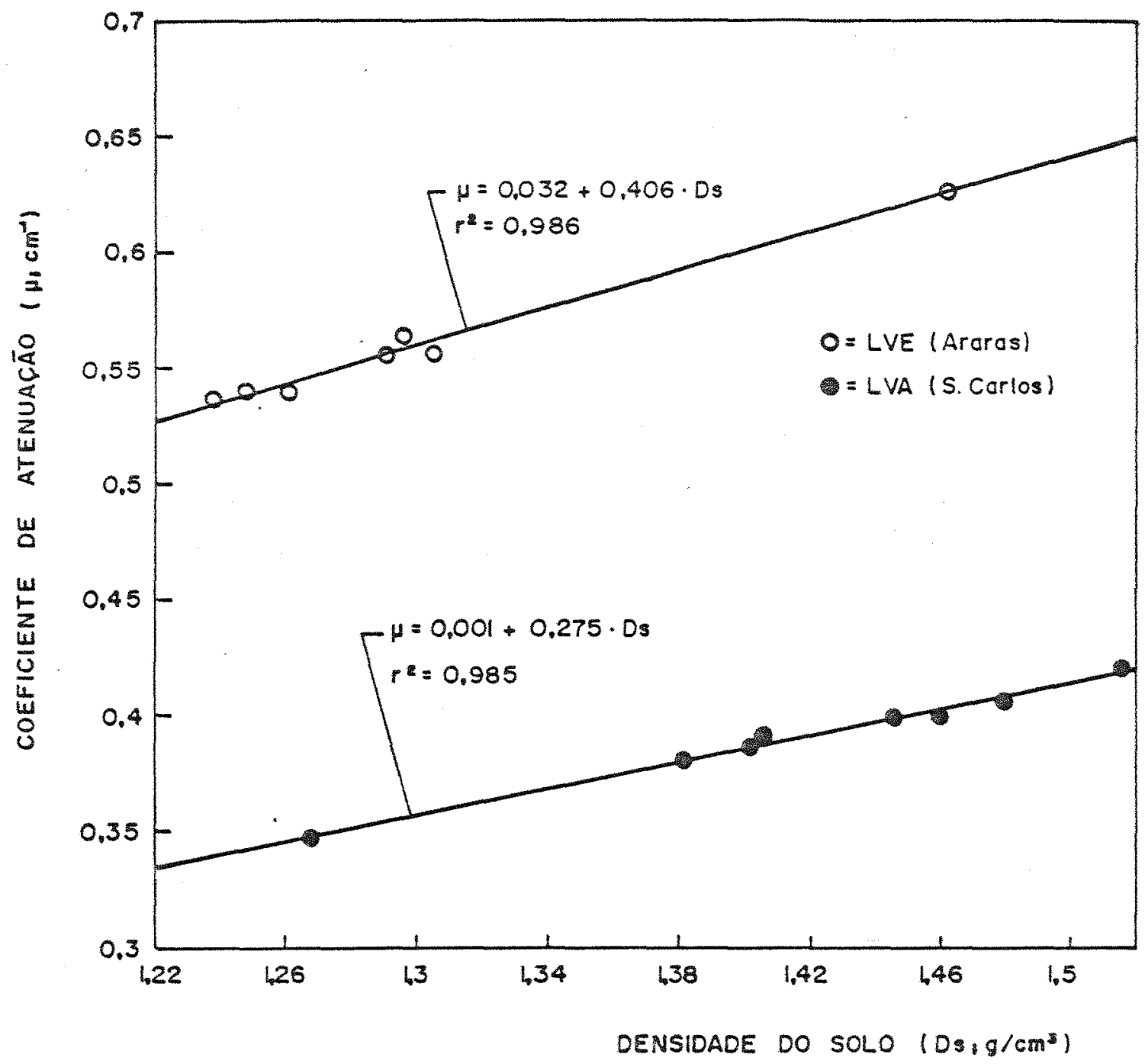

migura 27. Medidas do coeficiente de atenuacajo linear para amostras de varias densidades em dois solos.

\subsection{Tomografia: Calibracáo e quantificacăo}

A Eigura 28 mostra duas imagens (amostra umida e seca) de uma mesma secão transversal de uma amostra de solo LUE-sá carlos-sp (penesrado - $1 \mathrm{~mm}$ ).

Nas Iiguras 29 a) e b) sao apresentados os dados da regia central da matriz imagem da amostra, quando umida e seca respectivamente. 
a)

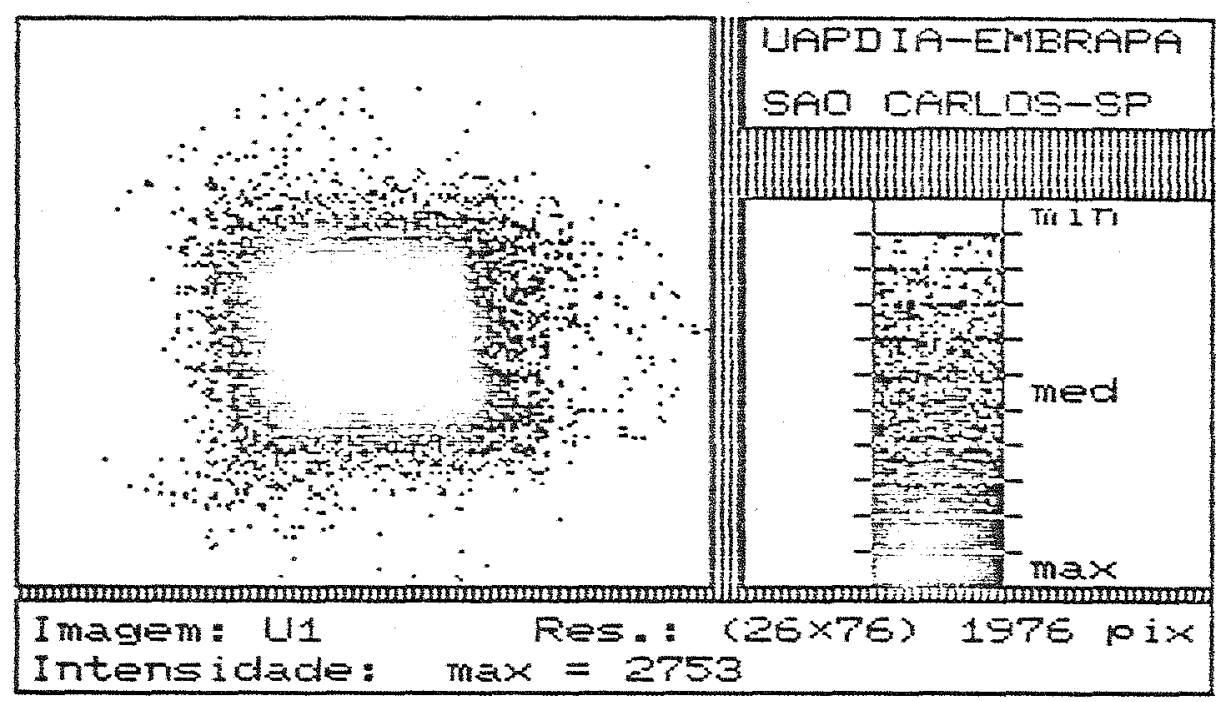

b)

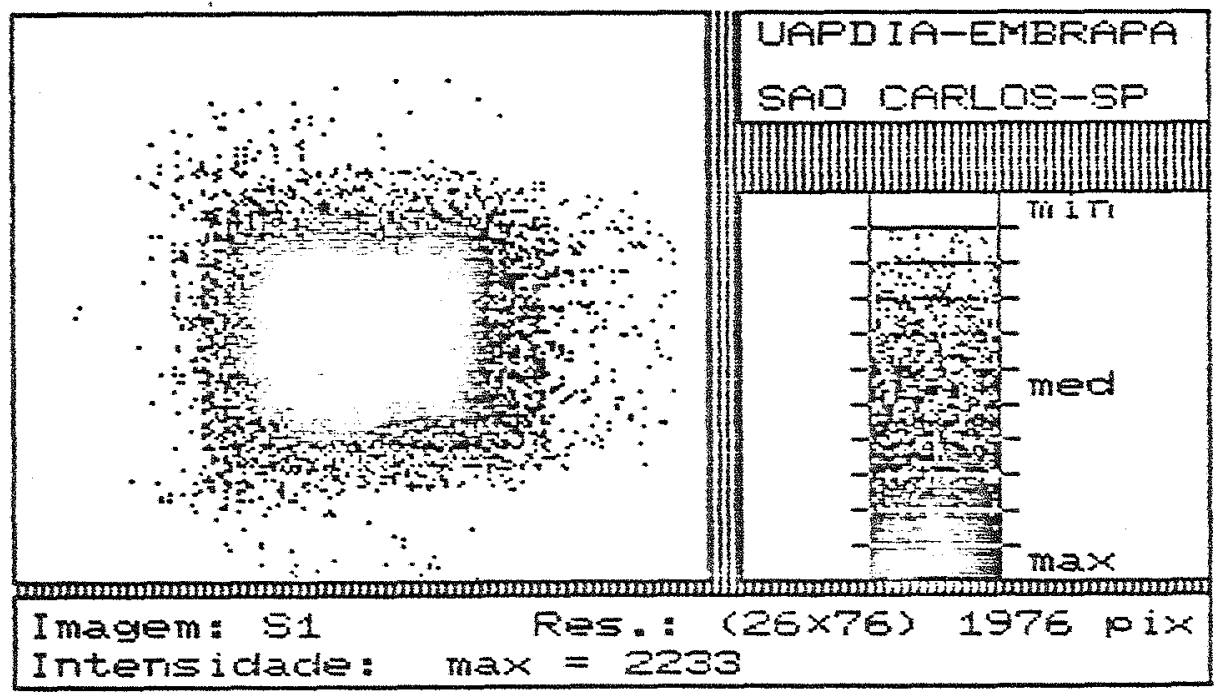

Fiqura 28. Imagens de uma secâo transversal de uma amostra de solo inno peneirado, quando umido (a) e seco (b). 
a)

UM1 $=$
(MATRIZ
IMAGEM
UMIDA) $\left[\begin{array}{ccccccccc} & \cdot & \cdot & \cdot & \cdot & \cdot & \cdot & \cdot & \\ \ldots & 2673 & 2697 & 2675 & 2627 & 2621 & 2645 & 2541 & \ldots \\ \ldots & 2683 & 2628 & 2753 & 2715 & 2676 & 2679 & 2597 & \ldots \\ \ldots & 2667 & 2739 & 2743 & 2691 & 2673 & 2682 & 2627 & \ldots \\ \ldots & 2642 & 2698 & 2724 & 2653 & 2641 & 2701 & 2639 & \ldots \\ \ldots & 2650 & 2694 & 2730 & 2690 & 2655 & 2672 & 2675 & \ldots \\ \ldots & 2608 & 2734 & 2684 & 2676 & 2640 & 2657 & 2622 & \ldots \\ \ldots & 2629 & 2722 & 2636 & 2604 & 2609 & 2544 & 2453 & \ldots \\ & \cdot & \cdot & \cdot & \cdot & \cdot & \cdot & \cdot & \end{array}\right]$

b)

\begin{tabular}{|c|c|c|c|c|c|c|c|c|c|}
\hline & & 0 & . & . & $=$ & - & $s$ & . & \\
\hline & & . & . & . & . & · & . & & \\
\hline & . & 2160 & 2121 & 2152 & 2151 & 2070 & 2070 & 2010 & $\ldots$ \\
\hline UM2 $=$ & & 2092 & 2152 & 2153 & 2132 & 2116 & 2062 & 1989 & $\ldots$ \\
\hline (MATRIZ & & 2116 & 2233 & 2172 & 2144 & 2139 & 2109 & 2084 & $\ldots$ \\
\hline IMAGEM & & 2064 & 2232 & 2170 & 2165 & 2119 & 2103 & 2055 & $\ldots$ \\
\hline SECA) & & 2125 & 2156 & 2198 & 2208 & 2149 & 2107 & 2065 & $\ldots$ \\
\hline & & 2098 & 2186 & 2178 & 2179 & 2125 & 2149 & 2023 & $\ldots$ \\
\hline & & 2080 & 2115 & 2135 & 2102 & 2039 & 2022 & 1953 & ... \\
\hline & & • & - & - & - & . & 。 & . & \\
\hline & 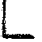 & . & . & . & 。 & . & 。 & . & \\
\hline
\end{tabular}

c)

d)

$D=$
$\left(\mathrm{g} / \mathrm{cm}^{3}\right)$$\left[\begin{array}{ccccccccc} & . & . & . & . & . & . & . & \\ \ldots & 1.072 & 1.053 & 1.068 & 1.068 & 1.028 & 1.028 & 0.998 & \ldots \\ \ldots & 1.039 & 1.068 & 1.060 & 1.058 & 1.050 & 1.024 & 0.987 & \ldots \\ \ldots & 1.050 & 1.109 & 1.078 & 1.064 & 1.062 & 1.047 & 1.035 & \ldots \\ \ldots & 1.023 & 1.108 & 1.077 & 1.075 & 1.052 & 1.044 & 1.020 & \ldots \\ \ldots & 1.055 & 1.070 & 1.091 & 1.096 & 1.067 & 1.046 & 1.025 & \ldots \\ \ldots & 1.042 & 1.085 & 1.081 & 1.082 & 1.055 & 1.066 & 1.004 & \ldots \\ \ldots & 1.033 & 1.050 & 1.060 & 1.043 & 1.012 & 1.004 & 0.970 & \ldots \\ & . & . & . & . & . & . & . & \end{array}\right]$

$$
\theta=\left[\begin{array}{ccccccccc} 
& \cdot & \cdot & . & . & . & . & . & \\
\ldots & 0.436 & 0.489 & 0.444 & 0.404 & 0.468 & 0.488 & 0.451 & \ldots \\
\ldots & 0.502 & 0.404 & 0.525 & 0.495 & 0.475 & 0.524 & 0.516 & \ldots \\
\ldots & 0.468 & 0.420 & 0.485 & 0.464 & 0.453 & 0.486 & 0.461 & \ldots \\
\ldots & 0.491 & 0.396 & 0.470 & 0.414 & 0.443 & 0.508 & 0.496 & \ldots \\
\ldots & 0.446 & 0.457 & 0.430 & 0.404 & 0.430 & 0.480 & 0.509 & \ldots \\
\ldots & 0.433 & 0.465 & 0.430 & 0.422 & 0.436 & 0.433 & 0.508 & \ldots \\
\ldots & 0.466 & 0.515 & 0.425 & 0.398 & 0.426 & 0.484 & 0.443 & \ldots \\
& . & . & . & . & . & . & . &
\end{array}\right]
$$

Figura 29. partes das matrizes imagens da comograria mostrada na ilgura 28 , quando imida (a) e seca (b) e das matrizes densidade (c) e unidade (d). 
78.

Nas figuras 29 c) e d) sao mostrados os resultados das densidades e das umidades, referentes a essa mesma regiäo central, conforme procedimento de calculo descrito no capitulo 4.

Neste exemplo, obteve-se matrizes de ordem $26 \times 76$ e cada elemento representa um pixel de $2 \mathrm{x} 2 \mathrm{~mm}^{2}$. A ordem da matriz e definida em funcão do tamanho da amostra e da resolucão pretendida.

Essa amostra de solo, possui uma densidade e umidade bastante homogeneas, pois foi preparada com soló seco e peneirado, usando um recipiente de acrilico de dimensōes $25 \times 25 \times 50 \mathrm{~mm}^{3}$.

As figuras 30 a) e b) apresentam as distribuicöes de frequencias dos dados das íiguras 29 a) e b). os resultados mostram uma dispersăo de aproximadamente $60 \mathrm{UM}$, em torno dos valores medios, que no caso sảo estatisticamente identicos ás suas modas. Essas dispersöes săo devidas d oscilacão eletrónica do sistema, comportamento estatistıco e espalhamento da radiacăo.

As variancias, tanto nos dados da matriz da amostra umida como da seca, foram de aproximadamente $2:$.

A tiqura 31a) mostra um pertil medio de UM, para as duas imagens. Esses dados nao revelam variacós significativas, o mesmo ocorrendo com os peris medios de densidades e umidades da amostra (figura 31 b). 
a)

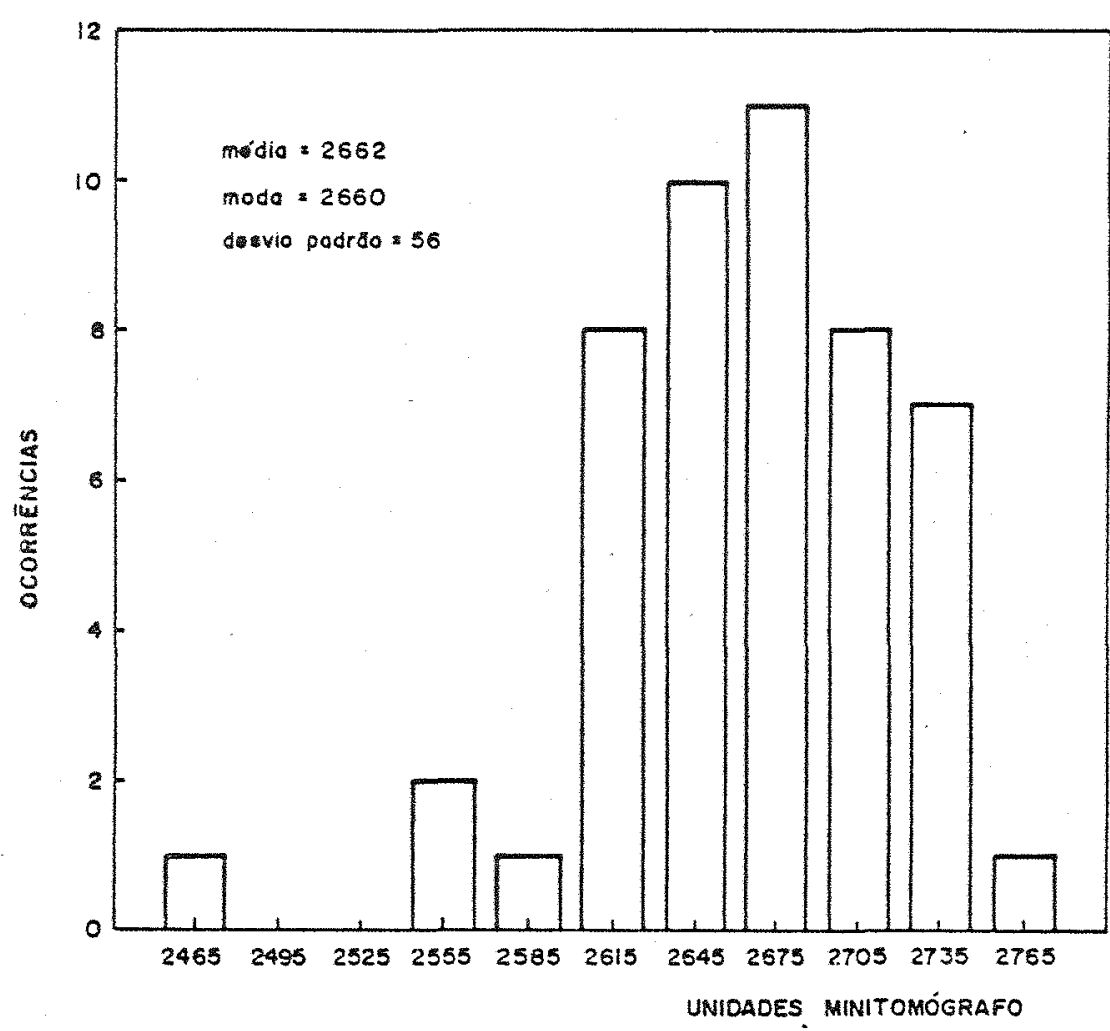

b)

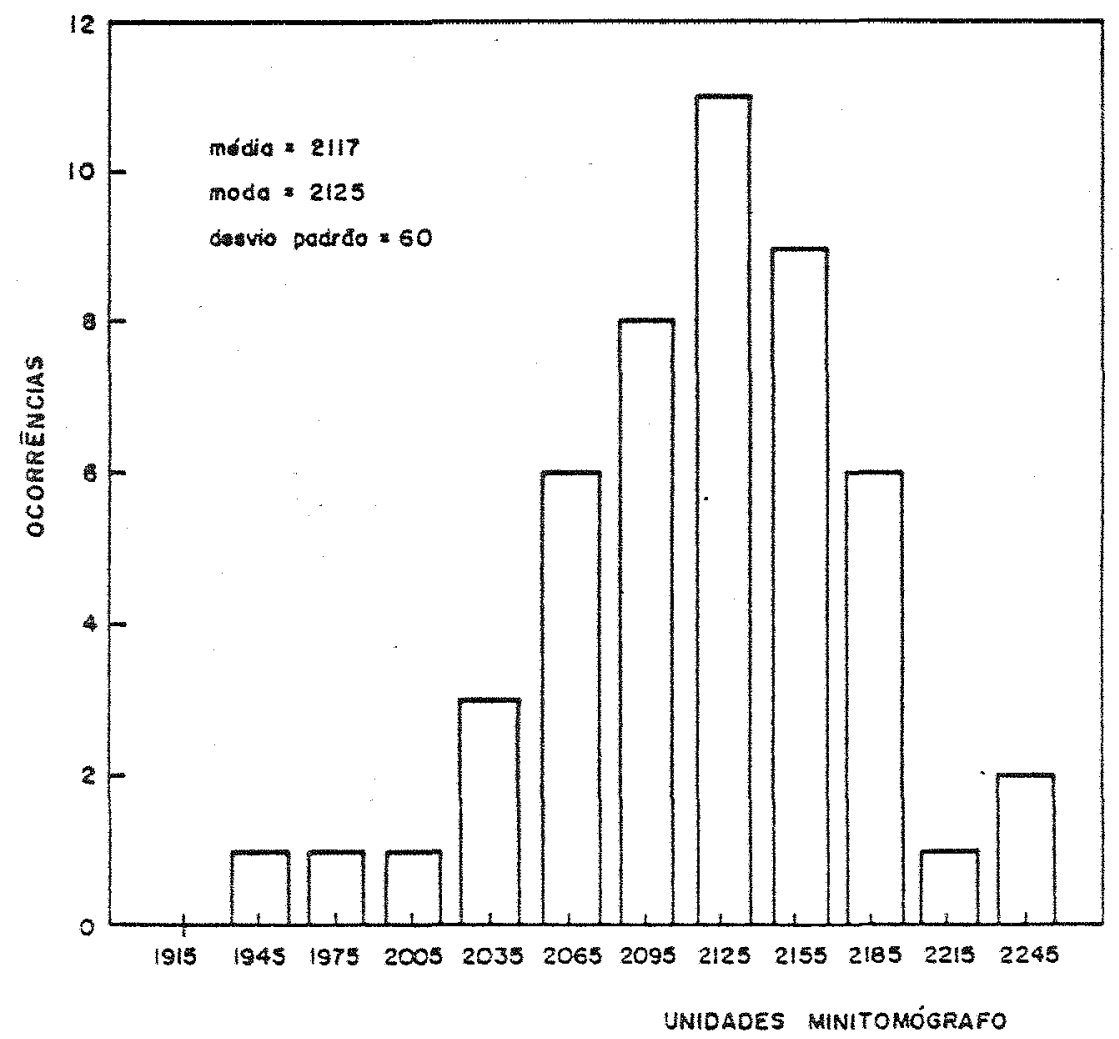

Fiqura 30. Distribulcoes de trequencias cos dados das ilguras 29 a) e b), para a amoscra tmida (a) e seca (b), respectivamente. 
80.

a)

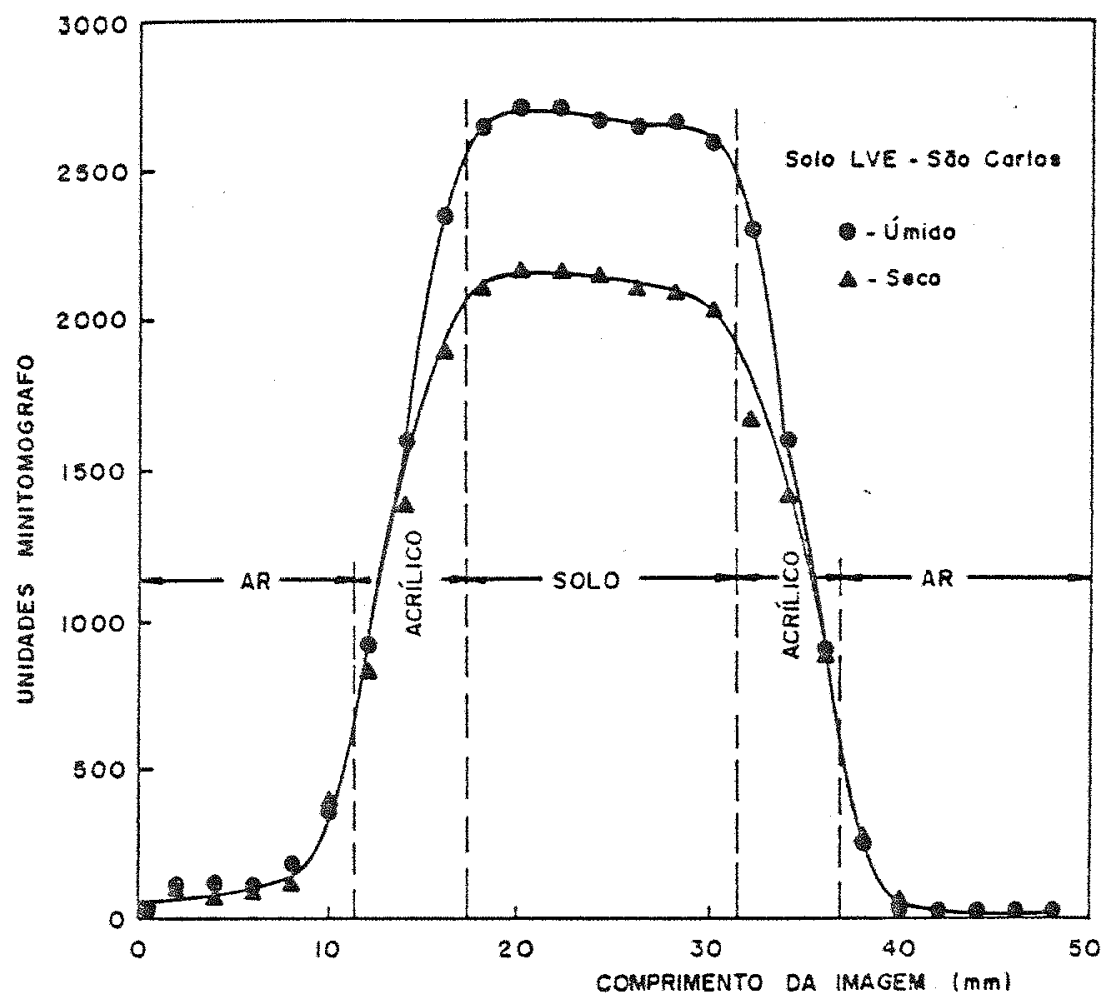

b)

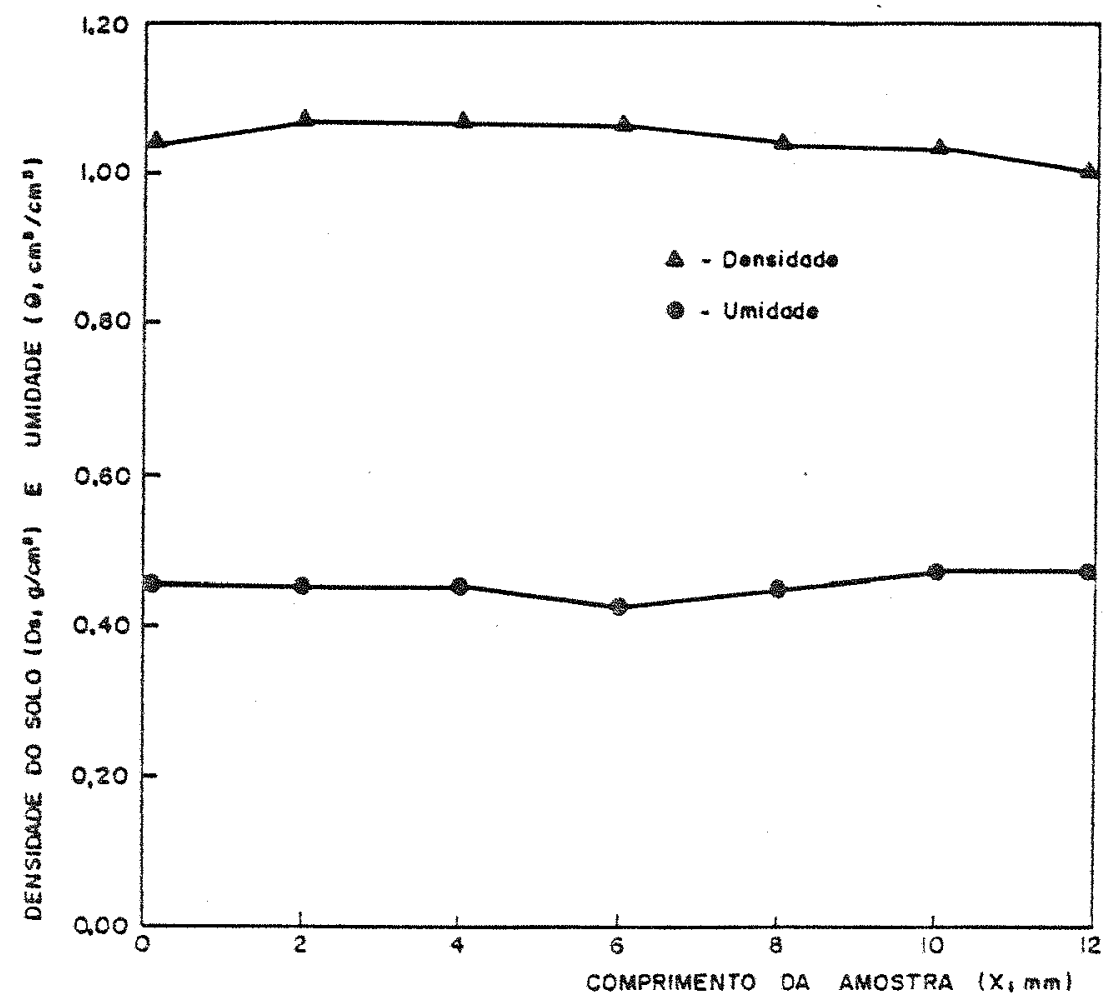

Elqura 31. perils das UM (a), densidades e undades (b), relacivos as iaagens da rigura 28. 
5.2.1. Dependéncia linear entre UM, Ds e $\theta$

Nas figuras $32 a$ e $32 b$ pode-se observar uma dependencia Iinear entre UM, Ds e $\theta$. Esses resultados confirmam a linearidade mostrada na eq. (27), quando um dos parametros $\mathrm{Ds}$ ou $\theta$ for mantido constante e o solo näo for expansivo.

5.3. Estudo da compactacăo de solos por tomografia

5.3.1. Finas camadas de solo compactado (laboratório)

A Ligura 33 mostra as tomografias de duas amostras de solo com finas camadas de solo compactado, de 4 e $8 \mathrm{~mm}$.

Devido ao tipo de apresentacão gráfica da matriz imagem, que è de pontos aleatorios num pixel com escala variavel, esta não fornece uma boa definicăo visual da lamina compactada. No entanto, atraves da quantificacáo em perfis (figura 34) pode-se analisar de uma forma mais segura, as regiobes compactadas das amostras.

As densidades das camadas foram de 1,49;

1.46 e $1.33 \mathrm{~g} / \mathrm{cm}^{3}$ para as camadas de 8,4 e 2 respectivamente. As diferencas nos valores da densidade sâ devidas as variacões de construcăo das amostras, artefatos gerados entre regiöes com mudancas abruptas nos coeficientes de atenuacáo e resolucăo, já que neste caso a resolucáo fol de $2 \mathrm{~mm}$. 
$0)$

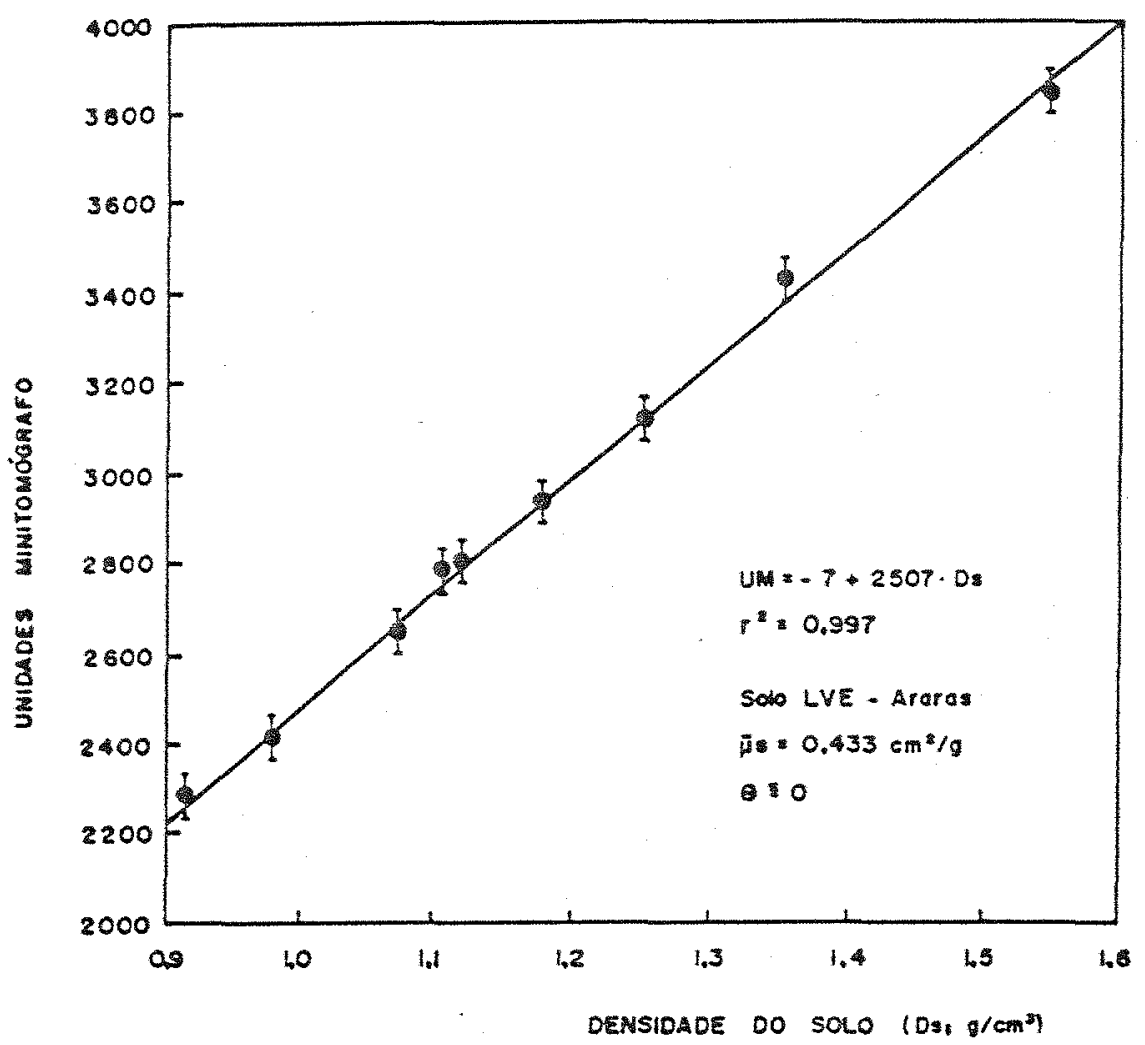

b)

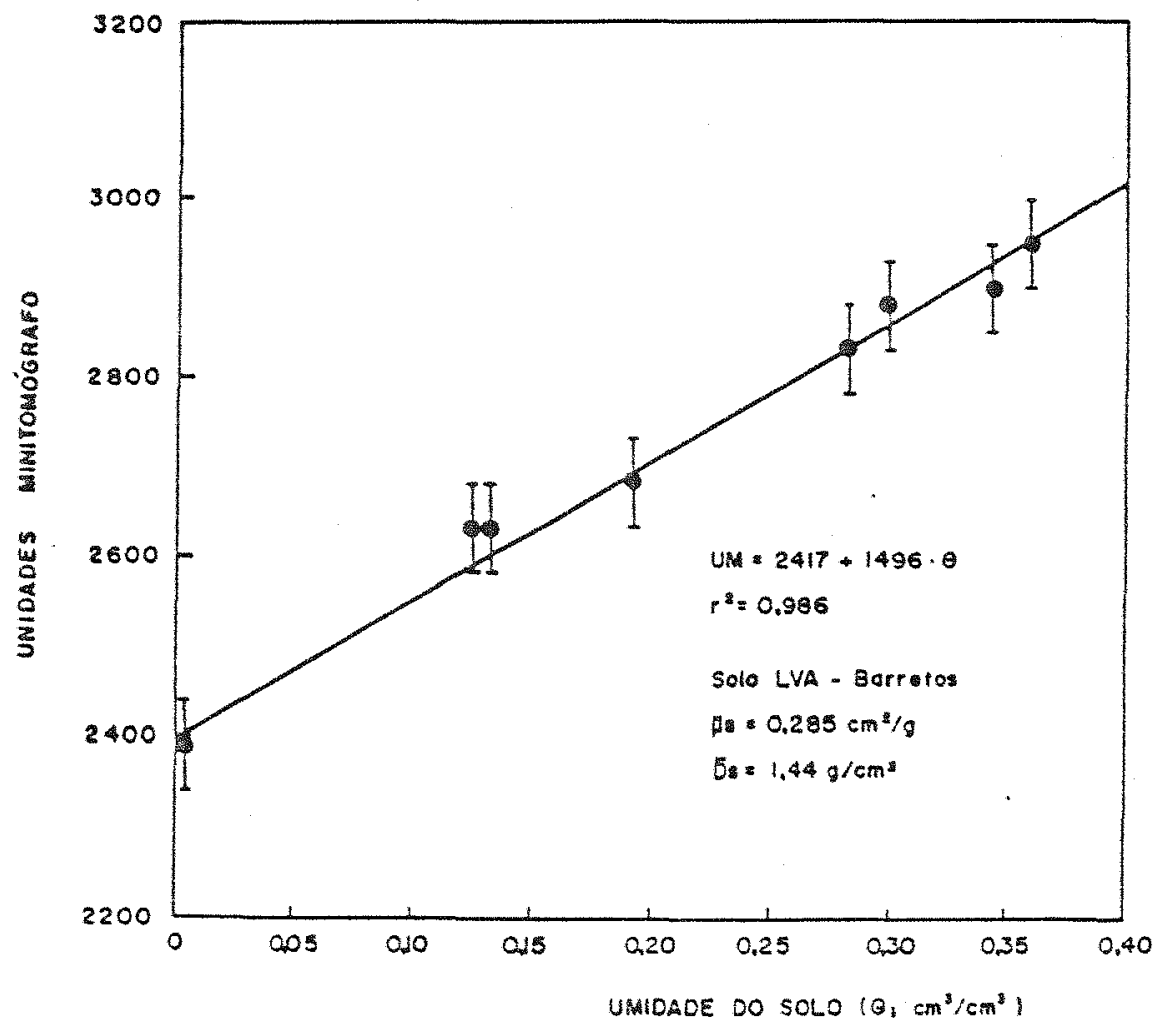

Elgura 32. Correlacão entre UM, a densidade (a) e a umade do solo (b) . 

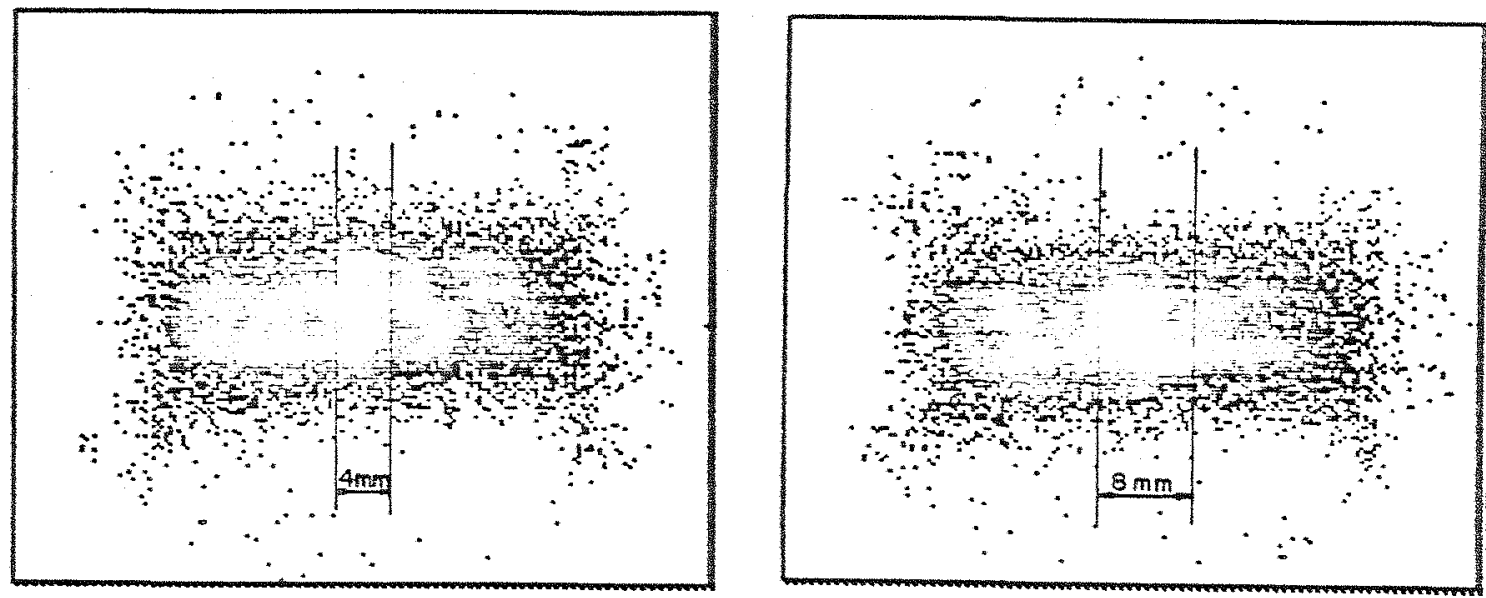

Figura 33. Imagens de duas amostras de solo com innas camadas de solo compactado.

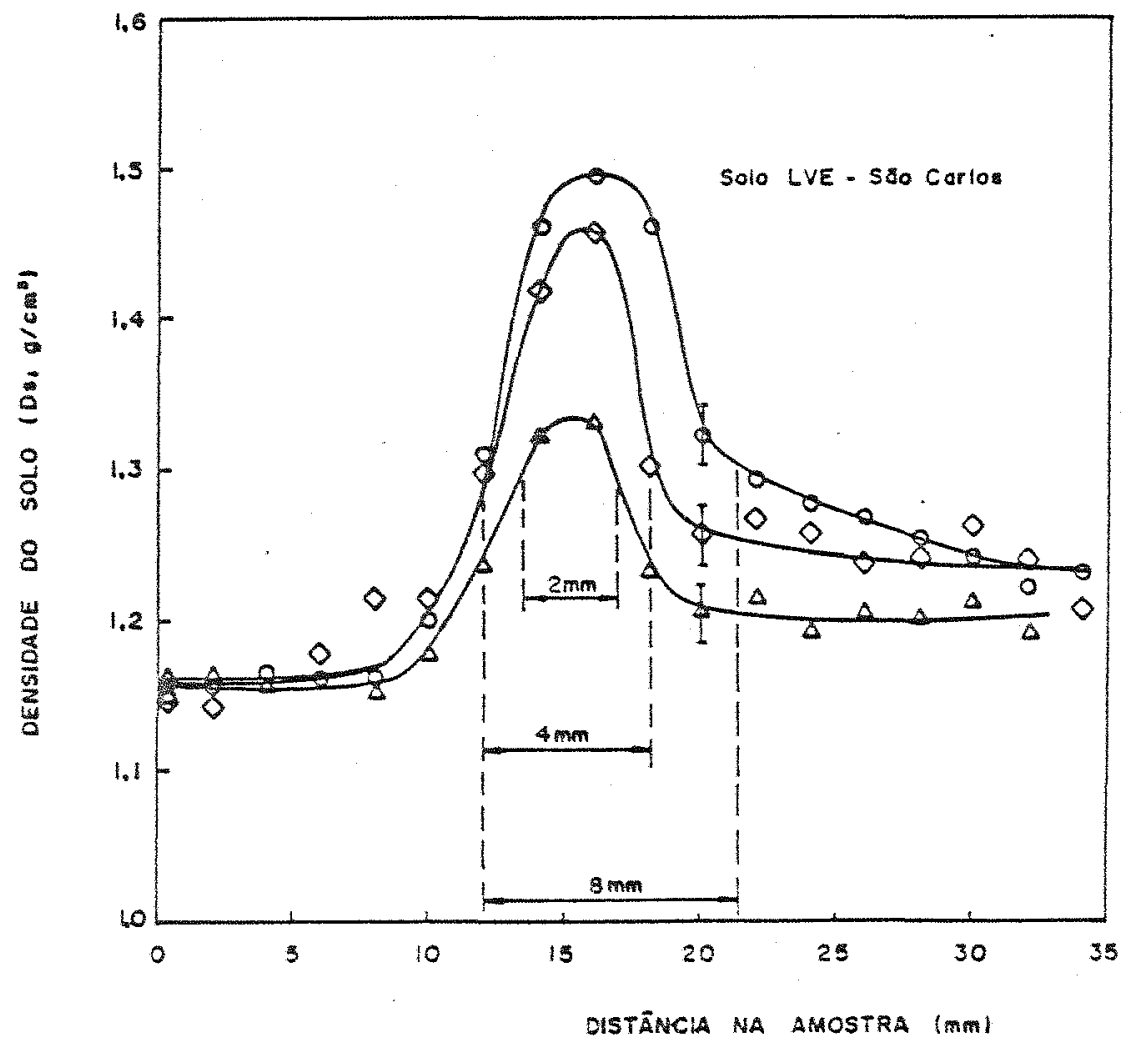

Pqura 34. peris mésos de UM. de amostras com innas camadas compactadas (Ijgura 33). 
5.3.2. Compactacáo por compressao estatica (1aboratório)

Na tabela III săo apresentados os resultados para cada recipiente, da densidade média inicial, da umidade e da densidade media apos a compressáo por uma pressäo de $0,8 \mathrm{MPa}$. A figura 35 moscra as imagens das secöes transversais de cada amostra e a figura 36 mostra um grafico da densidade media inal pela umidade. con os dados da tabela III.

Tabela III. Resultados obtidos por gravimetria para amostras compactadas pelo teste de proctor (máxima compactação).

\begin{tabular}{|c|c|c|c|}
\hline $\begin{array}{c}\text { RECIPIENTE } \\
\text { N. }\end{array}$ & $\begin{array}{l}\text { DENSIDADE } \\
\text { INICIAC } \\
\left(9 / \mathrm{cm}^{3}\right)\end{array}$ & $\begin{array}{l}\text { UMIDADE } \\
(g / g)\end{array}$ & $\begin{array}{c}\text { DENSIDADE } \\
\text { FINAL } \\
\left(g / \mathrm{cs}^{3}\right)\end{array}$ \\
\hline 1 & 1.041 & 0,08 & 1,189 \\
\hline 2 & 1,036 & 0,10 & 1,307 \\
\hline 3 & 1,040 & 0,20 & 1,578 \\
\hline 4 & 1.051 & 0,30 & 1,541 \\
\hline 5 & 1.056 & 0.36 & 1,522 \\
\hline
\end{tabular}

Neste grafico pode-se observar que a densidade do solo aumenta com o reor de agua ate atingir un maximo e depols decresce. Isso ocorre, pois a estabilidade dos agregados diminui com 0 aumento de umidade no solo e assim para una dada pressäo existe uma certa umidade (umidade de compactacáo maxima), na qual todos os poros saturam com a compactacăo. Aumentanco alnda mais a umidade, a aqua sera expelida do recipience e 


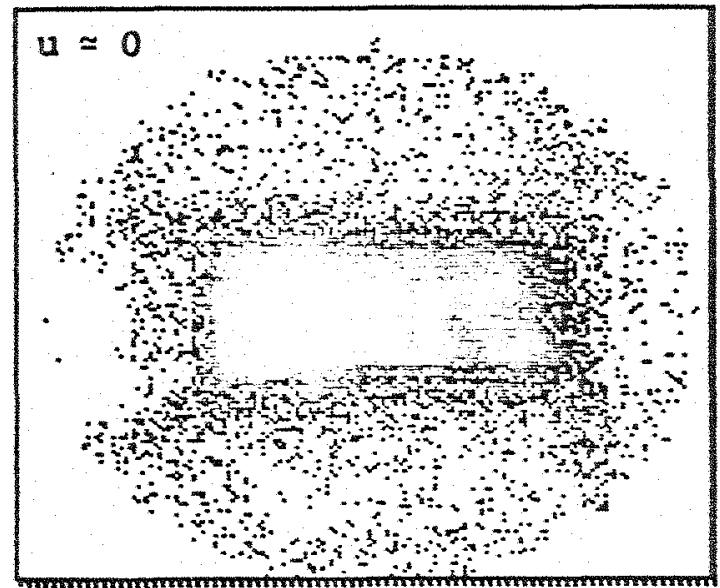

Intensidade Máxima $=2431$

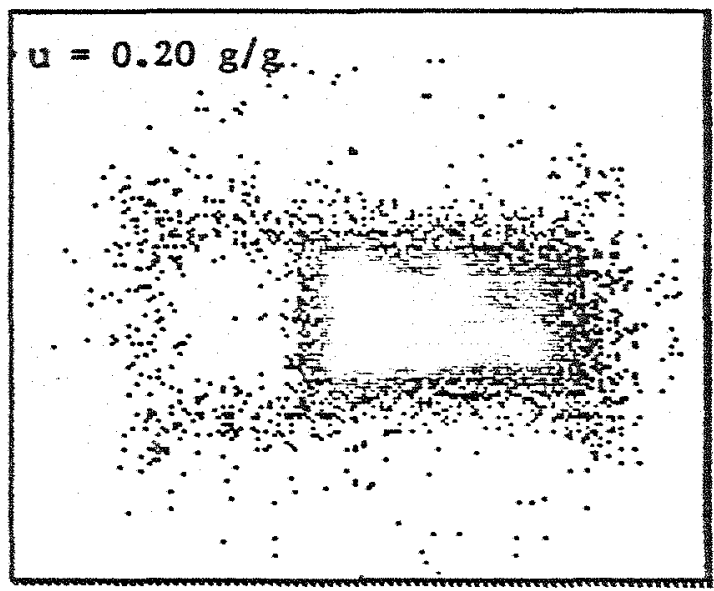

Intensidade Wáxima $=3321$

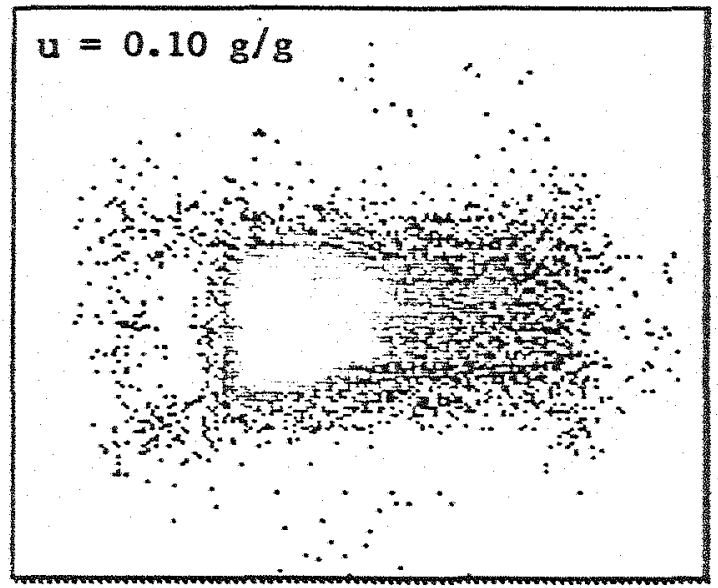

Intensidade Máxima $=3055$

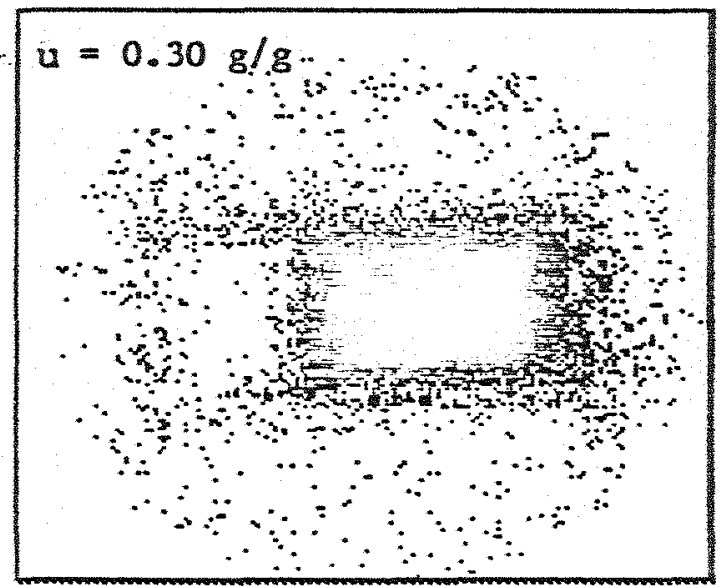

instensidade Máxima $=3335$

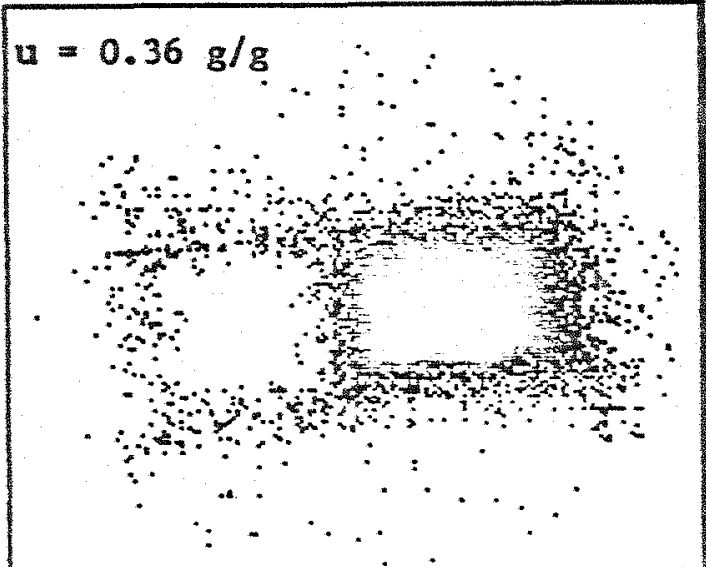

Intensidade máxima $=3290$

squra 35. Imacens de amostras de solo LVE-Săo carlos, compactacas com varios leores de aqua. 
86.

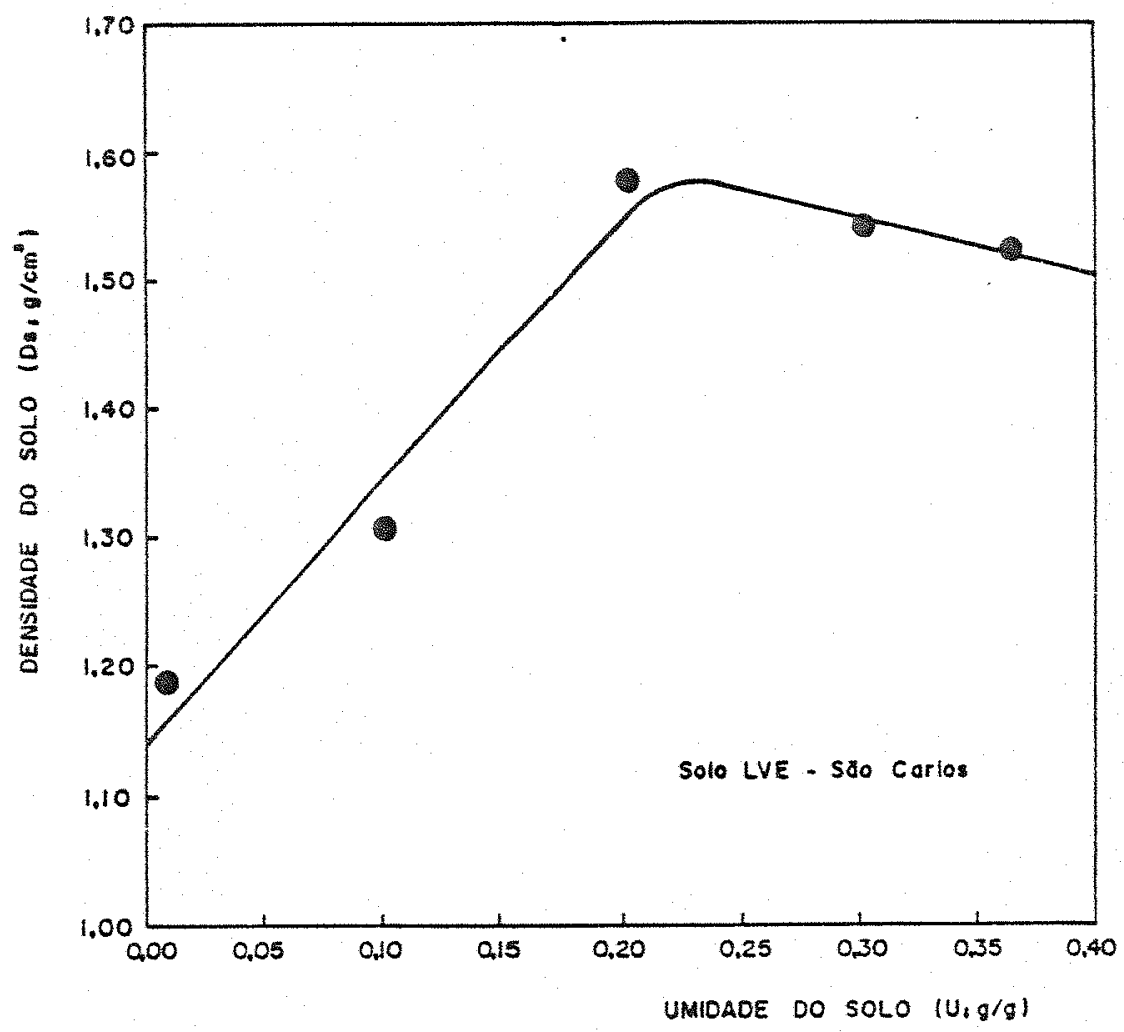

Fiqura 30. Grático da densidade media inal (medida por gravimecria) e a umidade de amostras de solo compactadas por uma pressäo de $0,8 \mathrm{MPa}$.

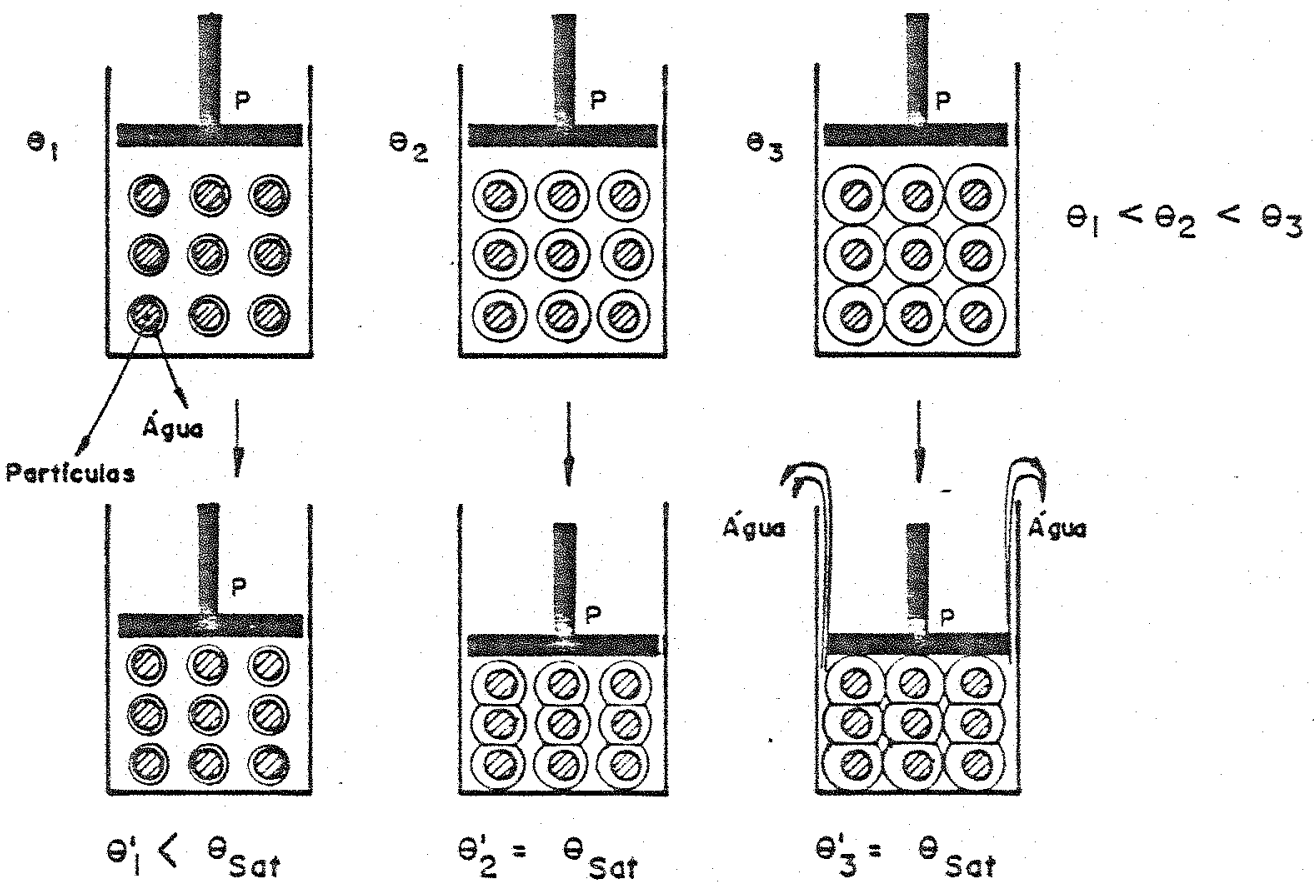

Figura 37. Processo de compactacao con carga conscante e varias unidades, evidenciando a maxina compactacao. 
conjuntamente com esta, particulas de solo. Deste modo a densidade média final decresce. Este processo descrito, e esquematizado na Iigura 37.

Isso e equivalente a se manter uma determinada umidade constante e se aumentar a pressao. Neste caso tamben existira uma pressão na qual a densidade media Inal sera márima, devido a acomodacăo da aqua nos poros. A partir desta pressäo haverá tambem diminuicão da densidade devido a perda de massa.

os resultados obtidos pela quantificacào das imagens por tomografia computadorizada em pertis, são apresentadas na Iigura 38. Nela pode-se observar os gradientes de densidades e 0 alcance das pressöes transmitidas ao longo da amostra.

os gradientes de densidades sao em primeira aproximacăo, linhas retas.

para o solo seco ao ar e com umidade inicial de $10 \%$, os gradientes säo retas paralelas e o alcance menor que o comprimento da amostra. ouando o alcance ultrapassa o comprimento total da amostra feurvas referentes as umidades 20,30 e $35 \%$ ) as retas mudam a inclinacao. para as umidades de 30 e 36 houve perda de massa e portanto houve uma deformacáo da amostra proximo ao contato solo-compactador, como pode ser observado na Eigura 38. 


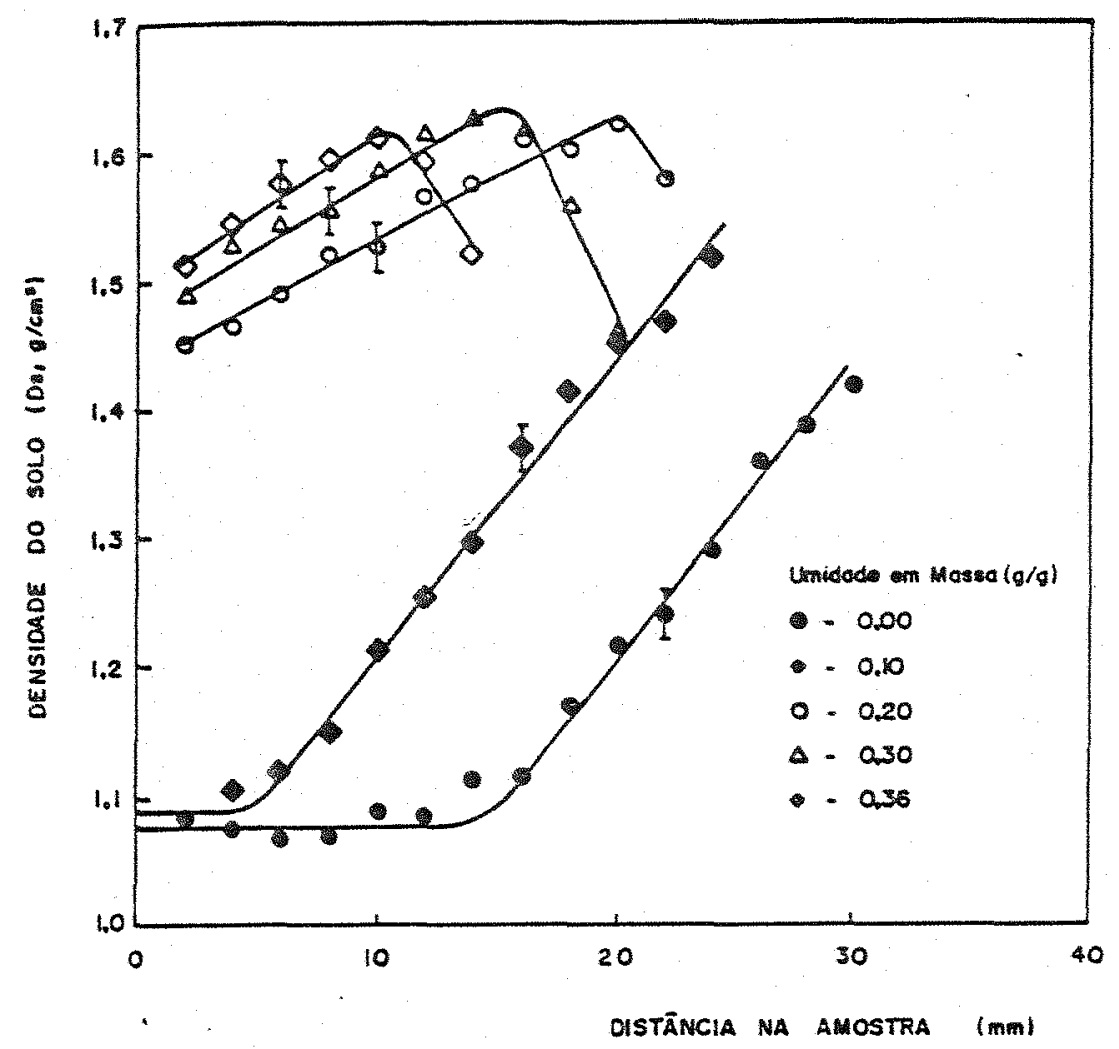

Higura 38. Uuantificaçăo dos perfis, en termos de densidade do solo, de amostras compactadas con varias unidades e pressào de 0,8 Ma.

5.3.3. Compactąa por compressão de implementos (campo)

Analisando-se amostras de solo coletadas após a passagem de sulcadores em varias condicöes de umidade e estrutura do solo, obteve-se aumentos de densidade na direcáo de propagacá das pressós, desde $0.08 \mathrm{~g} / \mathrm{cm}^{3}$ ate praticamente zero, dependendo das condicós Elsicas do solo e Lorma de utilizaca do implemento em cada experimento. 
Primeira amostragem (Araras - set/87)

Coletou-se as amostras numa area de trafego intenso após a passagem de um sulcador. A densidade média do solo estava em torno de $1.65 \mathrm{~g} / \mathrm{cm}^{3}$ e a umidade em torno de $0,20 \mathrm{~cm}^{3} / \mathrm{cm}^{3}$. A figura 39 mostra a quantificacá num perfil medio da matriz imagem de uma das amostras coletadas, a qual como se ve, nao apresenta nenhuma tendencia significativa de aumento da densidade do solo.

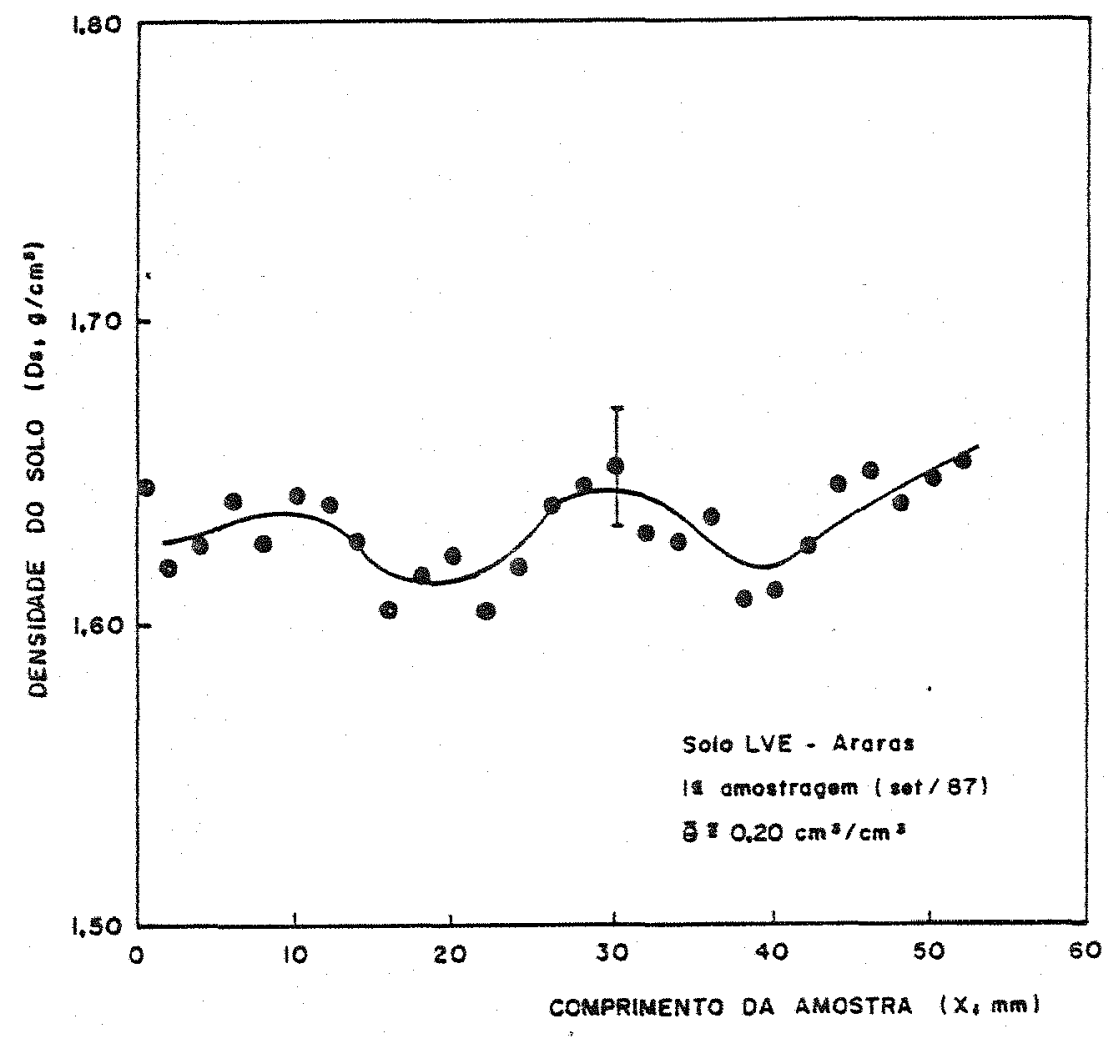

Sigura 39. Pertil de densidades numa amostra coletada após a passagem de un sulcador (la. amostragem).

Segunda amostragem (Araras - jan/88) 
preparada para o plantio de cana de actcar, cuja densidade e umidade do solo estavam em torno de $1.35 \mathrm{~g} / \mathrm{cm}^{3}$ e 0.13 $\mathrm{cm}^{3} / \mathrm{cm}^{3}$ respectivamente.

Na figura 40 , ve-se a quantificacão do peril de densidades de uma dessas amostras. Nela observase um gradiente negativo no peril, desde a extremidade esquerda (contato solo-implemento) ate a extremidade direita da amostra. Na tabela IV encontram-se os resultados das analises das outra amostras coletadas. 0 aumento medio de densidade no peril fol de $0.07 \mathrm{~g} / \mathrm{cm}^{3}$.

Terceira amostragem (Araras - ago/88)

Neste experimento a densidade e a umidade media do solo estavam em torno de $1.52 \mathrm{~g} / \mathrm{cm}^{3}$ e $0.15 \mathrm{~cm}^{3} / \mathrm{cm}^{3}$ respectivamente.

- resultado gráico da quantificacâo do perfil de uma amostra está mostrado na figura 4l. Os resultados dos aumentos de densidade causados nas outras amostras coletadas, são apresentadas na tabela $V$.

Analisando esses resultados, observa-se un aumento de densidade na regiao que esteve em contato com o 3ulcador. O alcance da compactacăo fol de aproximadamente $20 \mathrm{~mm}$ e o aumento medio tol de $0.08 \mathrm{~g} / \mathrm{cm}^{3}$. 


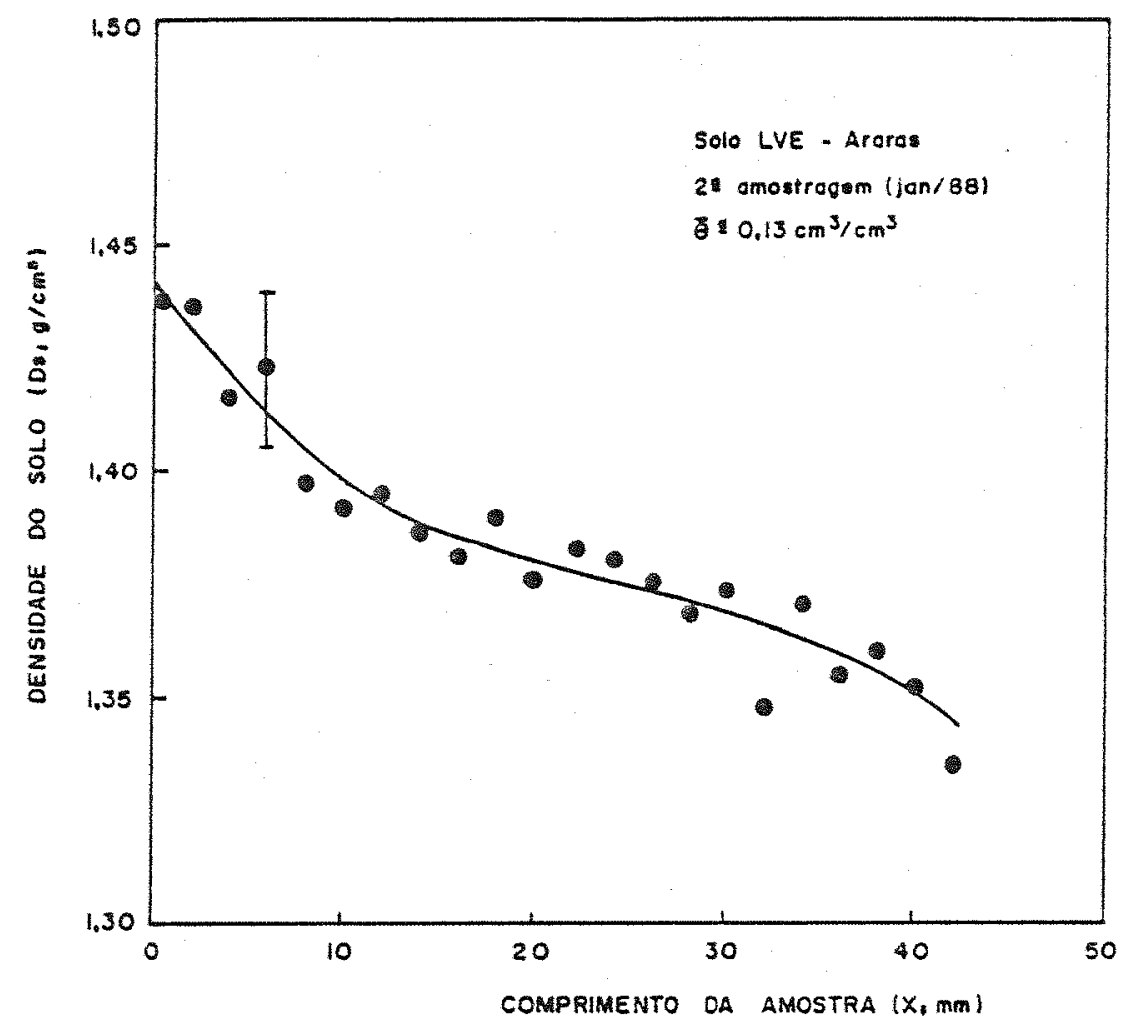

Figura 40. pertil de densidades numa amostra coletada apos a passagem de un sulcador (2a. amostragem).

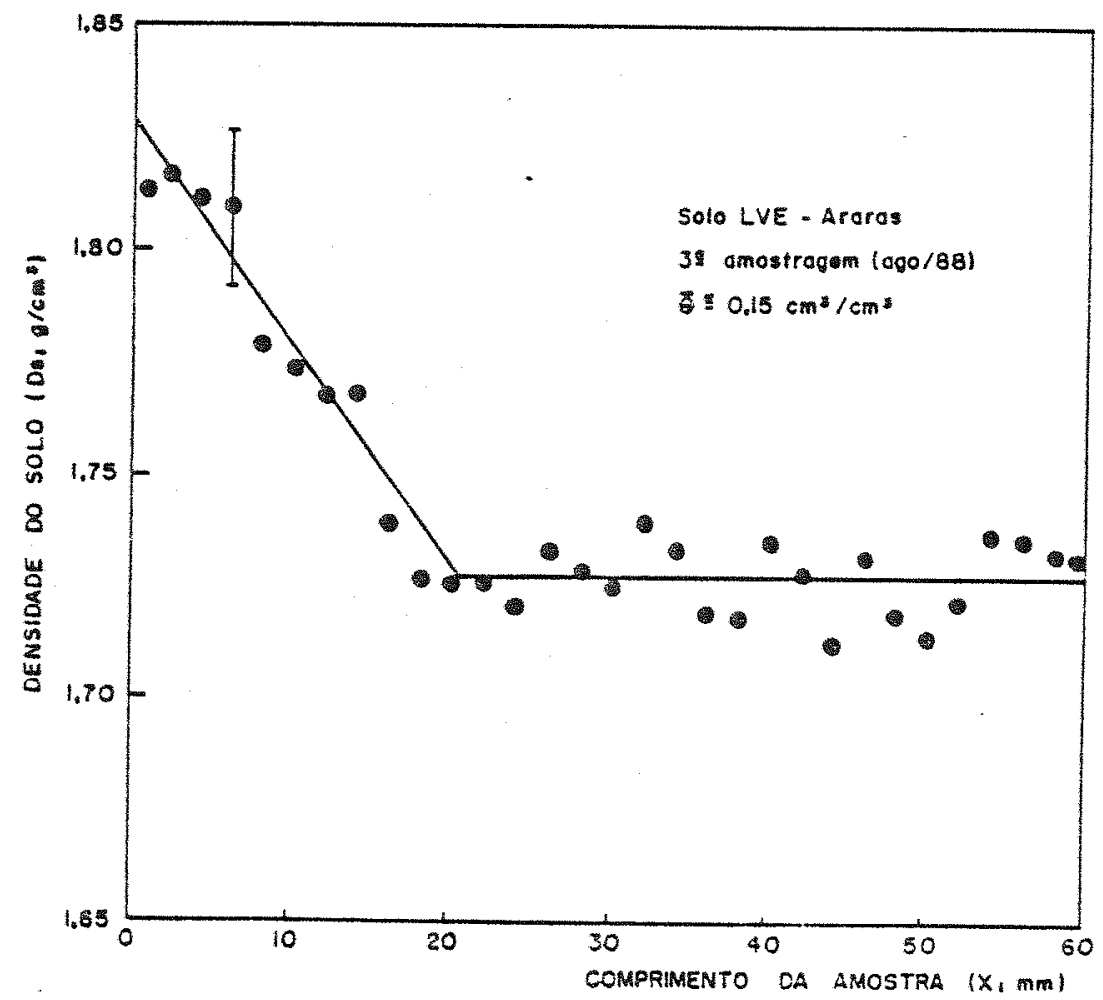

gloura 41. Pertil de densidades numa amostra colecada após a passagea de sulcador (3a. amostraçen). 
92.

Tabela IV. Resultados das quantificacóes dos perfls de densidade das amostras coletadas apos a passagem de um sulcador no solo (2a. amostragem).

\begin{tabular}{ccccc} 
AMOSTRA & $\begin{array}{c}\text { DENSIDADE } \\
\text { MEDIA } \\
\left(9 / \mathrm{cm}^{3}\right)\end{array}$ & $\begin{array}{c}\text { UMIDADE } \\
\text { MEDIA } \\
\left(\mathrm{cm}^{3} / \mathrm{cm}^{3}\right)\end{array}$ & $\begin{array}{l}\text { DENSIDADE } \\
\text { MANIMA } \\
\left(\mathrm{g} / \mathrm{cm}^{3}\right)\end{array}$ & $\begin{array}{l}\text { AUMENTO } \\
\text { DENSIDADE } \\
\left(\mathrm{g} / \mathrm{cm}^{3}\right)\end{array}$ \\
\hline 1 & 1,321 & 0,162 & 1,386 & 0,08 \\
2 & 1,361 & 0,100 & 1,465 & 0,08 \\
3 & 1,387 & 0,100 & 1,437 & 0,05 \\
4 & 1,242 & 0,157 & 1,327 & 0,06 \\
5 & 1,283 & 0,125 & 1,341 & 0,05 \\
6 & 1,284 & 0,136 & 1,397 & 0,09 \\
7 & 1,274 & - & 1,341 & 0,08 \\
8 & 1,276 & - & 1,319 & 0,03 \\
\hline
\end{tabular}

Tabela $v$. Resultados das quantificacoes dos perfis de densidade, das amostras coletadas apos a passagem de un sulcador no solo (3a. amostragem).

\begin{tabular}{|c|c|c|c|}
\hline $\begin{array}{l}\text { AMOSTRA } \\
\text { N. }\end{array}$ & $\begin{array}{c}\text { DENSIDADE } \\
\text { MDDA } \\
\left(9 / \mathrm{ca}^{3}\right)\end{array}$ & $\begin{array}{l}\text { DENSIDADE } \\
\text { MAXIMA } \\
\left(9 / \mathrm{cm}^{3}\right)\end{array}$ & $\begin{array}{l}\text { AUNENTO } \\
\text { DENSIDADE } \\
\left(g / \mathrm{cm}^{3}\right)\end{array}$ \\
\hline 1 & 1,52 & 1,58 & 0,06 \\
\hline 2 & 1.65 & 1.73 & 0.08 \\
\hline 3 & 1,56 & 1,63 & 0.07 \\
\hline 4 & 1.51 & 1,51 & 0,00 \\
\hline 5 & 1.52 & 1,52 & 0,00 \\
\hline 6 & 1.53 & 1,62 & 0,09 \\
\hline
\end{tabular}




\subsubsection{Tomografia vs penetrometro}

A fiqura 42 mostra os resultados da analise das amostras da trincheira 1 . O pertil de densidade representa uma média dos pertis densidade na tomografia a cada $2 \mathrm{~mm}$. Nota-se uma regiao compactada com Ds $=1,5 \mathrm{~g} / \mathrm{cm}^{3}$ em torno de $5 \mathrm{~cm}$. A partir desta profundidade a densidade decresce de uma forma aprozimadamente linear.

Para as sondagens com o penetrometro ao lado da trincheira, observa-se que a umidade influencia sensivelmente 0 espectro do penetrometro. Quanto mais Umido 0 solo, mais mascarada fica a regia compactada e quanto mais seco este solo, mais o perill do penetrometro se assemelha do da densidade do solo pela tomografia.

og resultados obtidos da trincheira 2 (Elqura 43) mostram tambem uma regia compactada con 1,5 $9 / \mathrm{cm}^{3}$, a partir de $12 \mathrm{~cm}$. A partir dal, ocorre um decaimento aproximadamente linear da densidade com a profundidade, como na trincheira 1.

Comparando os dados obtidos na trincheira 1 com os da trincheira 2 , observa-se uma certa variabilidade entre os pertis de densidades, mas uma mesma tendencia dos dados. A diferenca desses resultados podem ser atribuidos a variabilidade da area e a diferenca de nivel das superficies das duas trincheiras, ja que fol necessário se retirar uma camada de apoximadamente 15 cm da superficie, por estar com muito mato. 
Impactos por Decimetro

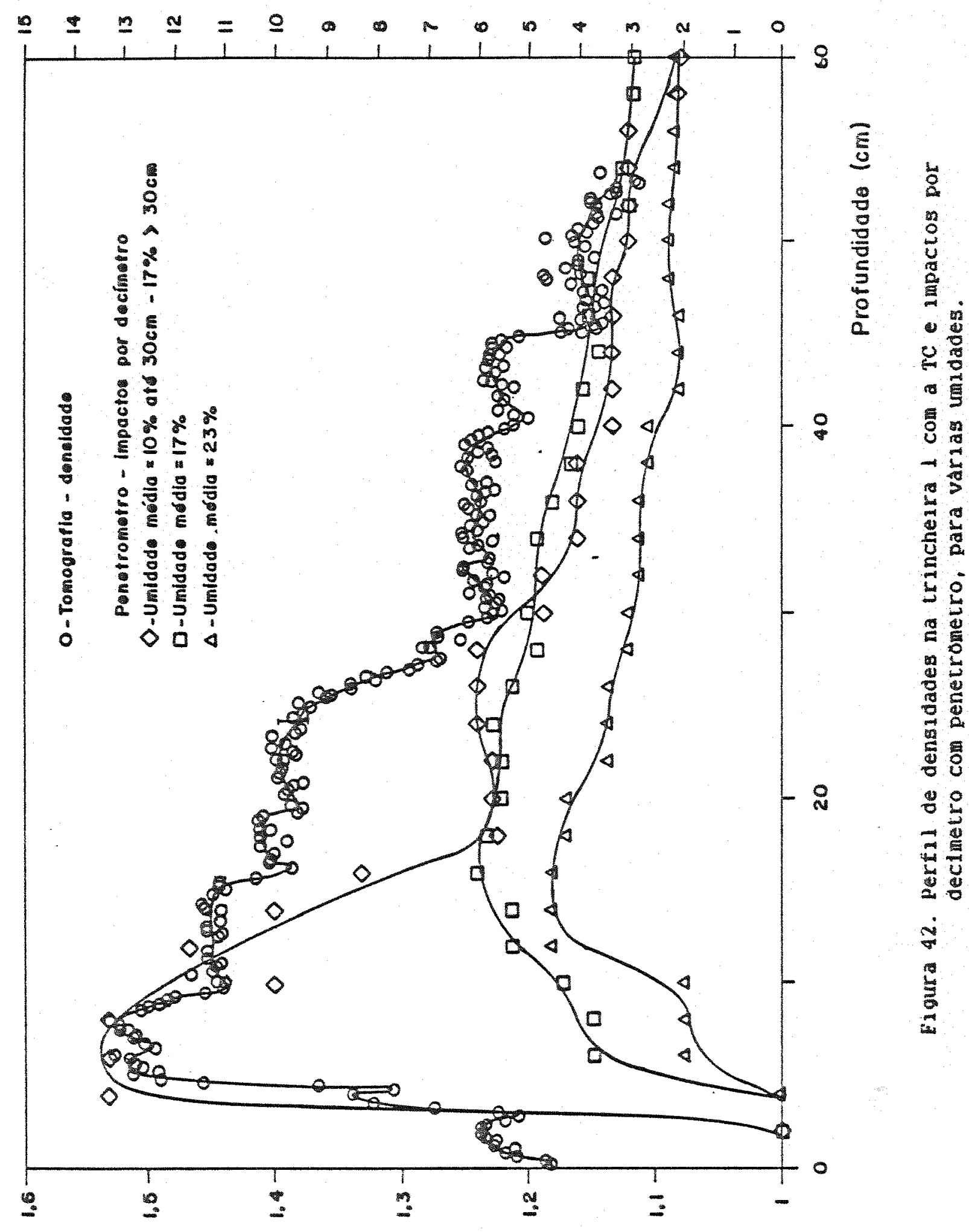

Densidade $\left(\mathrm{g} / \mathrm{cm}^{3}\right)$ 


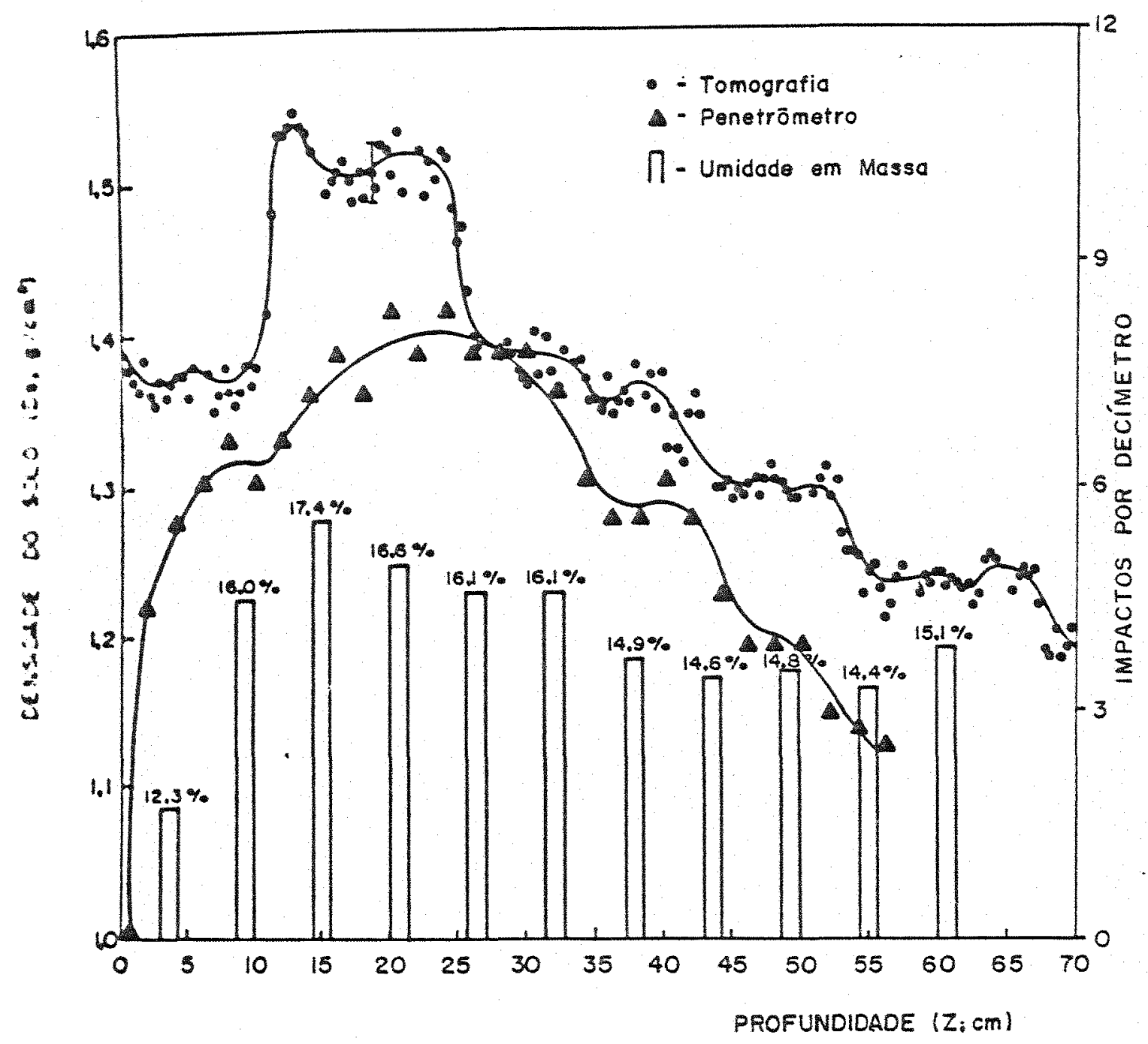

51gura 43. peril1 de densidades na trincheira 2 com a TC e impactos por deciatro com penecrometro. 
6. CONCLUSOES

Para avaliar se os objetivos foram alcancados, discutir as implicacöes do trabalho e a importancia da metodologia desenvolvida, são feitas os sequintes comentarios :

a) A TC e uma técnica que permite o calculo da distribuicäo de densidades numa secão transversal lou no volume) do solo. Como fol mostrado na secão 2.2 , são bastante conhecidas as relacoes de distribuica de pressóes no solo atraves de medidas com "strain-gage", mas as relacbes pressà-deformacăo sao conhecidas apenas empiricamente numa amostra de solo (somente o seu valor médio). A TC abre a possibilidade da obtencăo de relacŏes pressão-distribuicäo de deformacóes (espacialmente), como por exemplo as curvas da figura 38, tornando possivel um entendimento mais completo do processo de compactąäo do solo.

b) A resoluqão espacial da imagem tomografica produzida pelo equipamento utilizado (minitomógrafo) fol da ordem de 2 millmetros, portanto a densidade e umidade do solo, podem ser determinadas num 
elemento de volume de $(2 \times 2 \times 2) \mathrm{mm}^{3}$, no interior de uma amostra de solo.

c) A variancia dos elementos da imagem (pixel) em amostras homogeneas de solo com espessuras entre 30 e $100 \mathrm{~mm}$ foi de $2 \%$. Para os golos utilizados isto equivale em mèdia a um desvio padrão de 50 UM nos pixels e de $0,02 . / \mathrm{cm}^{3}$ e $0,03 \mathrm{~cm}^{3} / \mathrm{cm}^{3}$ na densidade e umidade respectivamente.

d) Comparada com outros equipamentos ou técnicas de medida, tira-se as sequintes conclusões:

d.1) A TC e mais precisa que a tecnica do penetrometro, pois pode tornecer um pertil de densidades com precisão de milimetros ao passo que o penetrometro fornece um perfil de impactos por decimetro com precisäo de varios centimetros. o pertil de impactos por decimetro e altamente dependente da umidade do solo, mas a medida que o solo torna-se seco este se aproxima do perill de densidades. No entanto, o penetrometro possui a vantagem de fornecer uma medida rapida no proprio campo, de ser facilmente manuseado e ter un preco bastante acessivel.

a.2) Comparado com metodos gravimetricos, a primeira vista parece ser menos preciso, pois medidas de massa e volume podem ser feitas com bastante precisão. No entanto, deve-se levar em conta a confiabilidade e a representatividade da amostragem, ja que com a TC é possivel analisar-se amostras realmente indeformadas e 
gravimetricamente quase sempre a amostra é perturbada. outra vantagem da TC e a resolucão, pois esta é de milimetros e na gravimetria dificilmente e melhor que $5 \mathrm{~cm}$ e Einalmente a TC possibilita a obtencão de informacöes sobre o interior da amostra, enquanto que a gravimetria fornece valores medios.

e) Para o sistema de medida utilizado, a imagem apresentada na tela do computador ou na impressora não e tão importante, pois e mais facil utilizar a matriz imagem para se quantificar a distribuica de densidade e umidade do solo.

f) Pelos gráricos da figura 32 , observase que o coeficiente angular da reta referente à densidade e bem maior que da reta da umidade e portanto a sensibilidade para medida da densidade maior que a da umidade. Essas sensibilidades podem ser aumentadas, usando uma fonte de raios gama de menor energia (ou raios $x$ ), de modo que os coeficientes de atenuacão em massa do solo e dgua e consequentemente as inclinacoes das retas, sejam maiores.

g) Nå fol considerado neste trabalho, a variabilidade espacial existente nos solos. No entanto acredita-se que a TC seja uma boa ferramenta para tais estudos, pois em pequena escala, pode fornecer dados nao acessiveig por outras tecnicas e en escala de campo pode fornecer uma boa caracterizacáo local. 
99.

A conclusão final deste trabalho é que a TC pode ser utilizada em estudos de compactacao de solos com um desempenho superior as tecnicas convencionais e con isso abre-se novas perspectivas para o estudo deste processo, que é de grande relevancia atualmente. 
100.

\section{SUGESTOES PARA FUTUROS TRABALHOS}

1) A carcterizacão detalhada de um pertil de densidade obtida pela TC, tal como a obtida neste trabalho, sugere que isto possa ser feito em escala de campo para se caracterizar o nivel de compactacäo em determinadas áreas. Deste modo, um trabalho possivel de ser executado e que pode trazer rezultados bastante elucidantes sobre a correlacăo entre compactacâo e manejo. geria a caracterizacão de diversas areas, as quais durante vários anos foram utilizadas para o plantio com manejos diferenciados. Assim, seria possivel se correlacionar o estálo de compactacăo do solo com o tipo de manejo utilizado e o tempo de cultivo, utilizando uma técnica de medida da densidade bastante precisa e de alta resolucăo, comparada con técnicas convencionais.

2) outro trabaiho bastante interessante seria determinar a nivel de laboratorio, a influencia dos Eatores pressä, tipo de solo, textura e outros, no processo de compactacäo, tal como fol feito com a umidade.

3) Do ponto de vista do equipamento alqumas modificacöes poderiam ser implementadas de modo que a 
resolucão e a precisào melhorassem e o tempo de medida diminuisse.

Para diminuir o tempo seria necessario uma fonte de raios gama com maior atividade da utilizada ou uma fonte de raios $x$. Atualmente hà na UAPDIA-EMBRAPA um projeto, em fase final, de construqäo de um ralo x para ser acoplado neste minitomografo.

A resolucão pode ser melhorada fazendo-se passos menores na mesa tomografica e espessura do feize mais fino. Isto também ja esta sendo implementado no minitomografo da UAPDIA, de modo a se obter imagens com resolucão submilimètrica.

A precisão do equipamento será melhorada em funcão de um bom compromisso entre uma boa resolucào. estabilidade do sigtema eletronico e a utilizacão de energias de radiacăo mais baizas e atividades mais altas.

Com este novo impulso na instrumentacào deste minitomografo, novas fronteiras se abrem para futuros estudos. Entre eles tem-se o estudo dinamico da åqua no solo e a possibilidade do acompanhamento do crescimento de rafzes e sua interacäo com a matriz do solo, áqua e nutrientes. outras possibilidades seriam estudos de interacâo de poluentes, pesticidas, etc, com a matriz do solo, que sào atualmente problemas de grande relevancia. 


\section{REFERENCIAS BIBLIOGRAEICAS}

ANDERSON, S.H.; GANTZER, C.J. \& BOONE, J.M. Rapid non destructive bulk density and soil water content determination by computed tomography. soil science Society of America Journal, Madson, $52: 35-40,1988$.

BACCHI, 0.0.S. Efeitos da compactacão sobre o sistema solo-planta em cultura de cana-de-actcar. Piracicaba, ESALQ, $1976.67 \mathrm{p}$. Tese Mestrado.

BARATA, F.E. Propriedades mecanicas dos solos: uma introducão ao projeto de fundacós. Rio de Janeiro, LTC, $1984.152 \mathrm{p}$.

BARROS, S.T. Deflection factor charts for two and three layer elastic system. Highway Research Record, 145 : $83-108,1966$.

BATEMAN, H.P. Effect of field machine compaction on soil physical properties and crop response. Transactions of the ASAE, St. Joseph, $6: 19-25,1963$. 
BOLLING, I.H. How to predict the soil compaction of agricultural tires. In: INTERNATIONAL CONFERENCE ON SOIL DYNAMICS, Ausburn, Alabama, 1985. Proceedings... Ausburn, USDA-ARS, 1985. v.5, p.6-52.

BROWN, J.M.; FONTENO, W.C.; CASSEL, D.K. \& JOHNSON, G.A. Computed tomography analysis of water distribution in three porous media. Soil science society of America journal, $51: 1121-5,1987$.

CAMPBELI, D.J.; DICKSON, J.W.; BALL, B.C. \& HUNTER, R. Controlled seedbed traffic after ploughing or direct drilling under winter barley in scotland, 1980-84. Soil Tillage Research, $8: 3-28,1986$.

COHAON, G.T. Forces causing soil compaction. In : COMPACTION of agricultural soils. St. Joseph, ASAE, 1971. Cap.4, p.106-22. (ASAE Monography).

COMPACTACAO do solo ja é problema limitante. Noticiario CPAC, Planaltina, (111): 1-2, 1985.

COOPER, A.W.; UANDEN BERG, G.E.; MCCOLLY, H.E. \& ERICKSON, A.E. Strain gage cell measures soil preassure. Agricultural Engineering, st. Joseph, $38: 232-5,46$, 1957

CORMACK, A.M. Representation of a function by its line integrals with some radiological applications. Journal of Applied Physics, New York, 34:2722-7, 1963. 
CORMACK, A.M. Representation of a function by its line integrals with some applications II. Journal of Applied Physics, New York, 35 : 2908-13, 1964.

- CRESTANA, S. A tomografia computadorizada como um novo metodo para estudo da fisica da aqua no solo. São Carlos, USP-IFQSC, 1985. 1400. Tese Doutorado-Fisica aplicada.

CREstana, S.; CESAREO, R. \& MAscarenhas, S. Using a computed miniscanner in soil science. Soil science, Baltimore, 142 : $56-61,1986$.

CRESTANA, S.; MASCARENHAS, S. \& POZZI-MUCELLI, R.S. statical and dynamical three dimensional studies of water in soil using computed tomography scanning. Soil science, Baltimore, $140: 326-32,1985$.

CRESTANA, S.; MASCARENHAS, S.; CESAREO, R. \& CRUUINEL, P.E. Soil research opportunities using $x$-ray and gammaray computed tomography techniques. In: RUIDOso INTERNATIONAL CONFERENCE, Ruidoso, Novo México, May 22-25, 1988. Proceedings... Ruidoso, s.ed., 1988. p.121-8.

CCRUVINEL, P.E. Minitomógrafo de raio-x e raio-gama computadorizado para aplicaøzes multidisciplinares. Campinas, UNICAMP-FEE, 1987. 329p. Tese Doutorado. 
FERNANDES, J. Subsolagem no controle da compactacáo de um solo na cana soca variedade $C B 41-76$ e seus efeitos no rendimento agricola e no sigtema radicular. Piracicaba, ESALQ, 1979. 158p. Tese Doutorado.

FERRAZ, E.S.B. \& MANSELL, R.S. Determining water content and bulk density of soil by gamma ray attenuation methods. Flóida, IFAS, 1979. 51p. (IFAS Techical Bulletin, 807).

FREITAG, D.R. Methods of measuring soil compaction. In: COMPACTION of agricultural soils. St. Joseph, ASAE, 1971. 471p. (ASAE Monography).

GAMEDA, S.; RAGHAVAN, G.S.V.; MCKYEs, E. \& THERIAULT, R. A review of subsoil compaction and crop response. In: INTERNATIONAL CONEERENCE ON SOIL DYNAMICS, AUSDUT, Alabama, 1985. proceedings... Ausburn, USDA-ARS, 1985. v. $5.970-8$.

GUPTA, S.C.; HADAS, S.; VOORHEES, W.B.; WOLE, D.; LARSON, W.E. \& SCHNEIDER, E.C. Field testing of a soil compaction model. In: INTERNATIONAL CONFERENCE ON SOIL DYNAMICS, Ausburn, Alabama, 1985. Proceedings... Ausburn, USDA-ARS, 1985. v.5, p.979-94.

HAINSWORTH, J.M. \& AYLMORE, L.A.G. The use of computerassisted tomography to determine spatial distribution of soil water content. Australian journal of soil Research, victoria, $21: 435-40,1983$. 
106.

HENDEE, W.R. The physical principles of computed tomography. Boston, Little \& Brown, c1983. 192p.

HENDEE, W.R. Medical radiation physics. 2.ed. Chicago, Year Book Medical publishers, 1984. 517p.

HERMAN, G.T. Image reconstruction from projections: the fundamentals of computerized tomography. New York, Academic press, 1980. 316p.

HERRIS, W.L. The soil compaction process. In: COMPACTION of aricultural soils. St. Joseph, ASAE, 1971. Cap.2, P.9-44. (ASAE monography).

HOOPKINS, E.F.; MORGAN, I.L.; ELLINGER, H.D.; KLINKSIEK, R.V.; MEYER, G.A \& THOMPSON, J.N. Industrial tomography applications. IEEE Transactions on Nuclear science, New York, (28) : 1717-20, 1981.

HOUNSFIELD, G.N. A method of and apparatus for examination of a body by radiation such as $x$ or gamma-radiation. London, EMI, 1972. (British Patent, 1283915. Aplication Eiled Aug. 1968).

HOVANESIAN, J.D. \& BUCHELE, W.F. DeVElopment of a recording volumetric transducer for studying effects of soil parameters on compaction. Transactions of the ASAE, St. Joseph, 2 : 78-81, 1959. 
107.

HVORLEV, M.J. Subsurface exploration and gampling of soils for civil engineering purposes. New York, ASCE, 1949. $521 \mathrm{p}$

JANSSEN, P.D. \& HEYERDAHL, P.H. SOIl column descriptions from $x$-ray computed tomography density images. Soil science, $146(2): 102-7,1988$.

FJHNS, H.E. \& LAUGHLIN, J.S. Interaction of radiation with matter. In: HINE, G.J. \& BROWNELL, G.L. Radiation dosimetry. 2.ed. New York, Academic Press, 1982.932p.

KIEHL, E.J. Manual de edafologia : relacões solo-planta. São Paulo, CERES, 1979. 262p.

* LANDINA, M.M. \& KLEVENSK, I.I. Effect of soil compaction and composition of soil air. Soviety soil science, Washington, $16(3): 46-54,1984$.

LAMBE, T.W. The engineering behavior of compacted clay. Journal of the Soil Mechanics and Foundation Division. A.S.C.E., 84(SM2): $1655.1-1655.35,1958$.

LAUNDRE, J.W. Estimating soil bulk density with expanding polyurethane foam. Soil science, Baltimore, 147 (3): $223-4, \quad 1989$. 
LIBARDI, P.L.; REICHARDT, K.; NIELSEN, D.R.; JOSE,C. \& BAZZA, M. An approximate method of estimating soil water diffusivity for different soil bulk densities. Water Resources Research, Washington, 18(1): 177-81, 1982 .

MCKIBBEN, E.G. Introduction. In: COMPACTION of agricultural soils. St. Joseph, ASAE, 1971. cap.1, p.36 (ASAE Monography).

MANTOVANI, E.C. A soil surface traffic-corn yield model for a soil under cerrado vegetation in Brazil with less then 10 years of cultivation. St. Joseph, ASAE, 1984 , 15p. (ASAE Paper, 84-1546).

MARCos, z.z. Ensaio sobre epistemologia pedologica. Cahiers onstom, Ser. Pedologie, $19: 5-28,1982$.

MITCHELL, J.K.; HOOPER, D.R. \& CAMPANELIA, R.G. Permeability of compacted clay. Journal of the soil Mechanics and Fundations Division. A.S.C.E., 91 (SM4): $41-65,1965$

NIMMO, J.R. \& AKSTIN, K.C. Hydraulic conductivity of a sandy soil a low water content after compaction by various methods. Soil science society of America Journal, Madison, 52 (2): $303-10,1988$.

NoGUEIRA, J.B. Mecanica dos solos. Såo Carlos, USP-EESC, 1988. $197 p$ 
OLDENDORF, W. Isolated flying spot detection of radiodensity descontinuities-displaying the internal structural pattern of a complex object. IRE Transactions of Biomedical Eletronics, $8: 68-72,1961$. ONOE, M. ; TSAO, J.W.; YAMADA, H.; NAKAMURA, H.; KOGURE, J.; KAWAMURA, H. \& YoShIMATSU, M. Computed tomography for measuring annual rings of a lives trees. Nuclear Instruments and Methods in Bhysics Research, Ansterdam, $221: 213-20,1984$.

PETROVIC, A.M.; SIEBERT, J.E. \& RIEKE, P.E. SOII buIK density in three dimensions by computed tomography scanning.. soil science society of America Journal, Madison, $46: 445-50,1982$

SILVA, A.P.; IIBARDI, P.L. \& CAMARGO, O.A. A Influencia da compactafão nas propriedades fisicas de dois latossolos. Revista Brasileira de ciencia do solo, Campinas, $10: 91-5,1986$.

SIMMONS. F.W. \& CASSEI D.K. Cone index and soil physical property relationships on a sloping paleaudult complex. Soil science, Baltimore, 147 (1): 40-6, 1989.

SOHENE, W. Fundamentals of pressure distribution and soil compaction under tractor tires. Agricultural Engeneering, st. Jogeph, $39: 276-81,290,1958$. 
STEINHARDT, G.C. Soil compaction: a hidden problem. Trad. de T. Yamada. Informacóes Agronomicas, Piracicaba, 21 : $1-3,1980$

VANDEN BERG, G.E.; COOPER, A.W.; ERICKSON, A.E. \& CARLETON, W.M. Soil preassure distribution under tractor and implement traffic. Agricultural Engineering. St. Joseph, $38: 854-5,9,1957$.

VANDEN BERG, G.E. \& GILL, W.R. Preassure distribuition between a smooth tire and the soil. Transactions of the ASAE, St. Joseph, $5: 105-7,1962$.

VOMICIL, J.A.P FLOCKER, W.J. Effect of soil compaction on storage and movement of soil, air and water. Transactions of the ASAE, St. Joseph, $4: 242-6,1961$. 